US Army Corps

of Engineers $S_{\overparen{B}}$

Engineer Research and

Development Center

Dredging Operations and Environmental Research (DOER)

\title{
Evaluating Effects of Dredging-Induced Underwater Sound on Aquatic Species: A Literature Review
}

Burton C. Suedel, Andrew D. McQueen, Justin L. Wilkens,

September 2019 and Morris P. Fields

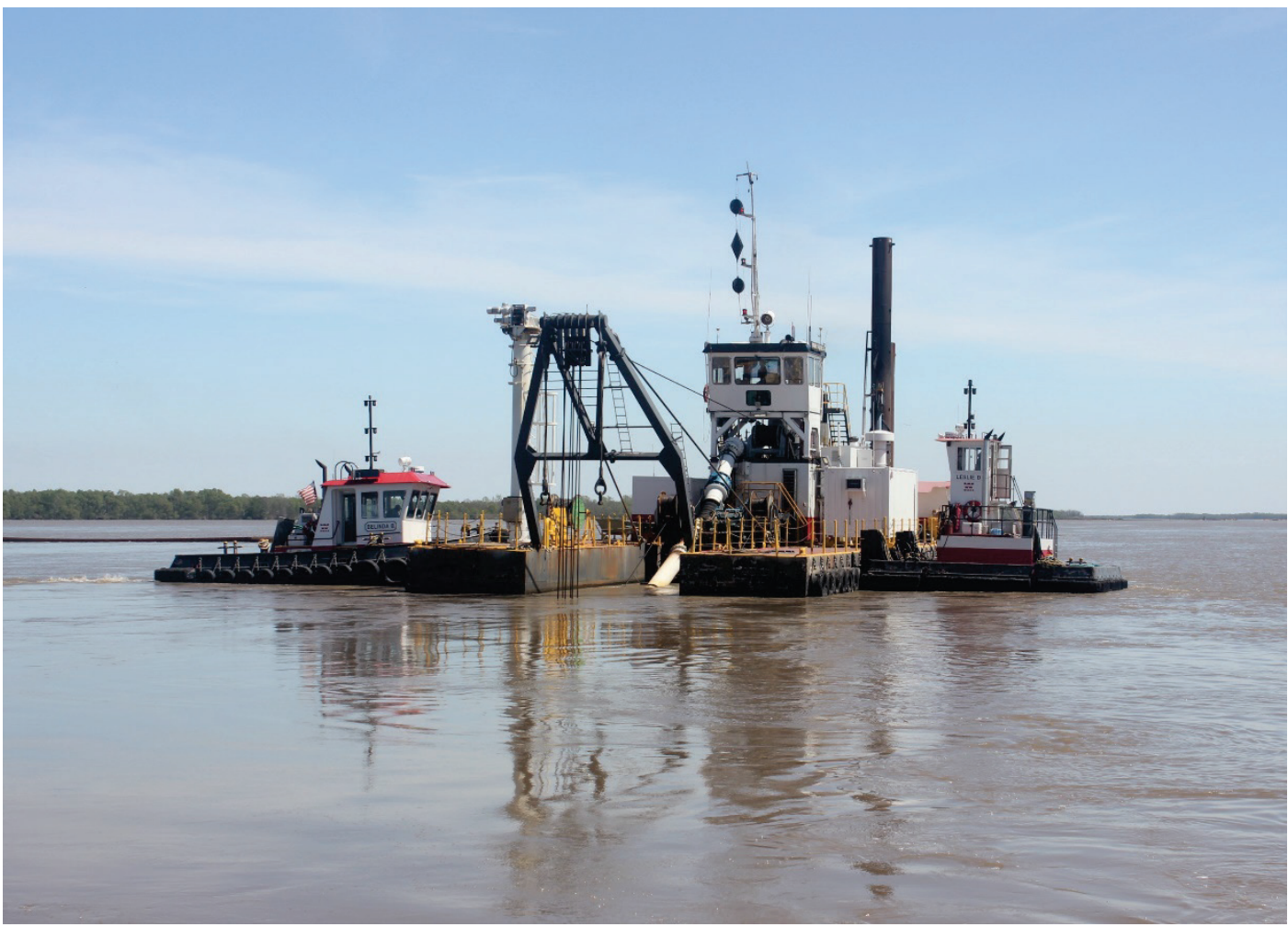


The U.S. Army Engineer Research and Development Center (ERDC) solves the nation's toughest engineering and environmental challenges. ERDC develops innovative solutions in civil and military engineering, geospatial sciences, water resources, and environmental sciences for the Army, the Department of Defense, civilian agencies, and our nation's public good. Find out more at www.erdc.usace.army.mil.

To search for other technical reports published by ERDC, visit the ERDC online library at http://acwc.sdp.sirsi.net/client/default. 


\section{Evaluating Effects of Dredging-Induced Underwater Sound on Aquatic Species: A Literature Review}

Burton C. Suedel, Andrew D. McQueen, Justin L. Wilkens, and Morris P. Fields

Environmental Laboratory

U.S. Army Engineer Research and Development Center 3909 Halls Ferry Road

Vicksburg, MS 39180-6199

Final Report

Approved for public release; distribution is unlimited.

Prepared for U.S. Army Corps of Engineers

Washington, DC 20314-1000

Under Work Unit 33143 


\section{Abstract}

At any given moment, there may be multiple underwater sounds emanating from both natural and anthropogenic sources. Dredging activities such as the excavation, transit, and placement of material generate underwater sound. This report documents research into the biological effects of underwater sound from dredging and other anthropogenic sources to help evaluate the potential ecological risks of dredging activities. Effects data generated from exposures to anthropogenic sound sources indicate that dredging-induced sounds do not pose a significant risk of direct injury or mortality to aquatic biota. A notable exception, and much less common, is blasting activities used to remove rock and other hard substrata in navigation channels. In terms of potential non-lethal responses, low-frequency sounds produced by dredging overlap with the hearing frequency ranges of select fish and mammal species, which may pose risks for auditory temporary threshold shifts, auditory masking, and behavioral responses. To better understand the ecological risk associated with dredging sounds, a risk-based approach is needed that utilizes the available data and other site-specific information appropriate for evaluating underwater sound. The information reported herein can be used in an exposure assessment as part of a broader framework for evaluating and managing underwater sound effects on aquatic life.

DISCLAIMER: The contents of this report are not to be used for advertising, publication, or promotional purposes. Citation of trade names does not constitute an official endorsement or approval of the use of such commercial products. All product names and trademarks cited are the property of their respective owners. The findings of this report are not to be construed as an official Department of the Army position unless so designated by other authorized documents. 


\section{Contents}

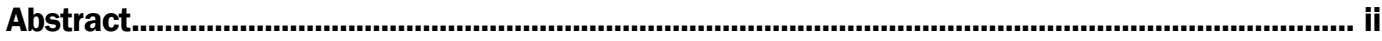

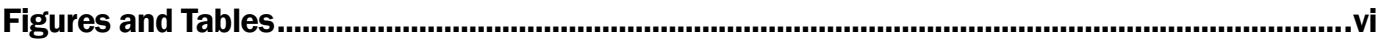

Preface .............................................................................................................................................. vili

Unit Conversion Factors............................................................................................................ix

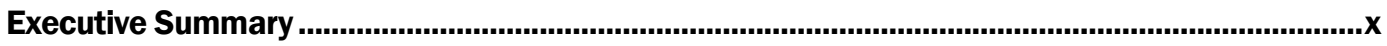

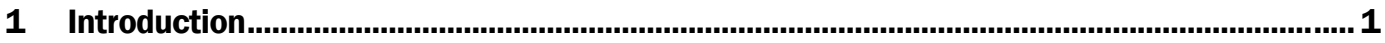

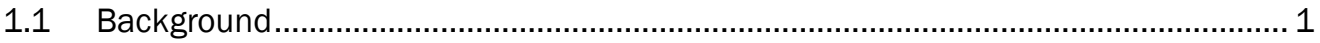

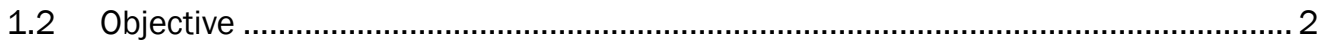

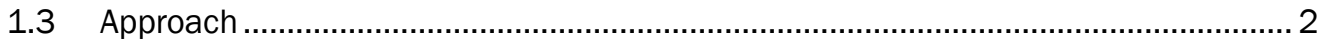

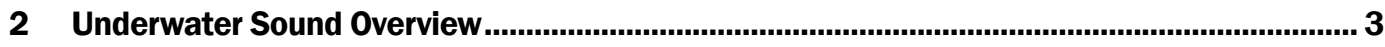

2.1 Wavelength, frequency, amplitude, and velocity............................................... 4

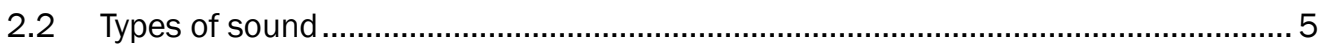

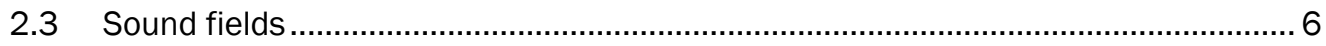

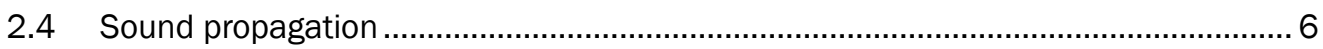

2.5 Frequency analysis .............................................................................................. 7

2.6 Sound pressure and particle motion ..................................................................... 8

2.7 Sound and noise ............................................................................................... 10

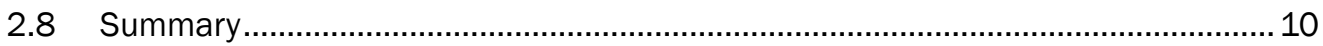

3 Review of Underwater Sounds Produced by Natural and Anthropogenic Sources ..............11

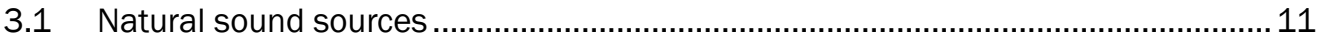

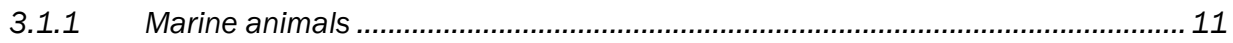

3.1.2 Natural earth sound sources and frequencies................................................ 12

3.2 Anthropogenic sound sources .................................................................... 14

3.2.1 Impulsive anthropogenic sound sources.......................................................... 15

3.2.2 Non-impulsive anthropogenic sound sources ................................................... 17

3.2.3 Summary of natural and anthropogenic underwater sound sources ................... 22

4 Review of Underwater Sounds Produced by Dredging Operations .......................................224

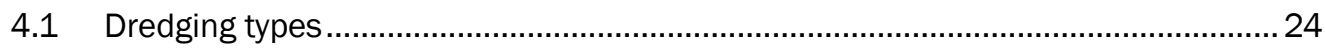

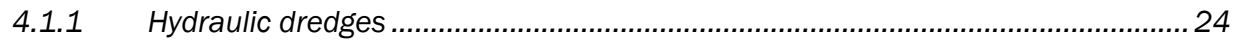

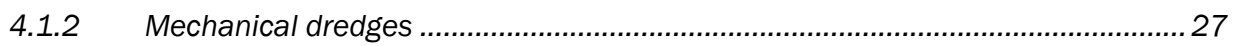

4.2.1 United Kingdom: Nedwell et al. (2008) ............................................................. 30

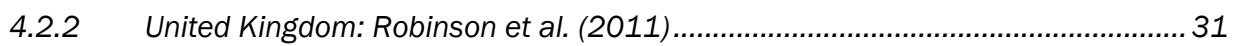

4.2.3 The Netherlands: Maasvlatke 2 studies ............................................................ 32

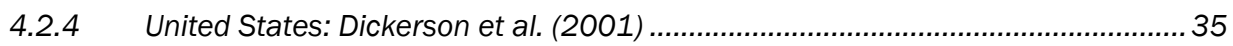

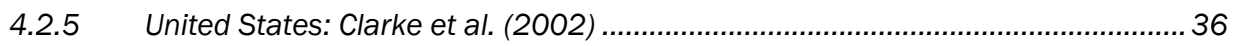

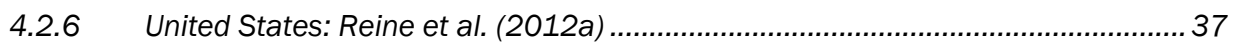

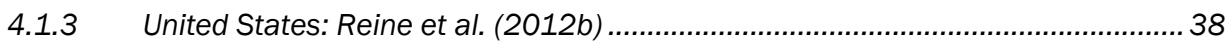




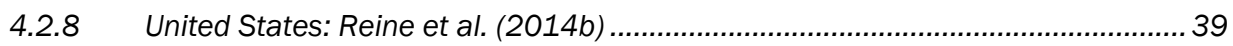

4.2.9 United States: Reine and Dickerson (2014) ...................................................... 41

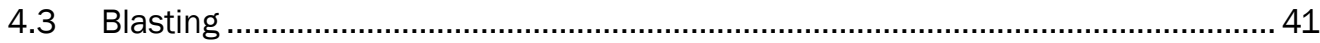

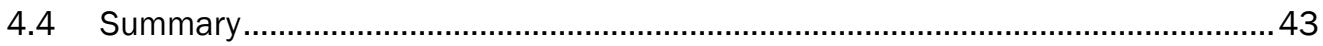

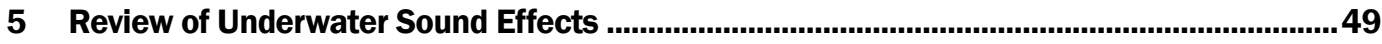

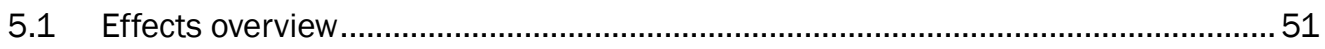

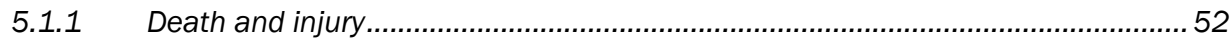

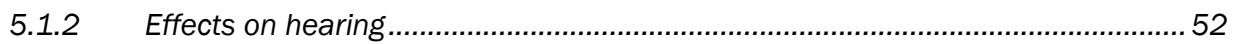

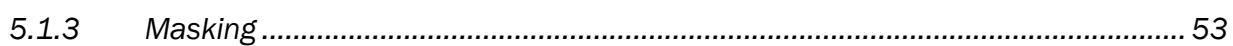

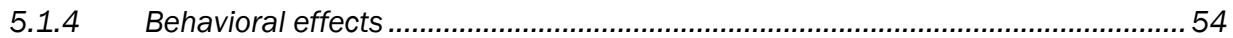

5.1.5 Population-level effects on fitness and survival ...............................................54

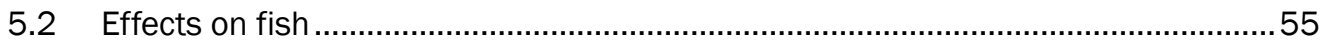

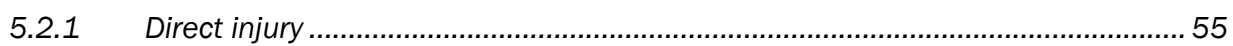

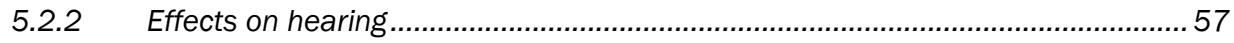

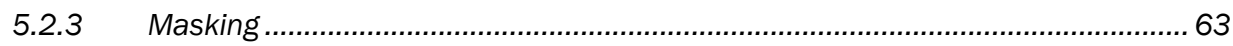

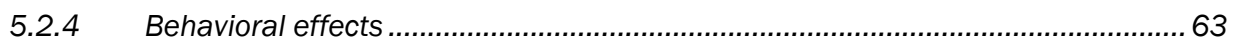

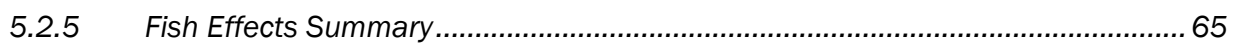

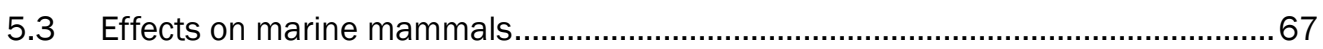

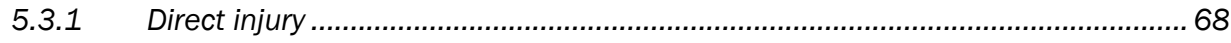

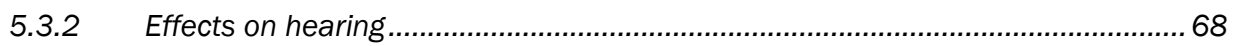

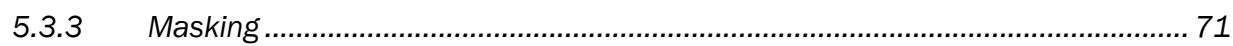

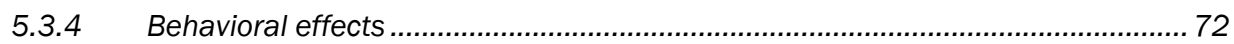

5.3.5 Marine mammals effects summary .............................................................. 74

5.4 Effects on other marine species................................................................... 78

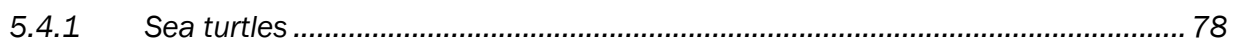

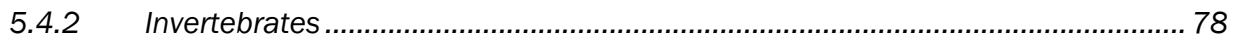

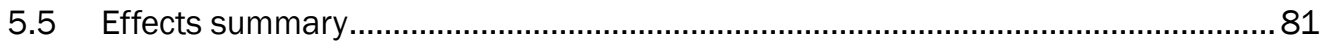

6 Managing Risks from Underwater Sound ............................................................................83

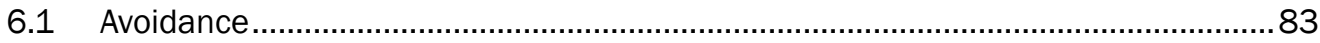

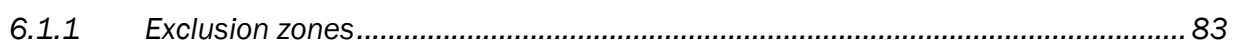

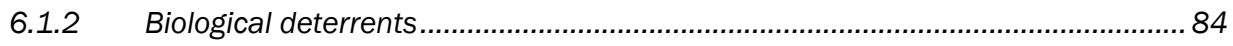

6.1.3 Spatial and temporal restrictions................................................................ 85

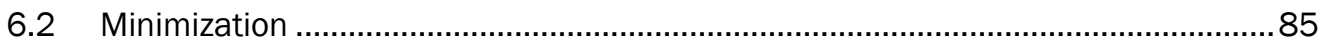

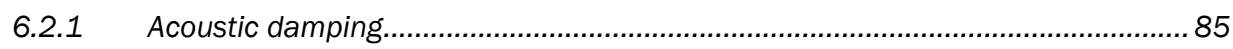

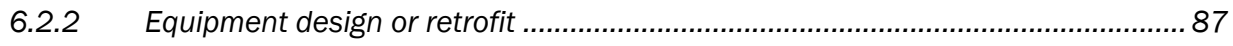

6.2.3 Equipment operation and maintenance.......................................................... 89

6.2.4 Reduction in operation power levels.................................................................... 89

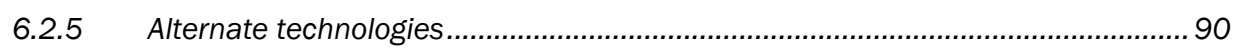

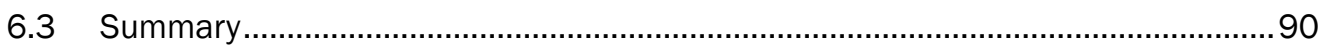

7 NOAA NMFS Marine Mammal Acoustic Technical Guidance ............................................. 91

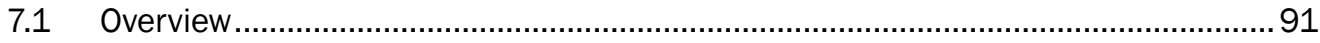

7.2 Background information.................................................................................... 92

7.3 Technical guidelines for marine mammals ............................................................95

7.4 Implication to dredging-induced underwater sound ................................................98 
7.4.1 Acoustic terminology - application to dredging sounds.................................... 99

7.4.2 Uncertainty and data limitations.................................................................... 100

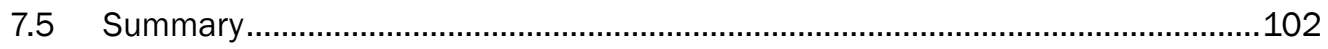

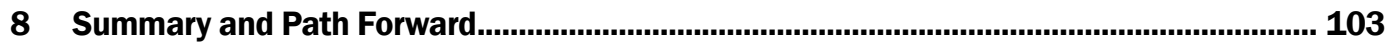

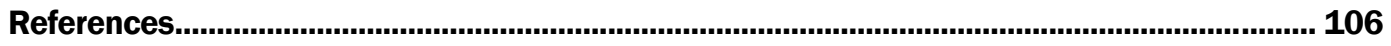

Appendix A....................................................................................................................... 123

Report Documentation Page 


\section{Figures and Tables}

\section{Figures}

Figure 1. Acoustic pressure or sound pressure measured in water. The top left figure shows a sine wave with a lower amplitude, resulting in a lower intensity sound in comparison to the figure in the top right. The lower frequency sine wave in the bottom left completed two cycles, while the higher frequency completed six in the same time. The lower frequency wave has the same amplitude as the higher frequency, but the lower frequency wave would travel further in water because there is less energy transferred to the medium.

Figure 2. Frequency ranges $(\mathrm{Hz})$ of marine mammal sounds as tonal (red) and impulsive (blue). Thicker lines indicated frequencies near maximum energy. Thin lines indicated the total range of frequency vocalizations. (from NRC 2003).

Figure 3. SPLs ( $\mathrm{dB}$ re $1 \mu \mathrm{Pa}$ ) and frequencies $(\mathrm{Hz})$ of marine ambient sound. (from NRC 2003 (adapted from Wenz 1962)).

Figure 4. Example SPL results ( $\mathrm{dB}$ re $1 \mu \mathrm{Pa}$ ) from 1/3-octave analysis for monitoring ambient underwater sound at 11 sites throughout New York Harbor (from Reine et al. 2012a)

Figure 5. Average received underwater SPLs at $1 / 3$ octave bands for recording stations in Cook Inlet from an oil platform (Blackwell and Greene 2003). Note: The numbers correspond with different recording station position distances around the platform.

Figure 6. Sounds emitting from a cutter suction dredge (from CEDA 2011)...................................2

Figure 7. Sounds emitting from a trailing suction hopper dredge (from CEDA 2011)...................... 26

Figure 8. Sounds emitting from a grab dredge (from CEDA 2011) ..............................................2

Figure 9. Sounds emitting from a backhoe dredge (from CEDA 2011) ..........................................2

Figure 10. Variation in spectral levels of underwater sound resulting from backhoe excavation dredging operations in Lerwick, Shetland (UK) (from Nedwell et al. 2008)

Figure 11. Comparison of spectral levels of underwater sound resulting from various backhoe excavation dredging movements in Lerwick, Shetland (from Nedwell et al. 2008).

Figure 12. Underwater sound output measured from seven TSHD in the UK fleet during typical operating conditions (taken from Robinson et al. 2011). Numbers in parentheses indicate study area where sounds were recorded along the UK coast.

Figure 13. Dipole source level ( $\mathrm{dB}$ re $1 \mu \mathrm{Pa}^{2} \mathrm{~m}^{2}$ ) in third octave bands (maximum of all measurements for each activity) for TSHD in transit, and while dredging, dumping, pumping, and rainbowing (from de Jong et al. 2010 (actually copied from Ainslie et al. 2012))

Figure 14. Comparison of dipole source level ( $\mathrm{dB}$ re $\left.1 \mathrm{mPa}^{2} \mathrm{~m}^{2}\right)$ in $1 / 3$ octave bands of 6 TSHD (from de Jong et al. 2010).

Figure 15. Underwater sound results for $1 / 3$ octave (SPL in $\mathrm{dB}$ re $1 \mu \mathrm{Pa}$ ) RMS versus distance from the dredge source $(\mathrm{m})$ (from Reine et al. 2012b).

Figure 16. 1/3 octave analysis for the three TSHD and dredging activities events combined (from Reine et al. 2014b). Scale at right is the range (m) from the source.

Figure 17. Summary of underwater SPLs by dredging type: cutter suction dredge (CSD); trailing suction hopper dredge (TSHD); grab dredge (GD); and backhoe dredge (BHD).

Source Level data from Table 5. 
Figure 18. The proportion of underwater sound publications across sources by decade (top) and proportion of publications across taxa by decade (from Williams et al. 2015). Note: The proportion of papers is based on a bibliometric analysis of published ocean sound research from 1940 to 2015 covering 576 unique records (Williams et al. 2015).

Figure 19. Theoretical zones of influence around a sound source (based on Richardson et al. 1995)

Figure 20. Weighting functions for all species groups from "Auditory weighting functions and TTS/PTS exposure functions for marine mammals exposed to underwater noise" (from NOAA Technical Memorandum NMFS-OPR-55 July 2016 Appendix A). .93

Figure 21. Hearing frequency ranges of selected fish and mammal species and main energy frequencies reported for anthropogenic sources. See Appendix A for source data.

\section{Tables}

Table 1. Intentional and unintentional anthropogenic underwater sound sources. 15

Table 2. Underwater sound frequency ranges of anthropogenic sources (NRC 2003; Appendix A).

Table 3. SPLs, frequency $(\mathrm{kHz})$, and main energy frequencies $(\mathrm{kHz})$ of natural and anthropogenic sound sources.

Table 4. SPLs (dB re $1 \mu \mathrm{Pa}$ RMS) recorded for six GD sound events measured at a distance of $150 \mathrm{~m}$.

Table 5. Summary of underwater sound measurements by dredging type.

Table 6. Shipping and continuous sounds exposure guidelines for fish (reported in Popper et al. 2014).

Table 7. Seismic airgun exposure guidelines for fish (reported in Popper et al. 2014). Mortality and recoverable injury data based on Halvorson et al. (2011, 2012a, b); TTS impairment based on Popper et al. (2005).

Table 8. Carlson et al. (2007) recommended interim sound exposure criteria for fish

Table 9. Fisheries Hydroacoustic Working Group (FHWG) recommended interim sound exposure criteria for fish (reported in Oestman et al. 2009).

Table 10. Pile-driving exposure guidelines for fish (reported in Popper et al. 2014). Mortality and recoverable injury data based on Halvorson et al. (2011; 2012a, b); TTS impairment based on Popper et al. (2005).

Table 11. Overview of effects of underwater sound on fish species from anthropogenic sources.

Table 12. Overview of effects of underwater sound on mammal species from anthropogenic sources.

Table 13. Summary of weighting function parameters and TTS/PTS thresholds. SEL thresholds are in $\mathrm{dB}$ re $1 \mu \mathrm{Pa}^{2} \mathrm{~S}$ and peak SPL thresholds are in $\mathrm{dB}$ re $1 \mu \mathrm{Pa}$ (from NOAA Technical Memorandum NMFS-OPR-55 July 2016 Appendix A). 


\section{Preface}

This report is part of a larger study, "Risk Characterization of Underwater Noise." This project was funded by the U.S. Army Corps of Engineers (USACE), Engineering Research and Development Center (ERDC), Dredging Operations and Environmental Research (DOER) program. Dr. Todd Bridges was the DOER program manager.

This report was written under the direct supervision of Mr. Warren P. Lorentz, Chief, Environmental Processes and Engineering Division, ERDC Environmental Laboratory (EL); Dr. Bill Nelson, Chief, Environmental Risk Assessment Branch, EL; and Dr. Ilker R. Adiguzel, Director, EL.

The authors thank Mr. Kevin Reine (ERDC-EL Wetlands and Coastal Ecology Branch (EEW)); Dr. Matthew Balazik (EEW); Mr. Frederick Roose (Central Dredging and World Dredging Associations); Mr. Robert Ramsdell (Great Lakes Dredge and Dock Company); Mr. Raymond Fisher (Noise Control Engineering, LLC); and Mr. Frank Thomsen (DHI) for reviewing an earlier version of this report.

At the time of publication, Dr. William M. Nelson was Chief, CEERD-EPR; Mr. Warren P. Lorentz was Division Chief, CEERD-EP; Mr. Mark R. Graves was the Chief, Environmental Systems (CEERD-EEC) Branch; and Mr. Mark D. Farr was the Division Chief, Ecosystem Evaluation and Engineering Division (CEERD-EE) branch. The Deputy Director of ERDCEL was Dr. Jack E. Davis, and the Director was Dr. Ilker R. Adiguzel. Ms. Kathy M. Griffin was Headquarters USACE Acting Navigation Business Line Manager, and Mr. Charles E. Wiggins, ERDC Coastal and Hydraulics Laboratory, was the ERDC Technical Director for Civil Works and Navigation, Research, Development, and Technology Transfer portfolio. This study was conducted for the DOER Program under Work Unit 33143. COL Teresa A. Schlosser was Commander of ERDC, and Dr. David W. Pittman was the Director. 


\section{Unit Conversion Factors}

\begin{tabular}{|c|c|c|}
\hline Multiply & By & To Obtain \\
\hline cubic feet & 0.02831685 & cubic meters \\
\hline cubic inches & 1.6387064 E-05 & cubic meters \\
\hline cubic yards & 0.7645549 & cubic meters \\
\hline degrees (angle) & 0.01745329 & radians \\
\hline degrees Fahrenheit & $(F-32) / 1.8$ & degrees Celsius \\
\hline Fathoms & 1.8288 & meters \\
\hline Feet & 0.3048 & meters \\
\hline foot-pounds force & 1.355818 & joules \\
\hline gallons (U.S. liquid) & $3.785412 \mathrm{E}-03$ & cubic meters \\
\hline Hectares & $1.0 \mathrm{E}+04$ & square meters \\
\hline horsepower (550 foot-pounds force per second) & 745.6999 & watts \\
\hline Inches & 0.0254 & meters \\
\hline inch-pounds (force) & 0.1129848 & newton meters \\
\hline Knots & 0.5144444 & meters per second \\
\hline Microns & 1.0 E-06 & meters \\
\hline miles (nautical) & 1,852 & meters \\
\hline miles (U.S. statute) & $1,609.347$ & meters \\
\hline miles per hour & 0.44704 & meters per second \\
\hline Mils & 0.0254 & millimeters \\
\hline square feet & 0.09290304 & square meters \\
\hline square inches & 6.4516 E-04 & square meters \\
\hline square miles & $2.589998 E+06$ & square meters \\
\hline square yards & 0.8361274 & square meters \\
\hline Yards & 0.9144 & meters \\
\hline
\end{tabular}




\section{Executive Summary}

In the last couple decades, there has been a growing concern about the potential adverse effects of underwater anthropogenic sounds on aquatic life. In the aquatic soundscape, sound can originate from many anthropogenic sources, including construction of marine infrastructure and industrial activities, such as drilling and subsea surveys, pile driving, military activities, vessel movements, and dredging. Understanding underwater sound effects of dredging in the context of other anthropogenic activities will allow the U.S. Army Corps of Engineers (USACE), which annually dredges approximately 200 million cubic yards of sediment, to manage dredging operations appropriately whenever underwater sound is a concern.

Underwater sound from natural and anthropogenic sources is composed of many frequencies and amplitudes, which produce a combination of acoustic waves. Sound pressure level (SPL) in decibels (dB) is commonly used to quantify underwater sound, and there are a variety of SPL quantification methods used to describe acoustical properties. Due to the diversity of acoustic metrics, it is critical to use caution when comparing reported sound levels across studies. Additionally, it is crucial to understand the differences between sound source levels and organism received levels (the latter is dependent on the sound source characteristics and the sound propagation in the aquatic environment, and receptor sensitivity).

Dredge-induced underwater sounds are temporally and spatially dynamic, and dependent on site-specific activities and conditions. Dredging activities produce predominantly low-frequency $(<1,000 \mathrm{Hertz}[\mathrm{Hz}])$ sounds, which are typically continuous and non-impulsive (e.g., do not exhibit a rapid sound pressure rise time and decay). A notable exception is during blasting activities when rock and other hard substrata need to be removed in ship channels to ensure navigation safety. Dredging sounds have lower intensities in comparison to other anthropogenic activities (e.g., explosions, pile driving, seismic airguns, echosounders, and powered movement of large ships). In general, SPLs are relatively consistent among dredging types, in spite of the variability of site-specific conditions present when they were measured. Direct mechanical injury and mortality in aquatic species following underwater sound exposures are generally limited to highintensity impulsive sounds (e.g., explosions, pile driving). The currently available effects data from anthropogenic sources indicate that dredging- 
induced sounds do not pose a significant risk to direct injury or mortality to aquatic biota. In terms of potential non-lethal responses, low-frequency sounds produced by dredging overlap with the hearing frequency ranges of select fish and mammal species, which may pose risk for auditory temporary threshold shifts, auditory masking, and behavioral responses.

A critical aspect of the underwater sound risk framework is to identify and mitigate appropriate ecological risks, and to avoid managing ecologically insignificant risks that would pose unnecessary constraints and costs on dredging operations. Mitigation strategies to manage risks of underwater sound effects on aquatic biota generally include avoidance and minimization. Prior to the application of mitigation technologies, cost of implementation should be weighed against risk reduction to ensure practical and cost-efficient approaches are selected (i.e., cost versus benefit comparisons).

Recently updated technical guidelines have been developed by the National Oceanic and Atmospheric Administration (NOAA) National Marine Fisheries Service (NMFS) that proposed acoustic exposure criteria for select classes of marine mammals (NMFS 2016). The NMFS (2016) technical guidance document does not specifically address dredgingrelated sounds and the proposed exposure criteria are not broadly applicable to dredging. In terms of evaluating risks associated with underwater sound for site-specific activities, the technical guidance recommends the use of effects thresholds to be used with site-specific characteristics such as the sound source, environmental site conditions that influence sound propagation, and marine mammal occurrence and behavior near the sound activity (e.g., species, density, occurrence, etc.). NMFS (2016) acknowledges that alternative approaches may be used if site-specific information or data indicate it can produce a more accurate estimation of auditory risk.

To effectively understand the ecological risk associated with dredging sounds, a risk-based approach is needed that utilizes the available data and other site-specific information appropriate for evaluating the underwater sound of concern. Overall, the information reported herein regarding underwater sound produced by dredges can be used in an exposure assessment as part of a broader framework for assessing and managing underwater sound effects on aquatic life. 


\section{Introduction}

\subsection{Background}

Underwater sounds can have a variety of adverse effects on aquatic life, ranging from subtle to strong behavioral reactions, even death. Some documented sub-lethal behavioral differences include startle response, habituation, attraction to or avoidance of the sound source, altered swimming behavior, and avoidance of habitat (e.g., feeding or spawning grounds) (Hawkins and Popper 2016). It is well documented that short and impulsive sounds such as those produced from pile-driving strikes, seismic airguns, and military sonar can cause behavioral reactions by fishes and cetaceans (i.e., whales, dolphins, and porpoises) up to distances of several miles from the sound source. Certain sounds can also mask communication between whales or fish (Clark et al. 2009; Erbe 2011). Masking may be particularly important for soniferous fishes (e.g., cods, croakers, groupers; Erbe 2011). These species produce sounds associated with spawning behavior, aggregating behavior, and orientation. If the anthropogenically produced sound level is sufficiently intense, sound can affect hearing and extreme sounds can lead to injury or even death. Factors that have been observed to influence response to sound stimuli include life history stage, size relative to wavelength of sound, anatomical differences, and location in the water column relative to the source (Hawkins and Popper 2016).

Research about the effects of underwater sound on aquatic life has been carried out for several decades, but there are still many uncertainties, especially with regard to the significance of sound risks posed by dredging activities. In particular, the extrapolation of effects on an individual to effects at the population or community level is highly uncertain. It is therefore important to develop a framework whereby the assessment of various sources of underwater sound can be made to improve the ability to manage such stressors.

There are multiple sources of underwater sound from natural and anthropogenic sources. Some natural sounds include vocalizations of marine life, and wind, waves, rain, and subsea volcanic and seismic activity. Some anthropogenic sources of sound originate from construction of marine infrastructure and industrial activities, such as drilling, subsea 
mining, military activities, vessel movements, and dredging. An important data gap is the impacts of dredging-induced sound (e.g., excavation, transit, placement) to aquatic biota and the potential impacts of dredginginduced sound in the context of other anthropogenic sources.

\subsection{Objective}

The objective of this report is to perform a focused literature review of the available studies to develop an improved understanding of the effects of underwater dredging sounds on aquatic life. Understanding underwater sound effects of dredging in the context of other anthropogenic activities will allow USACE, which annually dredges approximately 200 million cubic yards (myd3) of sediment, to manage dredging operations appropriately whenever underwater sound is a primary concern.

\subsection{Approach}

To address the stated objective, this report documents the peer-reviewed literature and government reports investigating underwater sound effects on aquatic life. Specifically, this report (1) includes a focused literature review of the natural and anthropogenic sources of underwater sound reported since 2000 (Section 3); (2) documents underwater sounds associated with anthropogenic sources (including dredging operations) and resultant effects on aquatic life (Sections 4, 5); (3) documents risk management options for underwater sound (Section 6); (4) summarizes the effects of underwater sound in the broader context of other natural and anthropogenic sources and as they relate to the NOAA NMFS underwater sound regulations published in 2016 (Section 7); and (5) recommends a path forward for assessing the risk of dredging-induced underwater sound on aquatic life (Section 8). This research is needed so the effects of underwater sound generated from dredging activities can be more completely understood-and such risks, if unacceptable, managed through application of appropriate risk management practices. The results of this work will be used to develop a framework for how underwater sound risks to aquatic life can be assessed and managed. 


\section{Underwater Sound Overview}

This section outlines basic acoustic concepts, terminology, metrics, and measurement methods as it relates to underwater sound. This includes a brief review of the primary sound characteristics (wavelength, frequency, amplitude, and velocity) and components (pressure and particle motion). Types of sounds, sound fields, and frequency analyses (e.g., octave band analysis) are also discussed, as they are commonly used to determine and describe the sources of sound presented in the report. In addition, sound propagation and the effects of the environment on sound are presented. More detailed information about the fundamentals of underwater sound or acoustics is available from multiple sources (e.g., Richardson et al. 1995; Bradley and Stern 2008; OSPAR 2009a; Van der Graaf et al. 2012; Nedelec et al. 2016; NMFS 2016). Other specific topics about sound found in the report but not discussed here will be introduced as they appear.

Underwater sound from dredging can emanate from a variety of sources. As an example, when a backhoe dredge lowers a digging bucket on the end of an articulated arm and contacts the bottom sediment, the action vibrates particles, resulting in a sound that propagates as a longitudinal wave with repeating areas of compression and rarefaction of particles and pressure. When the particles are compressed together, part of the absorbed energy dissipates as a result of being transformed into heat, and part is transmitted through the absorbing particle and into the next. The particles vibrate back and forth in the direction of the sound wave with the speed of sound, but do not move along with the wave. The sound wave propagates through the water before the energy eventually dissipates.

The major components of a sound wave are pressure (in Pascal) and particle motion (displacement, velocity and acceleration of water in the sound wave). Sound wave pressure is measured using a hydrophone, an underwater microphone that detects changes in pressure caused by sound waves, which are converted to electrical signals. Methods available to measure particle motion include (1) calculating pressure gradients between two hydrophones; (2) measuring with velocity sensors; and (3) measuring with accelerometers (Martin et al. 2016). Perception of sound by a biological receptor is primarily the function of wavelength, frequency, amplitude, velocity, time and space. Under harmonic conditions, a pure tone is graphically presented as a single sine wave, which describes the wave at a given point over time; however, a single sine 
wave is rare. More commonly, sound is complex and usually composed of many frequencies and amplitudes that produce a combination of sinusoidal waves that can be challenging to quantify. Metrics used to describe sound characteristics are described below.

\subsection{Wavelength, frequency, amplitude, and velocity}

Wavelength is the distance traveled between successive pressure waves, or the distance the wave travels in one cycle of vibration.

Frequency is described in units of $\mathrm{Hertz}(\mathrm{Hz})$, where $1 \mathrm{~Hz}$ is equal to one cycle per second (i.e., wavelengths per second). Humans are able to hear frequencies between $20 \mathrm{~Hz}$ and $20 \mathrm{kHz}(1 \mathrm{kHz}=1$, $000 \mathrm{~Hz})$. Sounds less than $20 \mathrm{~Hz}$ are referred to as infrasound, and sounds higher than $20 \mathrm{kHz}$ are ultrasound. Higher frequency $(>2 \mathrm{kHz})$ sounds have shorter wavelengths, faster cycles, and a higher pitch, whereas lower frequency $(<500 \mathrm{~Hz})$ sounds have longer wavelengths, slower cycles, and a lower pitch. In water, a low frequency wave travels further than a high frequency wave because there is less energy adsorbed.

The amplitude of sound pressure changes is proportional to the maximum distance a vibrating particle is displaced. The change in pressure can be described by maximum pressure amplitude $\left(P_{M}\right)$, or the root-mean-square (RMS) amplitude and is expressed in Pascal (Pa; Newton per meter squared). Decibel (dB) is a dimensionless unit commonly used as a metric to describe sound and is calculated using the ratio of a measured pressure to a reference pressure value. Amplitude determines the "loudness" or intensity. Unlike frequency and wavelength, which remain constant for a given sound, amplitude is dynamic and based on the energy of the sound (Figure 1). Low variations in amplitude results in quieter sounds, while higher variation results in more intense sounds.

The speed of sound is defined as the distance that a point on a wave travels per unit time and is often expressed as meters per second. Water is dense (e.g., air is 1.275 kilograms per cubic meter $\left[\mathrm{kg} / \mathrm{m}^{3}\right]$ or $\approx 800$ times less dense than water; freshwater $=1,000 \mathrm{~kg} / \mathrm{m}^{3}$; seawater $=1,025 \mathrm{~kg} / \mathrm{m}^{3}$ at $4^{\circ} \mathrm{C}$ ) and mostly incompressible (smaller changes in pressure); therefore, sound travels relatively fast (air 340 meters per second [m/s]; water $1,500 \mathrm{~m} / \mathrm{s}$ ) from particle to particle. If a sound in water and in air have the same amplitude, then the relative intensity is greater, speed is faster, and distance is longer in water. 
Figure 1. Acoustic pressure or sound pressure measured in water. The top left figure shows a sine wave with a lower amplitude, resulting in a lower intensity sound in comparison to the figure in the top right. The lower frequency sine wave in the bottom left completed two cycles, while the higher frequency completed six in the same time. The lower frequency wave has the same amplitude as the higher frequency, but the lower frequency wave would travel further in water because there is less energy transferred to the medium.

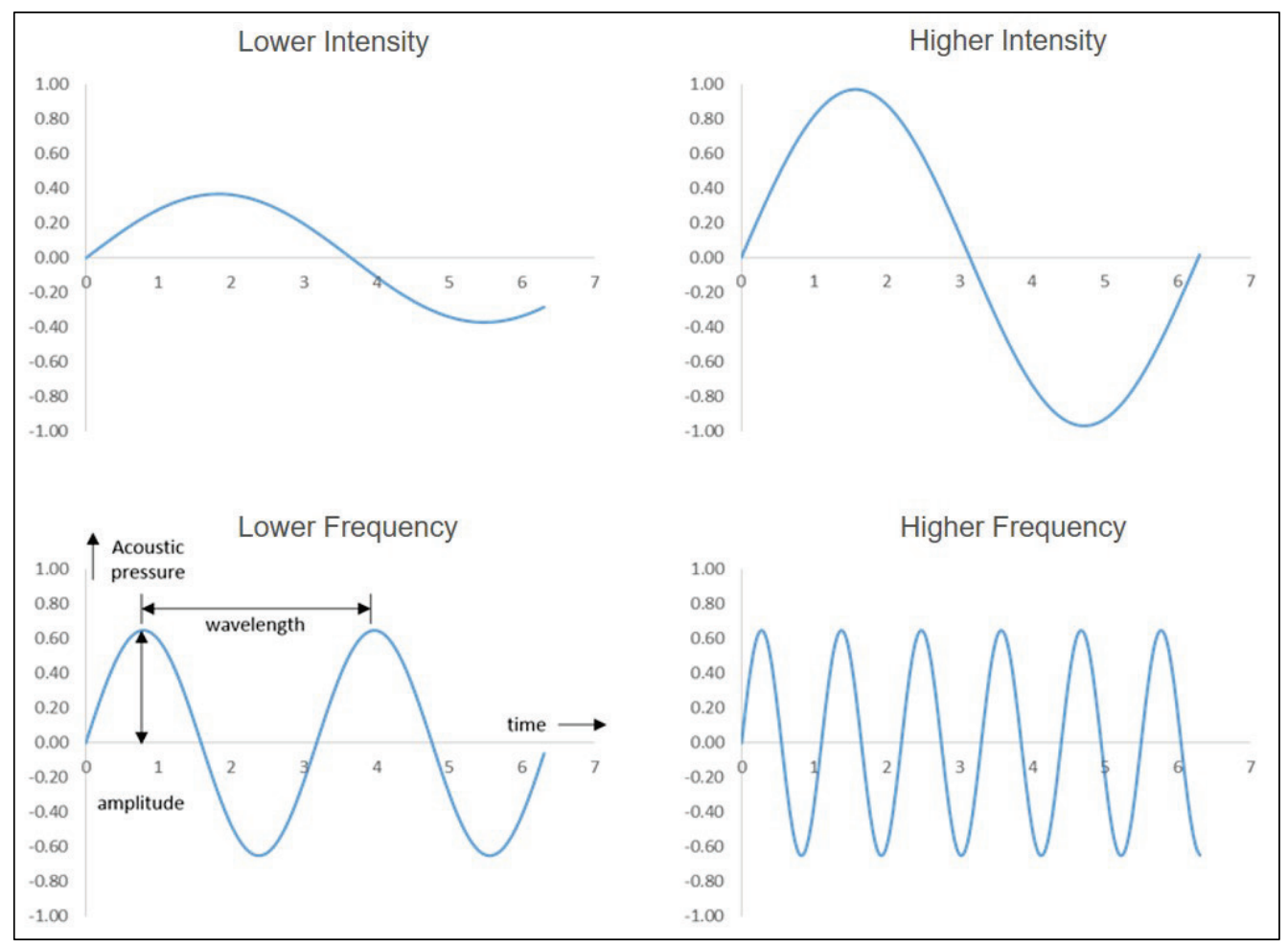

\subsection{Types of sound}

Time and space are commonly used to describe sound. Time is used to describe long or short events, while space is used to describe the temporal and spatial extent of the sound. There are many types of sounds characterized by their temporal variations in sound pressure levels, but sounds generally fall under the broad categories of continuous, noncontinuous, or impulsive (ISO 12001 (1996)). A continuous or steady sound has negligible fluctuations of sound pressure levels during the observation period, while a non-continuous or non-steady sound is described by significant fluctuating pressure levels during the observation period. Non-continuous may be further described as a fluctuating sound, whereby the sound level pressure changes continuously and is highly variable; or intermittent sound, whereby the sound level drops to the level of background repeatedly. An impulsive sound is one or more bursts or pulses of sound energy, each pulse less than $1 \mathrm{sec}$ in duration. Broadband and tonal sounds are discussed in underwater sound literature. Tonal 
sounds can be either continuous or non-continuous and characterized by one or two single frequencies, while broadband sound is sound in which the energy is distributed over a range of frequencies.

\subsection{Sound fields}

The area around a sound source has been categorized into several fields to help measurements and include near, far, free, direct, and reverberant fields (see ISO 12001 (1996)). Understanding the sound fields around a source is critical for placement of sound measurement devices (e.g., hydrophones) for accurate acoustic measurements. The near field is the region close to the sound source where the sound pressure and particle velocity are not in phase (i.e., the sound pressure level can vary significantly with small changes in position). The near field is generally about one wavelength in distance from the source. In the far field, the sound level drops about $6 \mathrm{~dB}$ each time the distance from a point source is doubled and the sound pressure and particle velocity are in phase (i.e., interferences associated with waves reaching the receiver at different time is minimal). The free field is a region in space where sound propagates free from any form of obstruction. The direct field is the part of the sound wave that has not been reflected by any surface or obstacle. The reverberant field is the part of the sound wave that has been propagated from a source that has been reflected at least once.

\subsection{Sound propagation}

The sources of sound mentioned so far are commonly categorized as point source or line source. In ideal conditions, sound pressure typically drops to half its value from a point source when the distance doubles. In a medium free of boundaries or reflecting surfaces, the sound source propagates a wave in all directions in the shape of a sphere. However, reflective surfaces make this a rare phenomenon. For example, a sphere may be present for a short time before it encounters a reflecting surface, such as the sea floor or water surface, and then becomes more cylindrical as the sphere spreads further. It has also been shown that the propagation of sound from a point source is often directional, whereby a greater amount of wave energy goes in some directions more than others. An example of a point source may be a stationary bucket dredge, piling, or an explosion. A line source, such as a busy highway, or-in the case of underwater sound-perhaps a pipe carrying dredged material, drops about $3 \mathrm{~dB}$ for a doubling of distance 
from the source because the sound spreads out from the source as a wave front in a direction perpendicular to the line source.

Reflecting surfaces underwater affect the sound propagated and make it more difficult to determine the direction and characteristics of the sound source because part of the energy is reflected, refracted, absorbed, scattered, and transmitted by the surface. Reflecting surfaces near the receiver (i.e., marine animal) also affect the sound heard. Adding to the complexity is multipath propagation whereby the sound can reach the receiver by two or more paths or directions due to reflection and refraction. This can make it difficult to isolate the sound source. Temperature, salinity, and pressure can also affect underwater sound propagation. Overall, many variables can affect the propagation and in turn the detection of sound, including levels of ambient sounds, sound-spreading characteristics (spherical, cylindrical, directional), channelization, absorption losses, scattering losses, and the initial sound intensity (amplitude) and frequency. The significance of each variable is relative to local site conditions and may vary for a number of reasons depending on, for example, temperature, salinity, depth, and bottom topography. Overall, it should be noted that direct comparisons of sound levels among studies should be done with caution. Studies are often not directly comparable as the sound source level is estimated by propagation (or transmission) loss based on scaling factors. Estimation of sound energy loss and prediction of source levels can be "back-calculated" using scaling factors (Equation 1).

$$
\text { Trasmission loss }=x \log \left(\frac{P_{0}}{P_{R}}\right)
$$

Where $\mathrm{x}$ is the scaling factor (e.g., spherical and cylindrical spreading), $\mathrm{P}_{\mathrm{o}}$ is the acoustic pressure at a point $1 \mathrm{~m}$ from the source, and $P_{R}$ is the acoustic pressure at a distance of " $R$ " in meters. Therefore, original reports detailing the scaling approach should be reviewed before making interpretations (WODA 2013).

\subsection{Frequency analysis}

Sounds have been described using frequency analysis. A frequency analysis is useful to show that a sound is composed of a number of discrete frequencies present simultaneously. The accuracy and precision of the analysis is user-defined and determines the number of discrete frequencies displayed. In underwater sound research, the pressure 
changes detected by a hydrophone are commonly displayed on a calibrated sound-level meter. To perform frequency analysis, a filter is commonly used between the hydrophone and meter, which only allows the electrical output of the hydrophone in $1 \mathrm{~Hz}$ intervals to the meter. The filter allows for the meter to provide the distribution of amplitudes for individual frequencies. A graph of the sound pressures in $1 \mathrm{~Hz}$ intervals over a range of frequencies is called its spectrum.

Frequency analysis has been used to help identify underwater sound sources. Frequency analysis using individual frequency bands is generally avoided because it is difficult to analyze. Instead, researchers often use bands of frequencies, which have been standardized to help facilitate comparison of measurements between instruments. The widest band used in this analysis is the octave band, which represents a doubling in frequency between adjacent bands. Each band is described by its center frequency. Each measurement band contains equal energy; thus the octave band level is constant with frequency. Resolution can be improved by separating the octaves into three parts, or $1 / 3$ octave. By using a $1 / 3$ octave band filter, the sound from each machine, for example, can be distinguished more easily.

\subsection{Sound pressure and particle motion}

Mammal hearing is more sensitive to sound pressure, whereas fish and invertebrates primarily sense particle motion, but a sound wave can also be a combination of both components.

The Sound Pressure Level (SPL), expressed as $\mathrm{L}_{\mathrm{p}}$ in $\mathrm{dB}$ is commonly used to describe sound (ANSI 1994). The decibel is a dimensionless unit calculated using the ratio of a measured value (p) to a reference value (Equation 2). Because the range of intensities that the receptor can respond to is large, the number is converted to a logarithmic scale for easier interpretation.

$$
S P L(L p ; \text { as } d B)=10 \log _{10} \frac{P^{2}}{P_{r e f}^{2}}
$$

where $P$ is the RMS sound pressure and $P_{r e f}$ is the reference pressure level. Decibels are a relative measurement that relate the intensity of a pressure wave to a standard reference pressure. In water, a standard pressure of 1 micropascal $(\mu \mathrm{Pa})$ is used, where $M=1 \times 10^{-6}$. The intensity of a sound at 
any point near the source of the sound is analogous to sound pressure level that reaches the receiver. The sound is more intense the closer the receiver is to the source and changes with time, space, and environmental factors. In the field, accurate SPLs are often difficult to obtain due to reflection off nearby objects and interference from other sound sources. Nonetheless, when appropriate controls and supporting information are available, meaningful SPLs can be obtained and compared. To make comparisons possible, it has been recommended that SPLs using the $\mathrm{dB}$ level should include, at minimum, the reference pressure (e.g., $20 \mathrm{~dB}$ re $1 \mu \mathrm{Pa}$ RMS) as well as how the sound pressure was measured (Madsen 2005).

Sound Exposure Level (SEL) is commonly used as a cumulative metric to describe single impulsive sounds and cyclical impulsive sounds. SEL is the total sound produced from a single sound event and is the integration of all the acoustic energy contained within the event. SEL takes into account both the intensity and the duration of a sound event. The reference value for SEL is in $\mathrm{dB}$ re $1 \mu \mathrm{Pa}^{2} \mathrm{~s}$. The SEL can represent either all energy received at a particular location in the water column of a given impulse or sequence of impulses (cumulative SEL or SELcum).

Peak and peak-to-peak sound pressure level may also be used to describe / quantify impulsive sounds. Peak pressure is the maximum sound pressured during a stated time interval, while peak-to-peak is sum of the peak positive (highest amplitude) and peak negative (lowest amplitude) sound pressure during a stated time interval. In terms of defining biological effect thresholds for underwater sound, SELs and Peak / Peakto-Peak sound pressure levels are commonly used (Southall et al. 2007; Carlson et al. 2007; Oestman et al. 2009; NMFS 2016).

Most fishes and invertebrates cannot directly sense the sound pressure component; rather, they detect particle-motion (Radford et al. 2012; Nedelec et al. 2016; Hawkins and Popper 2017; Popper and Hawkins 2018). The particle-motion component of sound can be expressed as displacement (meters), velocity (meters per second), or acceleration (meters per second squared) of the medium in the sound wave. Nedelec et al. (2016) noted under specific conditions particle motion can be calculated from sound pressure measurements, but relatively shallow water areas generally do not allow for direct comparison; therefore, a particle-motion sensor is recommended (Martin et al. 2016). In comparison to hydrophones, the use of underwater particle motion detectors is a relatively new method because only recently has the 
technology become commercially available (Nedelec et al. 2016). Particle motion is an important component, since fishes and invertebrates account for most of the marine animals (Hawkins and Popper 2017).

\subsection{Sound and noise}

Defined by the receiver or user, a sound can contain both useful information as well as be accompanied by useless information considered noise (Bradley and Stern 2008). Noise could be anthropogenic sounds, ambient sounds, or perhaps some type of mechanical interference when measuring the sound. In underwater sound research, noise is usually used in the context of something undesirable: noise is hazardous to health; it interferes with vocal animals. Communication noise is also otherwise disturbing and commonly propagating from an anthropogenic source and therefore useless. Because noise is defined by the receiver or user, it is often subjective, making it therefore challenging to use the term consistently. This document uses the less subjective and more scientifically established term, "sound" (e.g., Sound Pressure Level not Noise Pressure Level), except in cases where a scientific definition is used, such as ambient noise.

\subsection{Summary}

Sound results in a mechanical wave with pressure fluctuations. Sound pressure and particle motion are the primary components of a sound wave. Perception of sound is primarily the function of wavelength, frequency, amplitude, velocity, time, and space. Sound is complex and usually composed of many frequencies and amplitudes, which produce a combination of sinusoidal waves that can be disordered or random and difficult to spatially quantify. The SPL in decibels (dB) is commonly used to describe underwater sounds. SPLs are typically qualified by the methods used to estimate or summarize the acoustical properties. Common examples include RMS, peak-to-peak, or frequency bands (1/3 octave analysis or $\mathrm{Hz}$ range). Additionally, underwater sound propagation estimations are used to estimate SPLs at distances from the source (e.g., $1 \mathrm{~m}$ from source). In contrast, SELs are metrics used to estimate underwater sound exposures to biological receptors that have an integrated duration of acoustical exposure (e.g., $1 \mu \mathrm{Pa}^{2} \mathrm{~s}$ and cumulative SEL). This report uses the less subjective and more scientifically established term "sound," instead of "noise." 


\section{Review of Underwater Sounds Produced by Natural and Anthropogenic Sources}

To better understand the potential adverse effects from dredge-induced sounds, it is important to understand the contribution of the underwater soundscape from natural and anthropogenic sources.

\subsection{Natural sound sources}

Hearing and communication systems of marine animals are assumed to be adapted to natural sources of sound. Natural sound sources in the ocean include sound by marine animals and-more broadly-sounds produced by wind, waves, rain, thunder, earthquakes, and volcanic eruptions (Wenz 1962; Koper and Plön 2012; NRC 2003; Ainslie et al. 2009).

\subsubsection{Marine animals}

Marine animals actively and passively use underwater sound for a variety of functions, underscoring the important role sound plays for many marine species (NRC 2005; Hawkins and Popper 2016). Marine animals can actively produce sound for communication, orientation, navigation, and localization of prey (Koper and Plön 2012). Frequencies produced by marine animals can range from infrasound to ultrasound.

Examples of sounds made by shellfish include snapping shrimp (Alpheus spp. and Synalpheus spp.) that produce sounds from tens of Hertz to $>200 \mathrm{kHz}$, peaking between 2 and $5 \mathrm{kHz}$. Male ghost crabs (Ocypode spp.) produce a lower frequency sound $(150-800 \mathrm{~Hz})$. There is considerable variability in the sounds fishes produce. Fish sounds encompass a wide frequency band ranging from $0.4-4 \mathrm{kHz}$ to $0.1-2 \mathrm{kHz}$. Marine mammals, such as manatees, dugongs, and seals, produce sounds ranging between 1-25 kHz. Whales and dolphins produce both mid- and high-frequency sounds depending on the species. Toothed whales and dolphins produce low- to mid- and high-frequency sounds ranging from 1-200 kHz (OSPAR 2009a). Baleen whales produce low- and mid-frequency sounds of 0.01-28 kHz (NRC 2003; Koper and Plön 2012; Figure 2). 
Figure 2. Frequency ranges $(\mathrm{Hz})$ of marine mammal sounds as tonal (red) and impulsive (blue). Thicker lines indicated frequencies near maximum energy. Thin lines indicated the total range of frequency vocalizations. (from NRC 2003).

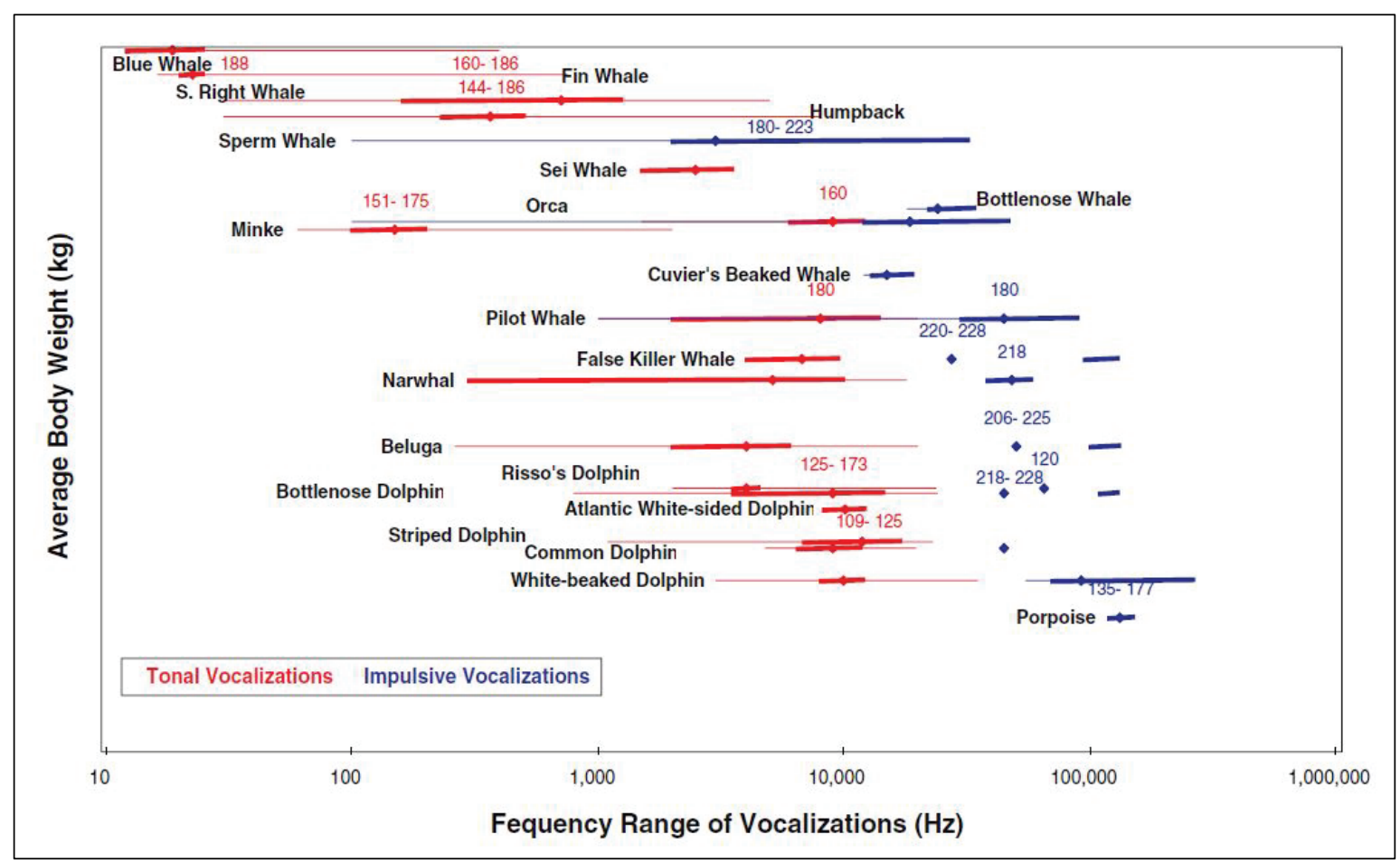

\subsubsection{Natural earth sound sources and frequencies}

The weather is the source of various underwater sounds and natural sound sources are the dominant long-term average ocean sound at all frequencies in the absence of shipping (NRC 2003). The natural movement of waves as driven by wind is the most dominant natural sound source. Such sound tends to increase with increasing surface wind speed. Sound generated by waves is typically below $10 \mathrm{~Hz}$, but ranges from $1 \mathrm{~Hz}$ to $100 \mathrm{kHz}$ (NRC 2003). Waves breaking along the shore produce sound in the 100 to $700 \mathrm{~Hz}$ range (Koper and Plön 2012; Figure 3).

During storm events, rain, thunder, and lightning produce sound in the ocean. Rain generates sound over a wide frequency band ( 1 to $50 \mathrm{kHz}$ ) (Wenz 1962). Thunder can increase sound levels by $10 \mathrm{~dB}$ within the 10-250 $\mathrm{Hz}$ frequency band at a depth of $400 \mathrm{~m}$ at distances between 5 and 10 kilometers $(\mathrm{km})$. A lightning strike on the water can generate an instantaneous sound of $260 \mathrm{~dB}$ in the frequency range of 10 to $1,000 \mathrm{~Hz}$, peaking between 100 and $300 \mathrm{~Hz}$ (NRC 2003; Koper and Plön 2012;

Figure 3). 
Figure 3. SPLs (dB re $1 \mu \mathrm{Pa}$ ) and frequencies $(\mathrm{Hz})$ of marine ambient sound. (from NRC 2003 (adapted from Wenz 1962)).

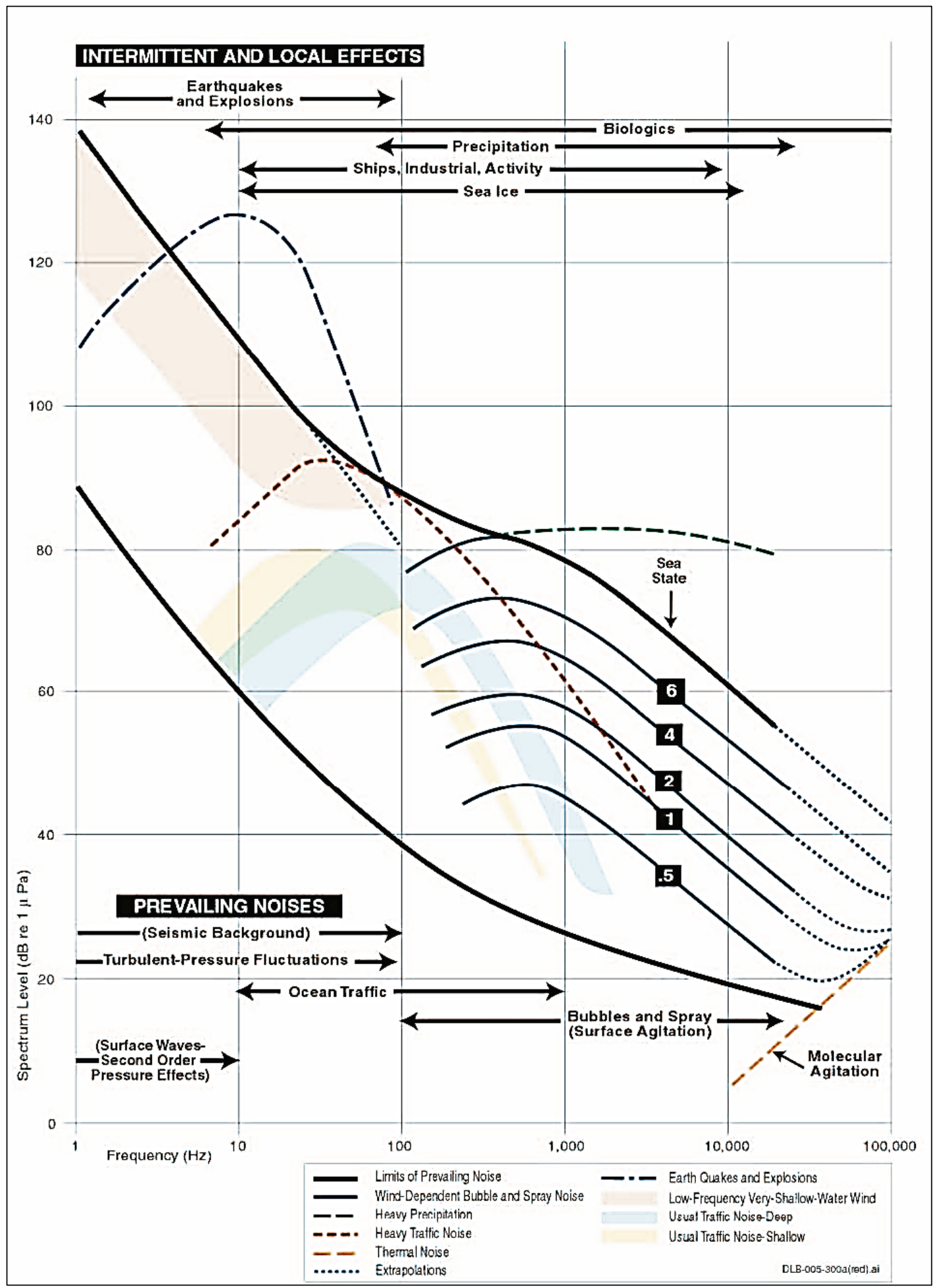


In Cook Inlet, Alaska, Dickerson et al. (2001) monitored ambient sound unrelated to anthropogenic sources. These sound sources were attributed to wind- and wave-driven turbulence, tidal flows, and precipitation. Ambient sound measurements were taken in a location away from the influence of dredging activities. Peak relative SPL was measured at $73.2 \mathrm{~dB}$ re $1 \mu \mathrm{Pa}-\mathrm{m}$ at a peak frequency of $57.8 \mathrm{~Hz}$. At Cook Inlet ambient sound relative SPL averaged $60 \mathrm{~dB}$ re $1 \mu \mathrm{Pa}-\mathrm{m}$ at frequencies less than $100 \mathrm{~Hz}$ and were about $50 \mathrm{~dB}$ re $1 \mu \mathrm{Pa}-\mathrm{m}$ level at frequencies ranging from $100 \mathrm{~Hz}$ to $1 \mathrm{kHz}$.

Earthquakes and volcanic eruptions can be a significant source of sound in the ocean at relatively lower frequencies $(<100 \mathrm{~Hz})$. Seismic activities in the Pacific Ocean are a relatively frequent source of sound, producing up to 10,000 events per year. Seismic events in the North Atlantic produce roughly 3,500 events per year. In both oceans, source levels of these events exceed 200 dB (Wenz 1962; NRC 2003; Koper and Plön 2012).

In colder regions, sea ice contributes to ambient underwater sounds, which include straining and cracking of ice due to thermal effects; and grinding, sliding, and crunching due to contact of pack ice and bergs (Wenz 1962). Frequencies associated with sea ice movement span a wide frequency range (10 to $>10,000 \mathrm{~Hz}$; Figure 3), with the main energy in the lower frequency bands (e.g., <1000 Hz; Wenz 1962; Lewis and Denner 1987). Lewis and Denner (1987) measured the ambient sound of sea ice movement in the Beaufort Sea (marginal sea of the Arctic Ocean). Underwater sound characteristics of sea ice movements were typically lower frequency, with the highest SPLs recorded in the 10 and $32 \mathrm{~Hz}$ frequency bands. In general, SPLs attributed to sea ice movement range from 60 to $90 \mathrm{~dB}$ re $1 \mu \mathrm{Pa}$ (Lewis and Denner 1987).

\subsection{Anthropogenic sound sources}

Anthropogenic underwater sound sources can be classified as impulsive (e.g., explosions, pile driving, geophysical surveys, acoustic deterrents) or non-impulsive (e.g., dredging, shipping, sonar and depth sounders) (Table 1). 
Table 1. Intentional and unintentional anthropogenic underwater sound sources.

\begin{tabular}{|l|l|}
\hline Anthropogenic Sound & \multicolumn{1}{|c|}{ Underwater Sound Source } \\
\hline \multirow{4}{*}{ Impulsive } & Explosions \\
\cline { 2 - 2 } & Pile Driving \\
\cline { 2 - 2 } & Geophysical Surveys (airguns) \\
\cline { 2 - 2 } & Sonar, Depth Sounders, Acoustic Deterrents \\
\hline \multirow{4}{*}{ Non-impulsive $^{\text {b }}$} & Dredging \\
\cline { 2 - 2 } & Commercial Shipping \\
\cline { 2 - 2 } & Energy Industry (e.g., oil and gas exploration and windfarms) \\
\hline
\end{tabular}

aimpulsive = brief duration $(<1 \mathrm{~s})$, with rapid rise time and decay, repetition or as single event (ANSI 2005; NMFS 2016)

${ }^{b}$ non-impulsive = typically do not have a high peak sound pressure with rapid rise time or decay. Can include broadband, narrowband or tonal, brief or prolonged, continuous or intermittent (ANSI 1995; NMFS 2016)

\subsubsection{Impulsive anthropogenic sound sources}

\subsubsection{Explosions}

The sounds generated by explosions are typically described by a large zeroto-peak SPL. Application of underwater explosions are typically limited to military (e.g., military ship hull integrity trials) and construction (blasting rock beds; NRC 2003; Popper et al. 2014), and sometimes by dredging operations to break up rock substrates (Section 4.5). Aspects describing the characteristics of the pressure waves produced by explosions include the peak pressures, SEL, rise time, and decay. In general, explosions characteristically have a nearly instantaneous pressure rise time and lower frequencies (<1000 Hz; OSPAR 2009a; Popper et al. 2014). As an example, SPLs reported for $\sim 0.5$ to $45 \mathrm{~kg}$ of TNT range from 272 to $287 \mathrm{~dB}$ re $1 \mu \mathrm{Pa}$ (zero-to-peak) at $1 \mathrm{~m}$ (OSPAR 2009a). In some instances, blasting is necessary to remove hard rock and substrate prior to dredging (Hempen et al. 2007; Carlson et al. 2011; Tripathy and Shirke 2015). However, it should be noted that open-water explosions have substantially greater pressure waves in the water column as compared to confined (borehole placement) blasts (Hempen et al. 2007; IADC 2016).

\subsubsection{Pile driving}

Impulsive sounds generated by pile driving can generate SPLs ranging from 243 to $257 \mathrm{~dB}$ re $1 \mu \mathrm{Pa}$ at $1 \mathrm{~m}$ (peak-to-peak). The predominate energy from 
pile driving is at frequencies ranging from 100 to $500 \mathrm{~Hz}$ (OSPAR 2009a). Characteristics of pile driving that can influence the source level include the following: method of pile driving (e.g., impact or vibropiling), pile material, diameter of the pile, and substrate (OSPAR 2009a; Popper et al. 2014; Reinhall et al. 2015). Sound characteristics of pile driving are impulsive, with a relatively rapid rise time. Due to the repetitive nature of pile driving, the sound exposure level (SEL) is commonly expressed as cumulative acoustic energy across a set number of strikes (Halvorsen et al. 2012a; Popper et al. 2014; Casper et al. 2012; 2016).

\subsubsection{Geophysical surveys (seismic airguns)}

Explorations surveying bottom substrates are commonly conducted using seismic airguns. The sound characteristics from seismic airguns are typically unidirectional (directed toward seafloor), with the main energy at a lower frequency (20-50 Hz) (OSPAR 2009b; Popper et al. 2014). These sounds are impulsive, occurring in regular intervals (typically every $~ 10 \mathrm{~s}$; Popper et al. 2014). The acoustic pressure from airgun arrays is directly proportional to its operating pressure, with SPLs from arrays backcalculated to $\sim 260 \mathrm{~dB} 1 \mu \mathrm{Pa}$ at $1 \mathrm{~m}$ (zero to peak; NRC 2003; OSPAR 2009a).

Acoustics surveys (e.g., seismology, tomography, thermometry) are conducted by research programs such as the Acoustic Thermometry of Ocean Climate (ATOC). These larger-scale acoustic experiments are generally infrequent (less than a dozen per year). A typical survey uses a low-frequency sound source $(30-900 \mathrm{~Hz})$ deployed at depths $>800 \mathrm{~m}$ with a source level of $195 \mathrm{~dB}$ re $1 \mu \mathrm{Pa}$ at $1 \mathrm{~m}$ (NRC 2003).

\subsubsection{Sonar, depth sounders, and acoustic deterrents}

Modern sonar used by the military typically operates in the frequency range of 0.2 to $10 \mathrm{kHz}$ (Sivle et al. 2015). Sonar operating in midfrequency ( 2.8 to $8.2 \mathrm{kHz}$ ) has underwater SPLs ranging from 223 to $235 \mathrm{~dB} 1 \mu \mathrm{Pa}$ at $1 \mathrm{~m}$ (peak; OSPAR 2009a). Low-frequency active sonar operates below $500 \mathrm{~Hz}$ (Popper and Hastings 2009), with peak SPLs reported up to $215 \mathrm{~dB} 1 \mu \mathrm{Pa}$ at $1 \mathrm{~m}$ (OSPAR 2009a).

In contrast to military sonars, fish finders and commercial depth sounders operate at higher frequencies, typically between 24 and $200 \mathrm{kHz}$ (OSPAR 2009a), and project a lower power signal and shorter pulse lengths 
(OSPAR 2009b). Although there is high variability among ecosounder source SPLs, some have source SPLs exceeding $220 \mathrm{~dB} 1 \mu \mathrm{Pa}$ at $1 \mathrm{~m}$ (at $15.5 \mathrm{kHz}$ with short $24 \mathrm{~ms}$ pulses; OSPAR 2009b).

Acoustic deterrents are devices to deter animals from approaching a specific area (e.g., fish farm, pile-driving operations; Ainslie et al. 2009). For example, the use of seismic airguns as deterrents have been investigated for repelling sea turtles from dredging operations at SPLs of 175 to $179 \mathrm{~dB}$ (Moein et al. 1994). Commercially available deterrents targeting dolphins and harbor porpoises have source levels ranging from 130-150 dB re $1 \mu \mathrm{Pa}^{2} \mathrm{~m}^{2}$ (at randomized intervals of 200-400 millisecond [ms]) with frequency ranges from 5 to $60 \mathrm{kHz}$ (Ainslie et al. 2009).

\subsubsection{Non-impulsive anthropogenic sound sources}

\subsubsection{Dredging}

In general, dredging sound is described by relatively low frequencies (typically <1,000 Hz; Robinson et al. 2011; Reine et al. 2014a,b; Reine and Dickerson 2014). Sound decibel levels recorded from various dredging types (i.e., CSD, TSHD, GD, and BHD) range from $\sim 100$ to $\sim 190 \mathrm{~dB}$ re $1 \mu \mathrm{Pa}$ at $1 \mathrm{~m}$ (Dickerson et al. 2001; Thomsen et al. 2009). Sounds emanating from dredging operations are discussed in greater detail in Section 4 .

\subsubsection{Commercial shipping}

Reine et al. (2012a) recorded measurements at 11 locations in New York Harbor to characterize ambient sound in the absence of dredging activities (e.g., wind, waves, tidal flows, precipitation, and traffic sound from fishing and commercial shipping vessels). The authors reported a range of ambient sounds from 97 to $131 \mathrm{~dB}$ re $1 \mu \mathrm{Pa}$ RMS (mean $=117 \mathrm{~dB}$ re $1 \mu \mathrm{Pa}$ ) (Figure 4). 
Figure 4. Example SPL results ( $\mathrm{dB}$ re $1 \mu \mathrm{Pa}$ ) from 1/3-octave analysis for monitoring ambient underwater sound at 11 sites throughout New York Harbor (from Reine et al. 2012a).

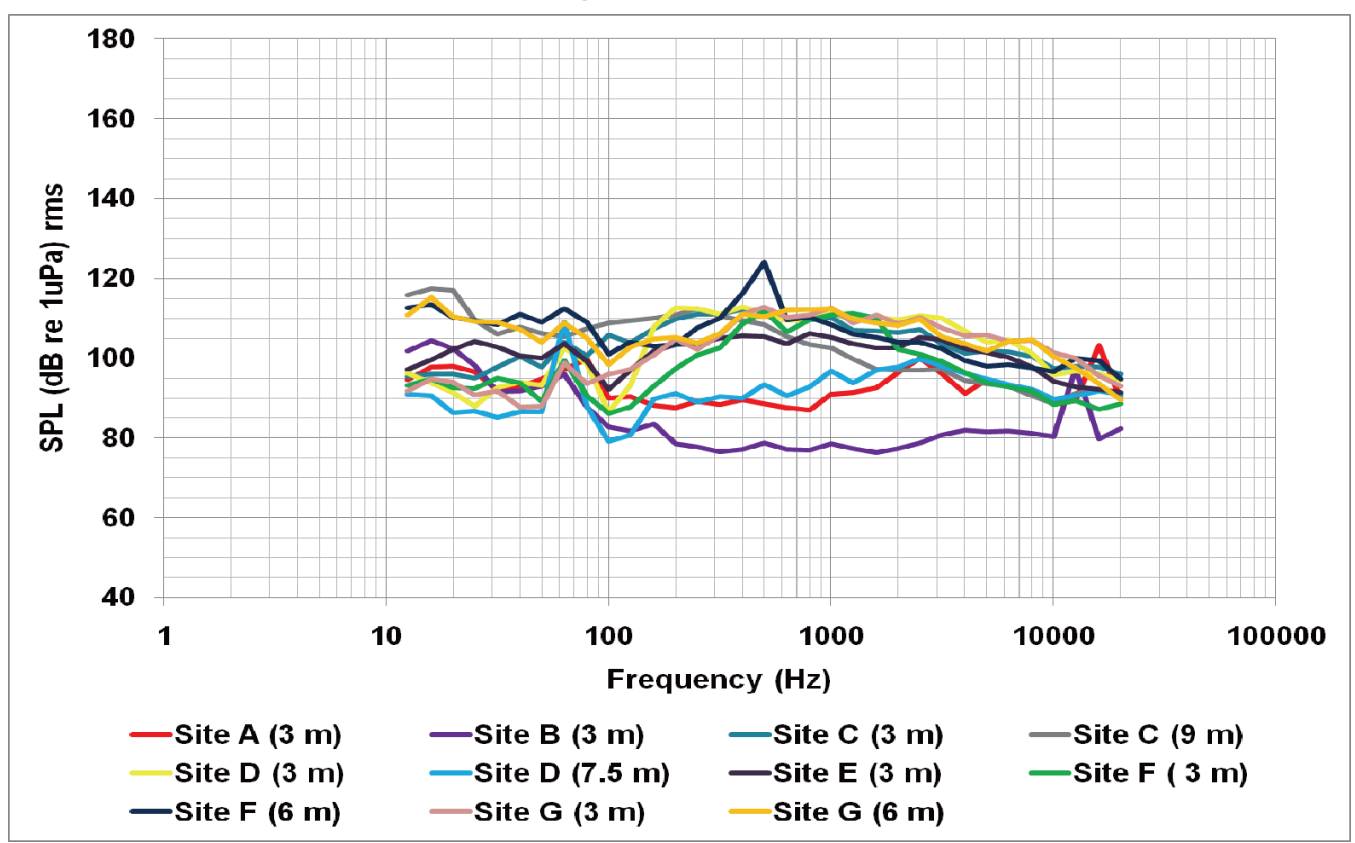

Reine et al. (2014a) measured ambient underwater sound (absent of dredging activities) at four locations (inshore, offshore, borrow area, and pump-out stations) and two water depths ( 3 and $6 \mathrm{~m}$ ) and across various wind speed conditions ranging from Beaufort 1 (1-2 knots) to Beaufort 4 (11-15 knots) at Wallops Island, Virginia. Combining measurements across all sampling days, sites, water depths, and weather conditions yielded an ambient SPL RMS of $117 \mathrm{~dB}$ re $1 \mu \mathrm{Pa}$ and a $1 / 3$ octave SPL of $121 \mathrm{~dB}$ re $1 \mu \mathrm{Pa}$.

To place underwater sounds produced by dredges into context with commercial shipping vessels, sound data were collected for several commercial ships and ferries (Staten Island ferry, NYK Constellation, Maersk Idaho, CSAV Licanten, and Zim Savannah) operating in New York Harbor, New York, and Newark Bay, New Jersey (Reine et al. 2014a; Reine and Dickerson 2014). In New York Harbor, sound measurements were obtained from the ferry servicing the Staten Island St. George Ferry Terminal to the Battery in lower Manhattan. The ferry is approximately 310 feet $(\mathrm{ft})(94 \mathrm{~m})$ in length and $70 \mathrm{ft}(21 \mathrm{~m})$ in width and weighs 3,200 tons. Propulsion is provided by a 10,000 horsepower (hp) diesel electric engine. Vessel draft is $13.6 \mathrm{ft}(4.1 \mathrm{~m})$. SPLs were recorded from either the port or starboard side, depending on the ferry's direction of travel at distances ranging from 298 to $830 \mathrm{~m}$. Received levels were lowest when the ferry was approaching the listening platform. For 
example, at $750 \mathrm{~m}$ from the source, SPLs RMS were $136 \mathrm{~dB}$ when the ferry was approaching the listening platform and $139.62 \mathrm{~dB}$ when the vessel was departing. An SPL RMS of $144.2 \mathrm{~dB}$ was recorded at a distance of $298 \mathrm{~m}$ from the source. Assuming a loss of $37.1 \mathrm{~dB}$ (propagation loss of $15 \mathrm{LogR}$ ), the source level would back-calculate to $181.3 \mathrm{~dB}$ re $1 \mu \mathrm{Pa}$ at $1 \mathrm{~m}$.

During a second monitoring event, the hydrophone was lowered to $30 \mathrm{ft}$ $(9.1 \mathrm{~m})$ in $45 \mathrm{ft}(13.6 \mathrm{~m})$ of water. SPLs were recorded as the ferry departed the Battery and concluded when the ferry arrived at the St. George Terminal. SPLs increased from $125.2 \mathrm{~dB}$ as the ferry was departing the Battery ( $900 \mathrm{~m}$ from the source), peaking at $142 \mathrm{~dB}$ at $352 \mathrm{~m}$ off the port side of the ferry, before decreasing to $132.2 \mathrm{~dB}$ before arrival in St. George Terminal. The lowest SPL measured (125.2 dB at $930 \mathrm{~m}$ ) exceeded the average background by $7.2 \mathrm{~dB}$. During this monitoring event, the ferry source SPL reached $180.2 \mathrm{~dB}$ re $1 \mu \mathrm{Pa}$ at $1 \mathrm{~m}$.

The NYK Constellation is a 55,000-gross-ton cargo vessel $294 \mathrm{~m}$ long and $32 \mathrm{~m}$ wide. Its fully loaded draft is $35 \mathrm{ft}(10.6 \mathrm{~m})$. Output power is 41,129 kilowatts $(\mathrm{kW})$. Underwater sounds were recorded as the ship entered Newark Bay, New Jersey. SPLs were recorded at distances ranging from 122 to $1,442 \mathrm{~m}$. Hydrophone depth was $10 \mathrm{ft}(3 \mathrm{~m})$ in $22 \mathrm{ft}(6.7 \mathrm{~m})$ of water. The vessel approached the listening platform from the bow at a distance of $1,400 \mathrm{~m}$. At this distance, the SPL was $134 \mathrm{~dB}$, exceeding background by $16 \mathrm{~dB}$. An SPL of $150 \mathrm{~dB}$ at $122 \mathrm{~m}$ occurred after the vessel passed the listening platform. Assuming a loss of $31.3 \mathrm{~dB}$ (propagation loss of $15 \mathrm{LogR}$ ), the source level back-calculated to $181.3 \mathrm{~dB}$ re $1 \mu \mathrm{Pa}$ at $1 \mathrm{~m}$.

The Maersk Idaho is a dry cargo container vessel, $300 \mathrm{~m}$ long and $32 \mathrm{~m}$ wide. It has a gross weight of 51,000 tons and a draft of $35 \mathrm{ft}(10.6 \mathrm{~m})$. Output power is $43,070 \mathrm{~kW}$. This vessel was monitored during departure from the South Elizabeth Terminal in Newark Bay. Two tugs were used to assist the Maersk Idaho from her berth. An SPL of $147 \mathrm{~dB}$ (at $622 \mathrm{~m}$ from the source) occurred during this phase of the departure in which underwater sounds were generated by both the cargo ship and the tugs assisting the vessel. Assuming a loss of $41.9 \mathrm{~dB}$ (propagation loss of $15 \mathrm{LogR}$ ) at $622 \mathrm{~m}$, the source level back-calculated to $188.9 \mathrm{~dB}$ re $1 \mu \mathrm{Pa}$ at $1 \mathrm{~m}$.

The CSAV Licanten is a 39,941-gross-ton cargo vessel measuring $260 \mathrm{~m}$ in length and $32 \mathrm{~m}$ in width. It has a maximum draft of $12.6 \mathrm{~m}$. The vessel was monitored as it passed through Anchorage Channel, New York 
Harbor, into the Kill van Kull waterway (KVK). The hydrophone was deployed at a depth of $30 \mathrm{ft}(9.1 \mathrm{~m})$ in $45 \mathrm{ft}(13.6 \mathrm{~m})$ of water. SPLs were recorded at distances ranging from 353 to $900 \mathrm{~m}$. An SPL of $141.8 \mathrm{~dB}$ was recorded $353 \mathrm{~m}$ from the source, exceeding background by $23.8 \mathrm{~dB}$. The source level reached $180 \mathrm{~dB}$ re $1 \mu \mathrm{Pa}$ at $1 \mathrm{~m}$, assuming a loss of $38.2 \mathrm{~dB}$ (propagation loss of $15 \mathrm{LogR}$ ). At a distance of $900 \mathrm{~m}$, the SPL (133.76 dB) still exceeded background by approximately $16 \mathrm{~dB}$.

The Zim Savannah is a 55,592-gross-ton container vessel, $294 \mathrm{~m}$ long and $32 \mathrm{~m}$ wide. It has one main engine (104 revolutions per minute [rpm]) capable of outputting $51,485 \mathrm{~kW}$. It has four auxiliary engines capable of generating $1,780 \mathrm{~kW}$. Bow-thruster output is $2,000 \mathrm{~kW}$. The vessel has a draft of $12.5 \mathrm{~m}$. This vessel was monitored passing through the KVK into Anchorage Channel, upper New York Harbor. Hydrophone depth was $30 \mathrm{ft}$ $(9.1 \mathrm{~m})$ in $46 \mathrm{ft}(13.9 \mathrm{~m})$ of water. SPLs were recorded at distances ranging from 230 to $1,269 \mathrm{~m}$. SPLs decreased across this range from 141.7 to 129.2 dB. The source level, assuming a loss of $35.43 \mathrm{~dB}$ (propagation loss of $15 \mathrm{LogR})$ and an SPL of $141.7 \mathrm{~dB}(321 \mathrm{~m})$, the authors estimated the source level SPL as $179.3 \mathrm{~dB}$ re $1 \mu \mathrm{Pa}$ at $1 \mathrm{~m}$.

Merchant et al. (2016) reported results from a two-year underwater sound field monitoring project that was conducted to support UK policy objectives under the EU Marine Strategy Framework Directive (MSFD). Field data were collected at 12 sites around the UK during 2013 and 2014. Among the monitored 12 field locations, sound exposure varied considerably, ranging from a relatively remote site in the Celtic Sea to several sites within the North Sea with fishing vessel traffic. Median sound ranged from 81 to $95 \mathrm{~dB}$ re $1 \mu \mathrm{Pa}$ for $1 / 3$ octave bands from $63-500 \mathrm{~Hz}$. Despite the relatively close distance to shipping lanes, the Celtic Sea site was determined to be relatively undisturbed by anthropogenic sounds, with the lowest measured sound levels at $125 \mathrm{~Hz}$ and below. The median SPL in the Celtic Sea and Southern North Sea were 82 and $95 \mathrm{~dB}$ re $1 \mu \mathrm{Pa}$, respectively.

Merchant et al. (2016) also demonstrated the relative sensitivity of the RMS method to outliers when processing acoustical data. At all frequencies and locations measured, the calculated RMS exceeded the $97^{\text {th }}$ percentile (Merchant et al. 2016), indicating that RMS metrics are greatly influenced by upper bound values. This study also demonstrated that based on the variability associated with ambient noises, monitoring programs are unlikely to be able to detect upward or downward trends 
within reasonable timeframes (e.g., decades). Therefore, the results indicate that for monitoring ambient noise levels, absolute noise thresholds would be more beneficial than trend-based indicators.

\subsubsection{Energy industry (oil and gas, windfarms)}

Blackwell and Green (2003) measured underwater sounds near an offshore oil platform in Cook Inlet, Alaska. The highest broadband (10$20,000 \mathrm{~Hz}$ ) sound level recorded was $114 \mathrm{~dB}$ re $1 \mu \mathrm{Pa}$ at a distance of $1.2 \mathrm{~km}$ (Figure 5). In general, the acoustic signature measured from the oil platform was lower frequency $(<1,000 \mathrm{~Hz})$, with the majority $(84 \%)$ of the strongest tones occurring below $500 \mathrm{~Hz}$. One third octave band levels underwater for all recording stations had a peak noise around $80 \mathrm{~Hz}$.

Figure 5. Average received underwater SPLs at $1 / 3$ octave bands for recording stations in Cook Inlet from an oil platform (Blackwell and Greene 2003). Note: The numbers correspond with different recording station position distances around the platform.

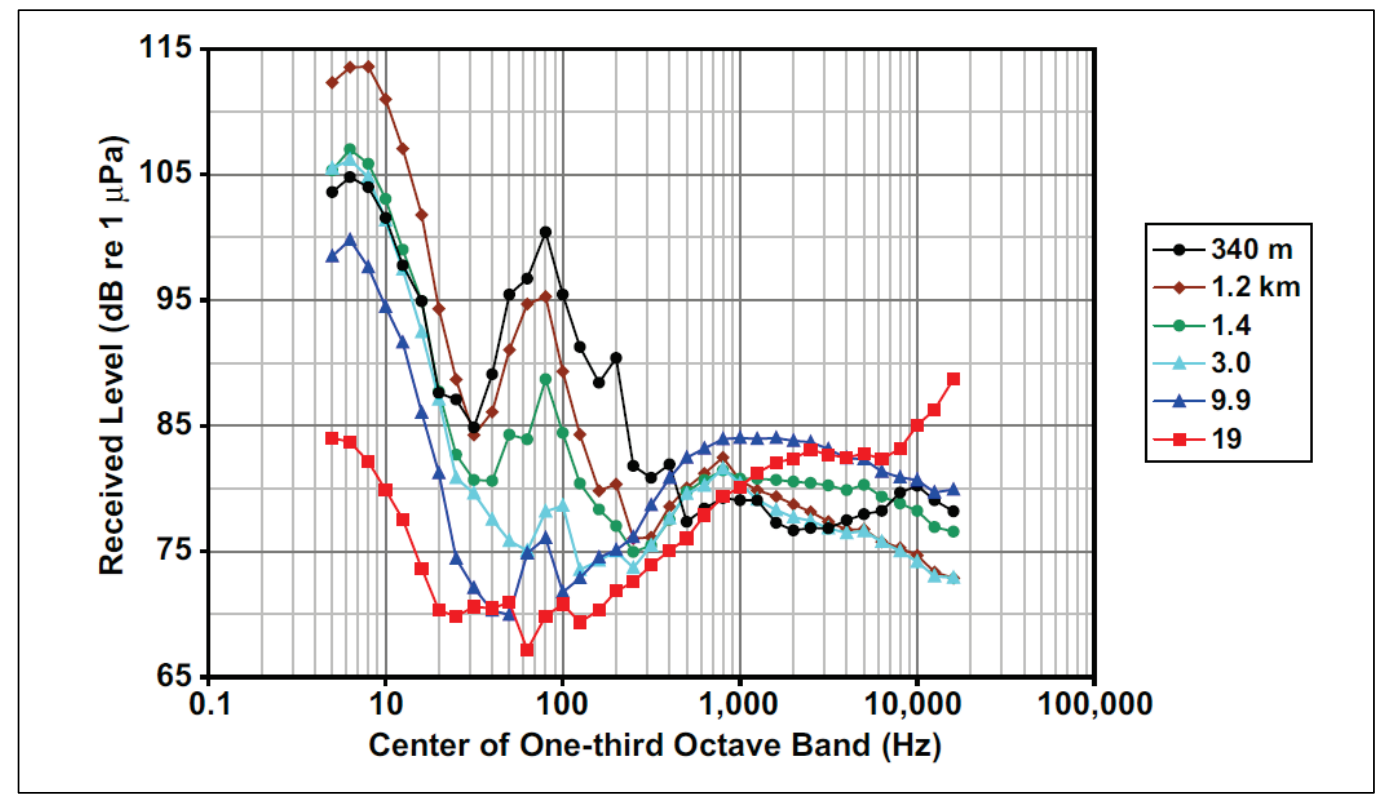

Operation of offshore wind farms are also a source of underwater sound. During operation, wind turbines produce sounds with frequencies at peak energies of 30 to $200 \mathrm{~Hz}$ (OSPAR 2009a). "Low-power" (<1MW) turbines have sound source levels ranging from 142 to $153 \mathrm{~dB}$ (peak spectral energy at $16 \mathrm{~Hz}$; Nedwell and Howell 2004). Nedwell et al. (2007) monitored sound at a windfarm and found that operational underwater sound was comparable to ambient background conditions, with underwater source levels near $(<5 \mathrm{~m})$ the turbines measured at $124 \mathrm{~dB}$ as compared to $122 \mathrm{~dB}$ outside the $500 \mathrm{~m}$ proximity. In addition to operation, the construction 
and decommissioning also are potential sound sources (i.e., pile driving, drilling, rock layering; Nedwell and Howell 2004).

\subsubsection{Summary of natural and anthropogenic underwater sound sources}

The ambient underwater soundscape is diverse, with natural physical and biological sounds contributing a wide spectrum of frequencies and SPLs (Table 2 and 3). In general, underwater sounds can be categorized by impulsive and non-impulsive. Common metrics to describe sound characteristics include SPL (e.g., peak, RMS), frequency (bandwidth and "main energy" (i.e., the majority of energy of a sound event occurring in a given frequency range)), and signal duration. Natural or ambient conditions can be diverse, with biological sounds from vocal species having high intensity (SPLs), which can exceed $200 \mathrm{~dB} 1 \mu \mathrm{Pa}$ at $1 \mathrm{~m}$ (Table 3). The highest intensity anthropogenic sounds (>200 dB $1 \mu \mathrm{Pa}$ at $1 \mathrm{~m}$ ) are from impulsive sounds, which include explosions, pile driving, seismic surveys, and sonar (Table 3). Non-impulsive anthropogenic sounds include shipping, dredging, and energy production (e.g., wind turbine and oil/gas drilling), which typically have SPLs $<200 \mathrm{~dB} 1 \mu \mathrm{Pa}$ at $1 \mathrm{~m}$ (Table 3 ).

Table 2. Underwater sound frequency ranges of anthropogenic sources (NRC 2003;

Appendix A).

\begin{tabular}{|c|c|}
\hline Frequency & Underwater Sound Source \\
\hline \multirow{2}{*}{1 to $10 \mathrm{~Hz}$} & explosions \\
\hline & ship propellers \\
\hline \multirow{6}{*}{10 to $1,000 \mathrm{~Hz}$} & explosions \\
\hline & seismic airguns \\
\hline & sonar (low frequency) \\
\hline & dredging \\
\hline & shipping \\
\hline & construction and industrial activities \\
\hline \multirow{4}{*}{1,000 to $10,000 \mathrm{~Hz}$} & seismic airguns \\
\hline & sonar (mid-frequency) \\
\hline & seafloor profiles \\
\hline & depth sounders \\
\hline \multirow{3}{*}{10,000 to $100,000 \mathrm{~Hz}$} & sonar (high-frequency) \\
\hline & fish finders \\
\hline & acoustic Doppler profiles \\
\hline \multirow{4}{*}{$>100,000 \mathrm{~Hz}$} & mine hunting \\
\hline & fish finders \\
\hline & high-resolution seafloor mapping \\
\hline & research sonars \\
\hline
\end{tabular}


Table 3. SPLs, frequency $(\mathrm{kHz})$, and main energy frequencies $(\mathrm{kHz})$ of natural and anthropogenic sound sources.

\begin{tabular}{|c|c|c|c|c|}
\hline Sound Source & $\begin{array}{c}\text { Source Level } \\
\mathrm{dB} \text { re } 1 \mu \mathrm{Pa} \text { at } 1 \mathrm{~m}, \\
\text { (unless otherwise stated) }\end{array}$ & Frequency (kHz) & Main Energy (kHz) & Reference \\
\hline \multicolumn{5}{|l|}{ Natural } \\
\hline \multicolumn{5}{|l|}{ Biological } \\
\hline sperm whale click & 236 (RMS) & 5 to 40 & 15 & Mohl et al. 2003 \\
\hline snapping shrimp & 183 - 189 (peak) & $<2$ to 200 & 2 to 5 & Au and Banks 1998 \\
\hline harbor porpoise click & 205 (peak) & 110 to 160 & 130 to 140 & Villadsgaard et al. 2007 \\
\hline \multicolumn{5}{|l|}{ Physical } \\
\hline waves & $\sim 40-80$ & 0.001 to 100 & NR & Wenz 1962; NRC 2003 \\
\hline weather (rain, thunder) & $\sim 80$ & 1 to 50 & NR & Wenz 1962; NRC 2003 \\
\hline ambient harbora & $60-73.2$ & 0.1 to 100 & NR & Dickerson et al. 2001 \\
\hline \multicolumn{5}{|l|}{ Anthropogenic } \\
\hline \multicolumn{5}{|l|}{ Offshore Construction } \\
\hline explosives & 272 - 287 (peak) & 0.002 to 1 & 0.006 to 0.021 & OSPAR 2009a \\
\hline confined blasting & 220 (peak) & 0.004 to 1 & NR & Hall 2010 \\
\hline pile driving & 243 - 257 (peak) & 0.02 to 20 & 0.1 to 0.5 & OSPAR 2009a \\
\hline \multicolumn{5}{|l|}{ Seismic surveys } \\
\hline airgun array & 260 - 262 (peak) & 0.01 to 100 & 0.01 to 0.12 & OSPAR 2009a \\
\hline \multicolumn{5}{|l|}{ Sonar } \\
\hline echosounders & 235 (peak) & variable & 1.5 to 36 & OSPAR 2009a \\
\hline $\begin{array}{l}\text { military sonar } \\
\text { (low-frequency) }\end{array}$ & 215 (peak) & 0.1 to 0.5 & NR & OSPAR 2009a \\
\hline $\begin{array}{l}\text { military sonar } \\
\text { (mid-frequency) }\end{array}$ & 223 - 235 (peak) & 2.8 to 8.2 & 4 & OSPAR 2009a \\
\hline \multicolumn{5}{|l|}{ Offshore industrial activities } \\
\hline wind turbine & 142 (RMS) & 0.016 to 20 & 0.03 to 0.2 & OSPAR 2009a \\
\hline drilling & 145 - 190 (RMS) & 0.010 to 10 & $<0.1$ & OSPAR 2009a \\
\hline \multicolumn{5}{|l|}{ Shipping } \\
\hline small boats and ships & 160 - 180 (RMS) & 0.02 to 1 & $>1$ & OSPAR 2009a \\
\hline large vessels & 180 - 190 (RMS) & 0.006 to 30 & $>0.02$ & OSPAR 2009a \\
\hline $\begin{array}{l}\text { New York Harbor } \\
\text { (ambient) }^{\mathrm{b}}\end{array}$ & $75-125$ & & & Reine et al. 2014 \\
\hline Dredging & & & & $\begin{array}{l}\text { Greene 1987; Reine et } \\
\text { al. 2012b; Reine and }\end{array}$ \\
\hline CSD & $168-175$ & 0.03 to 20 & 0.02 to 1 & $\begin{array}{l}\text { Dickerson } 2014 \\
\text { Nedwell et al. } 2008 \text {; de }\end{array}$ \\
\hline TSHD & $172-190$ & 0.03 to 20 & 0.03 to 1 & Jong et al. 2010 \\
\hline GD & $107-124 c$ & 0.03 to 20 & 0.02 to 1 & $\begin{array}{l}\text { Dickerson et al. } 2001 \\
\text { Nedwell et al. 2008; }\end{array}$ \\
\hline $\mathrm{BHD}$ & $163-179$ & 0.03 to 20 & 0.13 to 1.25 & Reine et al. 2012a \\
\hline aAmbient sound measured & ook Inlet, Alaska (absent & hipping noise) & & $\begin{array}{l}\text { peak = maximum } \\
\text { pressure }\end{array}$ \\
\hline $\begin{array}{l}\text { bAmbient harbor sounds ( } \\
\text { c124 dB was measured at }\end{array}$ & $\begin{array}{l}\text { shipping) measured at } 3 \mathrm{~m} \\
8 \mathrm{~m} \text { from sound source }\end{array}$ & th & & $\begin{array}{l}\text { RMS = root mean } \\
\text { square } \\
\text { NR = not reported }\end{array}$ \\
\hline
\end{tabular}




\section{Review of Underwater Sounds Produced by Dredging Operations}

In this section, what is currently known about sources of underwater sound produced by dredging activities is presented. Studies reporting underwater sounds emanating from operating dredges are limited to the last couple of decades. The Central Dredging and World Dredging Associations (CEDA and WODA, respectively) and the Convention for the Protection of the Marine Environment of the North-East Atlantic (OSPAR) have recently published general overviews of underwater sounds produced by various dredge types (CEDA 2011; WODA 2013; OSPAR 2009a,b).

The following sections describe the common dredge types followed by a review of studies conducted to describe sounds emanating from these dredge types. In addition, acoustical properties associated with confined rock blasting are discussed below due to the association with dredging operations to remove hard rock or substrate.

\subsection{Dredging types}

Most dredges share three main categories of activities that produce most of the underwater sound: excavation, transit, and dredged material placement (CEDA 2011). Dredging produces sounds that are continuous, discontinuous, and/or cyclic in nature. The two main categories of dredges are hydraulic and mechanical dredges.

\subsubsection{Hydraulic dredges}

Hydraulic dredges work by sucking a mixture of dredged material and water from the bottom. The two main types of hydraulic dredges are cutter suction dredges and trailing suction hopper dredges (CEDA 2011; WODA 2013).

\subsubsection{Cutter suction dredges (CSD)}

Cutter suction dredges (CSD) suck material through an intake pipe and then push the material out of a discharge pipeline directly into a transport barge or a placement site. A cutterhead at the suction end of the intake pipe rotates in contact with the sediment bed while swinging laterally into the sediment surface. Some cutterheads are capable of dredging rock-like 
formations such as basalt or limestone. The dredge incrementally advances forward by alternately swiveling on spud poles or pushing ahead on a travelling spud while anchored cables on each side of the dredge control lateral movement. Because CSDs use pipelines to dispose of dredged material directly into a transport barge or a placement site, the operations are usually continuous (i.e., 24 hours, 7 days a week) until the job is completed. Figure 6 illustrates the sources of sounds associated with CSDs (CEDA 2011).

Figure 6. Sounds emitting from a cutter suction dredge (from CEDA 2011).

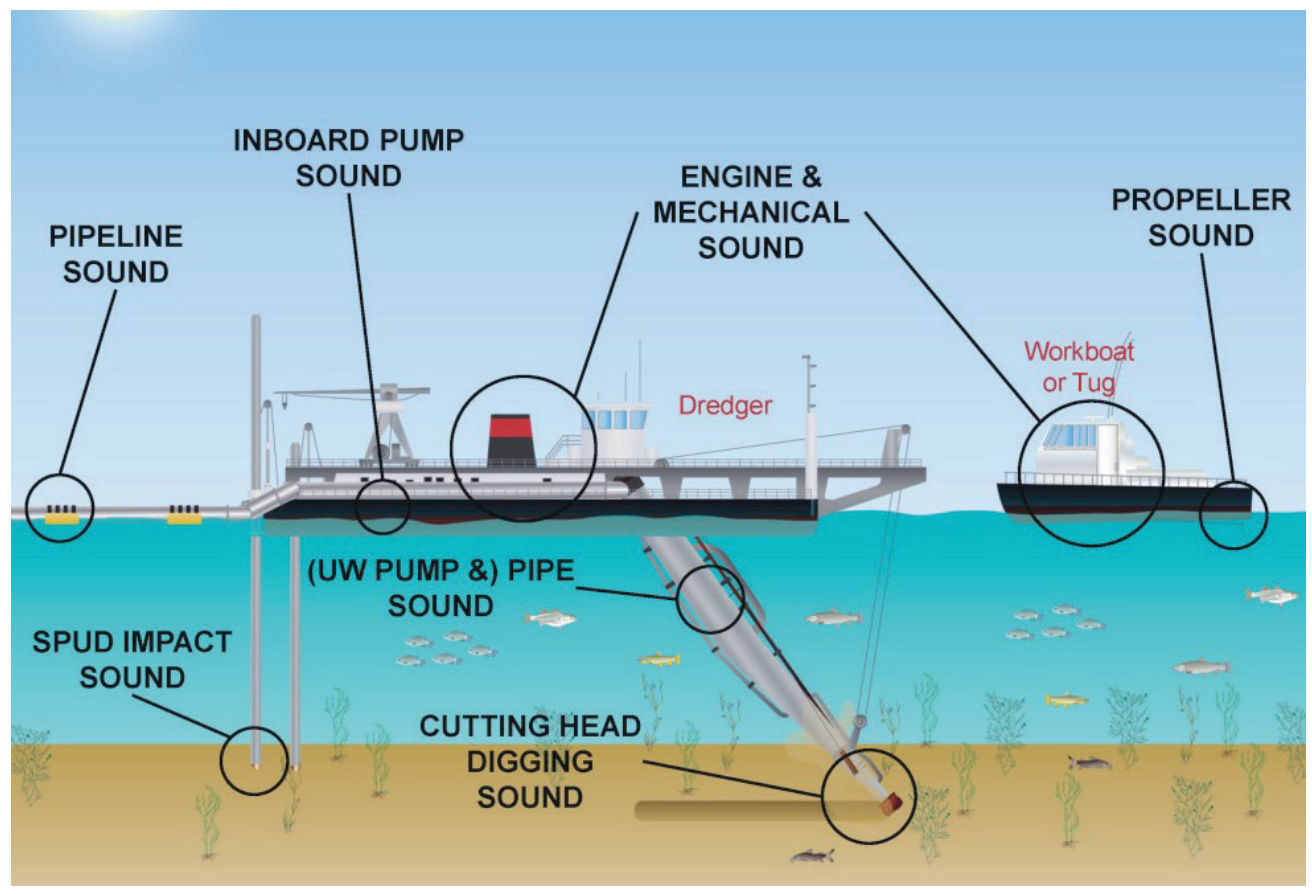

Primary sources of continuous CSD sounds include: (1) dredged material collection sounds originating from the rotating cutterhead in contact with the sediment and intake of the sediment-slurry; (2) sounds generated by pumps and impellers pushing sediment-slurry through pipes; (3) transport sounds resulting from the movement of sediment-slurry through pipes; and (4) ship machinery sounds, including those associated with the lowering and lifting of spuds and moving anchored cables.

The duration of production cuts in dredging activities depends on depth of cutterhead insertion, type of material being excavated, and width of the navigation channel (Reine et al. 2012b). The USACE Navigation Data Center (NDC) (www.navigationdatacenter.us) contains historical data for dredging projects, including start and end dates for CSD projects dating back to 1983. The average duration of a contracted dredging project was 107 days 
(median $=64$ days), while a federal dredging project average was 41 days (median $=32$ days). There have been approximately 2,779 CSD projects since the 1980s, making this the most widely used dredging method contracted or used by USACE in the United States.

\subsubsection{Trailing suction hopper dredges (TSHD)}

Trailing suction hopper dredges (TSHD) are ships with propulsion and large hoppers for containing dredged material. During dredging, long intake pipes, termed drag arms, extend from the ship and drag along the bottom. Erosion, teeth, and water jets loosen the material, and pumps are then used to suck the material from the bottom into the hopper. When the hopper is full, dredging stops, and the ship travels to a dredged material placement site where the material is discharged from the bottom of the ship, or pumped out through a discharge pipeline. The length of time dredging stops is dependent on the haul distance to the placement site. Figure 7 illustrates the sources of sounds associated with TSHDs (CEDA 2011).

Figure 7. Sounds emitting from a trailing suction hopper dredge (from CEDA 2011).

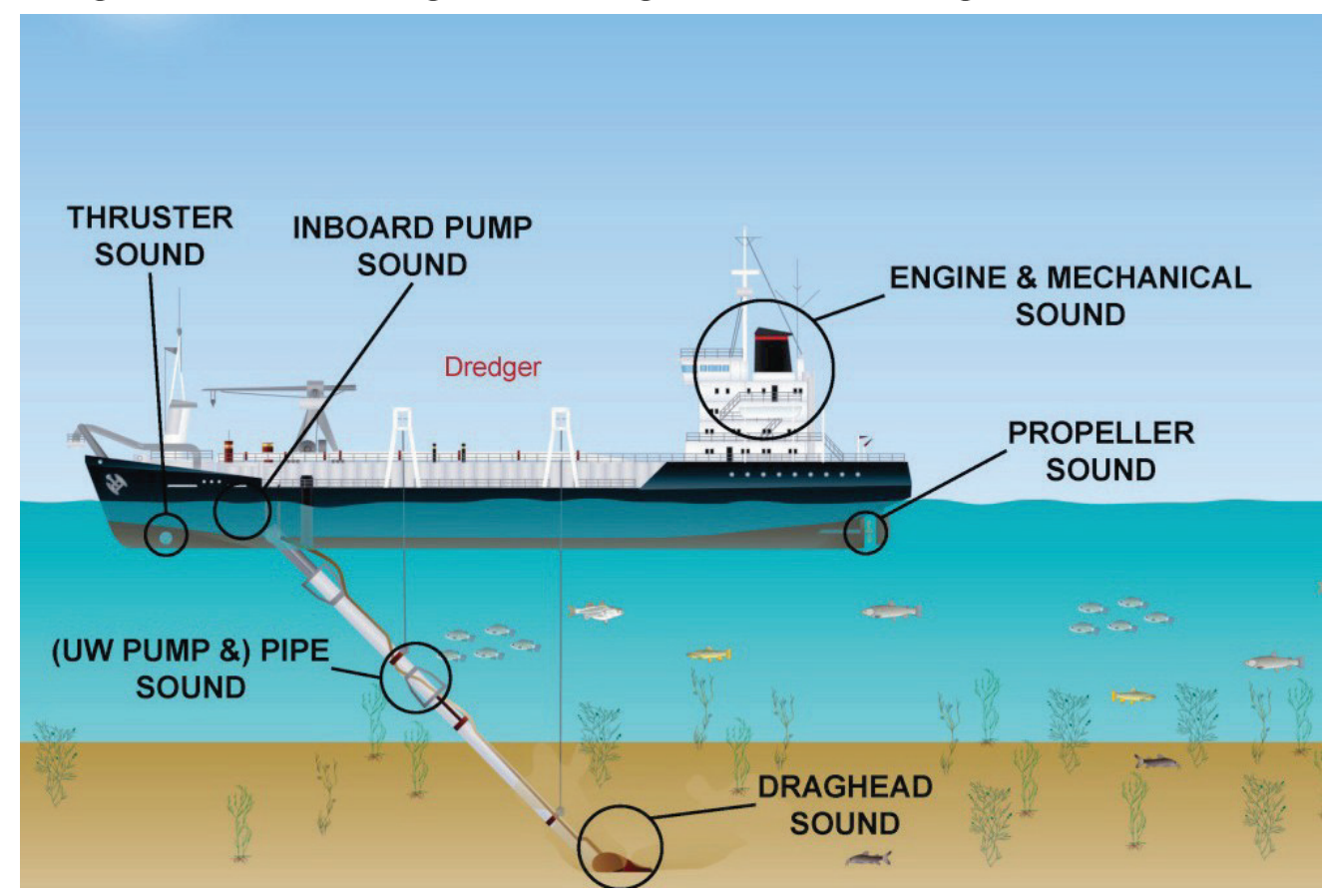

Continuous TSHD sounds are produced from the ship's propulsion during dredging and transit to the placement site. Sounds associated with dredging are considered discontinuous and cyclic because dredging stops when the hopper is full and the ship moves to and from the dredging area and placement site. During dredging, the draghead produces continuous 
sounds when it makes contact with the bottom substrate as the draghead trails beneath the dredge during advancement. The sound produced during filling of the hopper is associated with propeller and engine sound, with additional sounds emitted by pumps and generators. It was determined with historical data obtained from the USACE NDC (http://www.navigationdatacenter.us/dredge/dredge.htm) that the average duration of a contracted TSHD project was 99 days (median $=70$ days), while the average duration of federal dredging projects was 27 days (median $=$ 14 days). There have been approximately 1,697 TSHD projects since the 1980 s, and it is the second most-used dredging method behind CSD by the USACE in the United States.

\subsubsection{Mechanical dredges}

Mechanical dredges remove material by scooping it from the bottom substrate. The two main types are grab dredges and backhoe dredges (CEDA 2011, WODA 2013). Both dredge types are relatively stationary operations and commonly use barges to transport material to the placement site. The USACE NDC

(http://www.navigationdatacenter.us/dredge/dredge.htm) does not distinguish between a grab dredge and a backhoe dredge, so all bucket and mechanical dredge start and end dates were reviewed. The average duration of a project was 102 days (median $=58$ days). There have been approximately 1,077 mechanical dredging projects since the 1980 s, and mechanical dredging is the third most-used dredging method behind CSD and TSHD, respectively, in the United States.

\subsubsection{Grab dredges (GD)}

The GD, also referred to as a clamshell or bucket dredge in U.S. parlance, is a commonly used mechanical dredging method in the United States. The GD is a stationary operation with or without propulsion. Grab dredges can be held in place with spuds or anchors. Often, several barges are used to store and transport the dredged material for placement. The dredging activity occurs in intervals and is regularly repeated whereby the grab is lowered, closed, hoisted, swung to the barge, and the bucket opened to release the material. Figure 8 illustrates the sources of sounds associated with GDs (CEDA 2011). 
Figure 8. Sounds emitting from a grab dredge (from CEDA 2011).

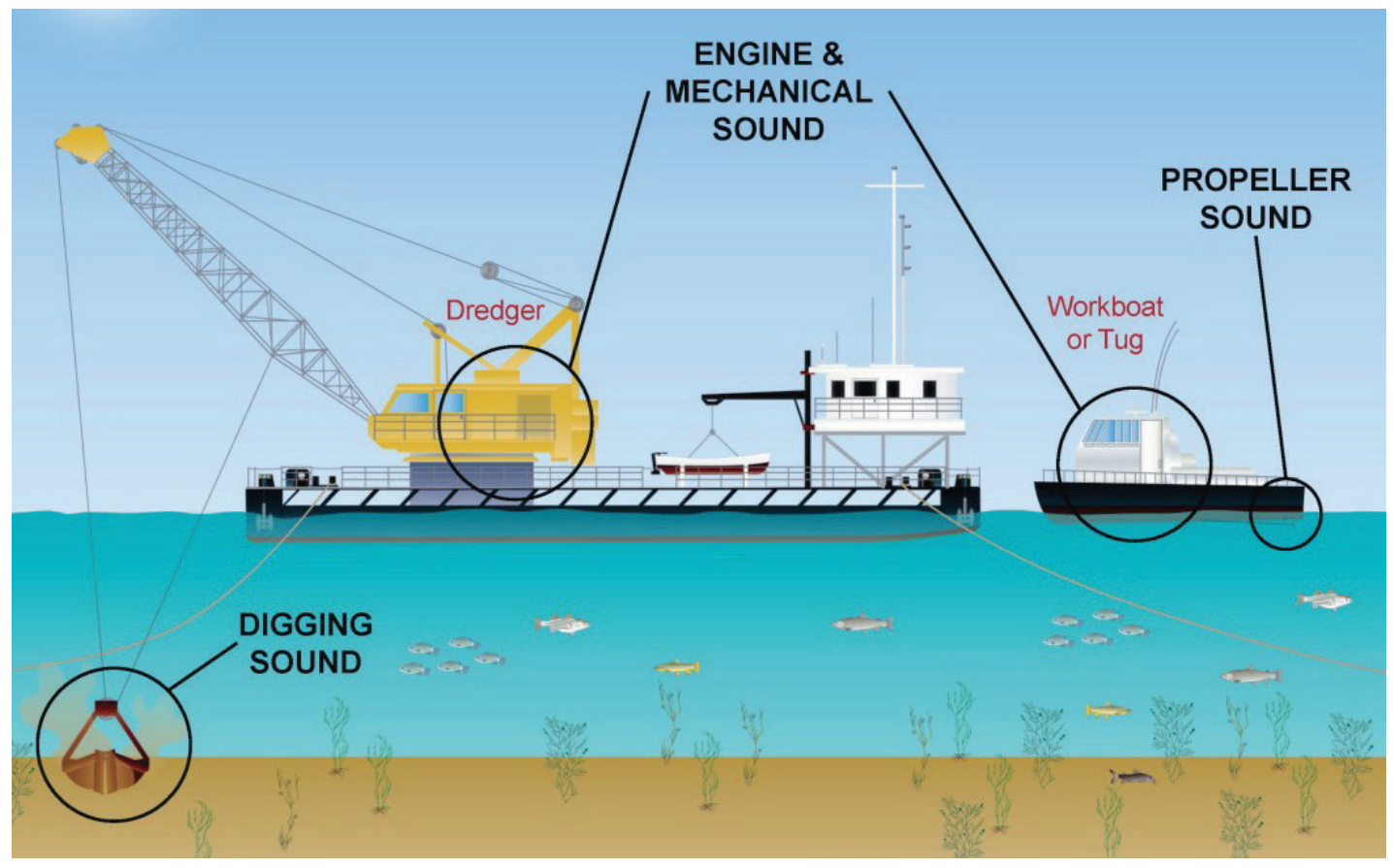

Dickerson et al. (2001) and Clarke et al. (2002) described GD operations as a discontinuous and cyclic sound produced by winches and derrick movement, bucket contact with the substrate, digging into substrate, bucket closing, and emptying of material into a barge or scow. The sounds are repeated approximately every minute, with intermittent interruptions due to barge maneuvering and maintenance activities.

\subsubsection{Backhoe dredges (BHD)}

A BHD is a stationary platform with a hydraulic excavator having a single digging bucket positioned on the end of an articulated arm. The BHD digs by drawing bottom sediment backwards and is typically used to work in harder material than GDs. The BHD sits on a barge that is anchored, and the position is maintained with spud poles to provide a stable platform to account for the reaction forces from digging. Similar to the GD, several barges are used to store and transport material dredged by the BHD. The workflow is also similar to the GD in that dredging occurs in regular intervals (discontinuous) and is repeated (cyclic), whereas the backhoe is lowered, drawn backwards to fill with sediment, lifted, swung to the barge, and the bucket inverted to release the material. Figure 9 illustrates the sources of sounds associated with BHDs (CEDA 2011). 
Figure 9. Sounds emitting from a backhoe dredge (from CEDA 2011).

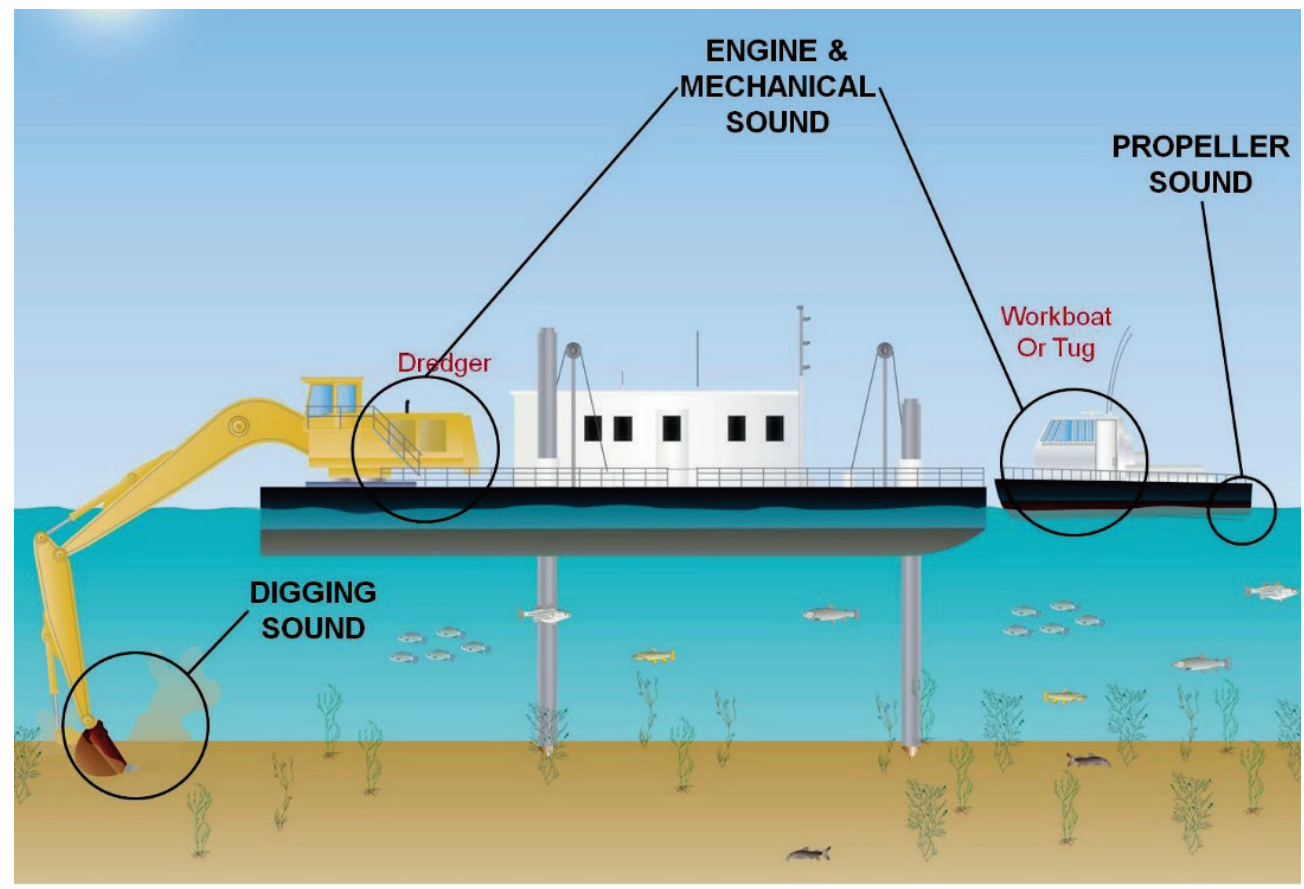

Sound sources produced by BHD originate from several sources. Grinding and scraping sounds are produced when the backhoe is drawn backwards to fill with material. Sounds are produced by hydraulic pumps and the articulated bucket support arm during subsequent lifting of the material from the substrate through the water column. Sounds are transmitted through the hull of the receiving barge during placement into it. Onboard machinery associated with winches, generators, and engines also produce sounds. Other periodic sounds include the movement of spud poles or anchor cables. Engine sounds are produced by tugboats and tenders when they are used to transport barges with sediment to placement sites.

\subsection{Dredging studies: hydraulic and mechanical dredges}

Field studies have been performed that investigated the sounds produced during dredging operations, predominantly conducted in the United Kingdom (UK) and U.S. Nedwell et al. (2008) and the Marine Aggregate Levy Sustainability Fund (MALSF) published reports that documented the underwater sound generated from dredging operations in UK harbors. Numerous field studies have been performed by various investigators when the Port of Rotterdam was expanded in the Netherlands. In the United States, investigators at the USACE published a series of reports on the underwater sounds produced by various dredge types operating in nearshore and offshore scenarios. 


\subsubsection{United Kingdom: Nedwell et al. (2008)}

Nedwell et al. (2008) measured underwater sound produced by the BHD Manu Pekka as it operated in a harbor in Lerwick, Shetland. After excavation by the BHD, the dredged material was transferred into an adjacent moored scow. Once loaded, the scow was transported to a reclamation area where the material was placed.

At a distance of $7 \mathrm{~m}$ from the BHD, the underwater sound generated by the dredge was reported as being caused by the ship generators (continuous sound) and movement of the articulated bucket support arm (noncontinuous sound; Figure 10). Based on a $10 \log (\mathrm{R} / 1 \mathrm{~m})$ scaling, the source level was estimated to range from 140 to $145 \mathrm{~dB}$ re $1 \mu \mathrm{Pa}$ (10 to $15 \mathrm{~Pa}$ ) at $1 \mathrm{~m}$. An increase in underwater sounds was observed when the bucket struck the seabed, followed by more intense sound levels as the bucket was drawn backwards, which produced grinding and scraping sounds when the bucket was filled with material (Figure 11). During this period, the underwater sound source levels were estimated increased from 145 to $162 \mathrm{~dB}$ re $1 \mu \mathrm{Pa}$ at $1 \mathrm{~m}$. The material dumped into the scow was also measured at a distance of $7 \mathrm{~m}$, but this sound source did not significantly contribute to the overall measured sound level.

Figure 10. Variation in spectral levels of underwater sound resulting from backhoe excavation dredging operations in Lerwick, Shetland (UK) (from Nedwell et al. 2008).

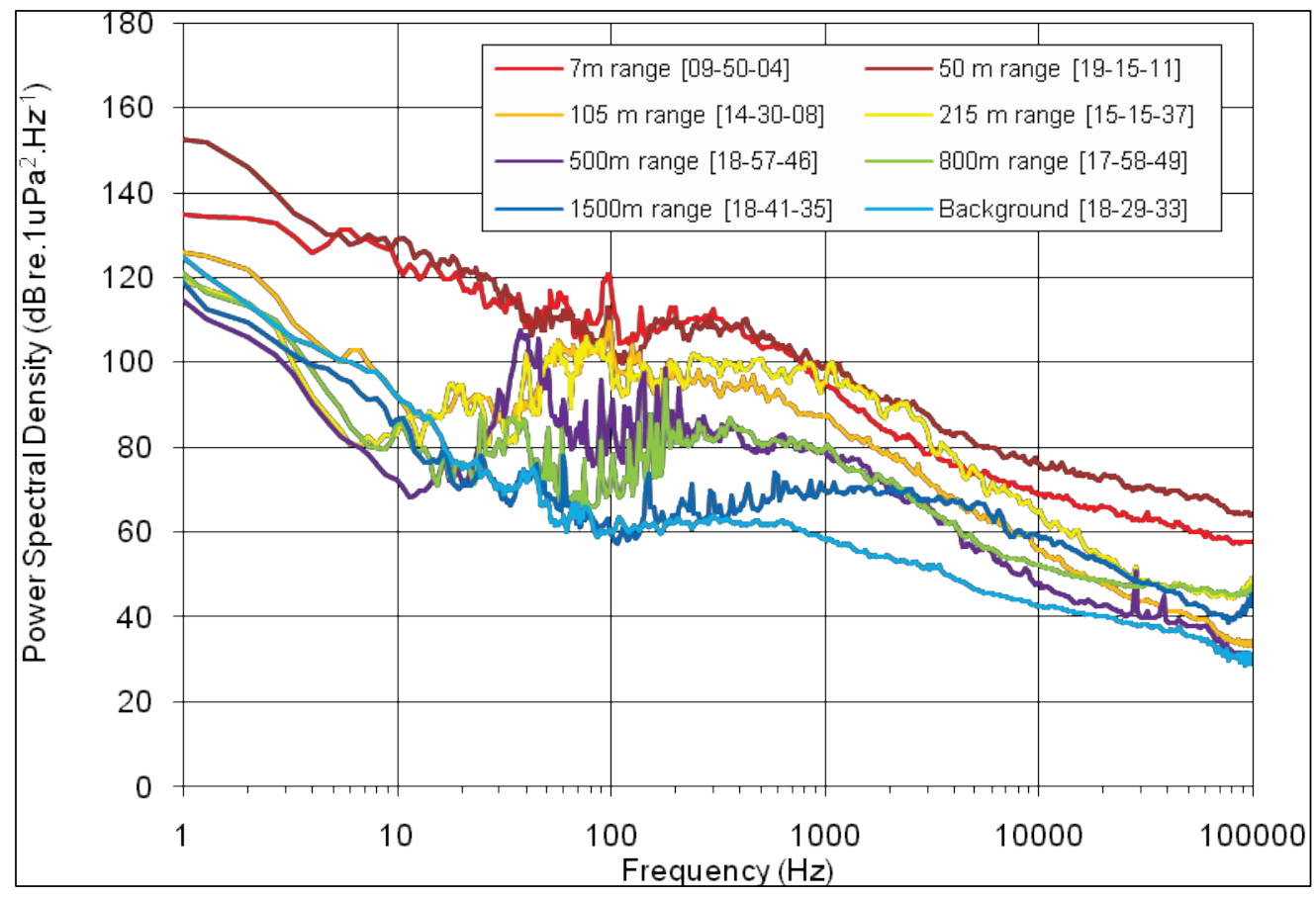


Figure 11. Comparison of spectral levels of underwater sound resulting from various backhoe excavation dredging movements in Lerwick, Shetland (from Nedwell et al. 2008).

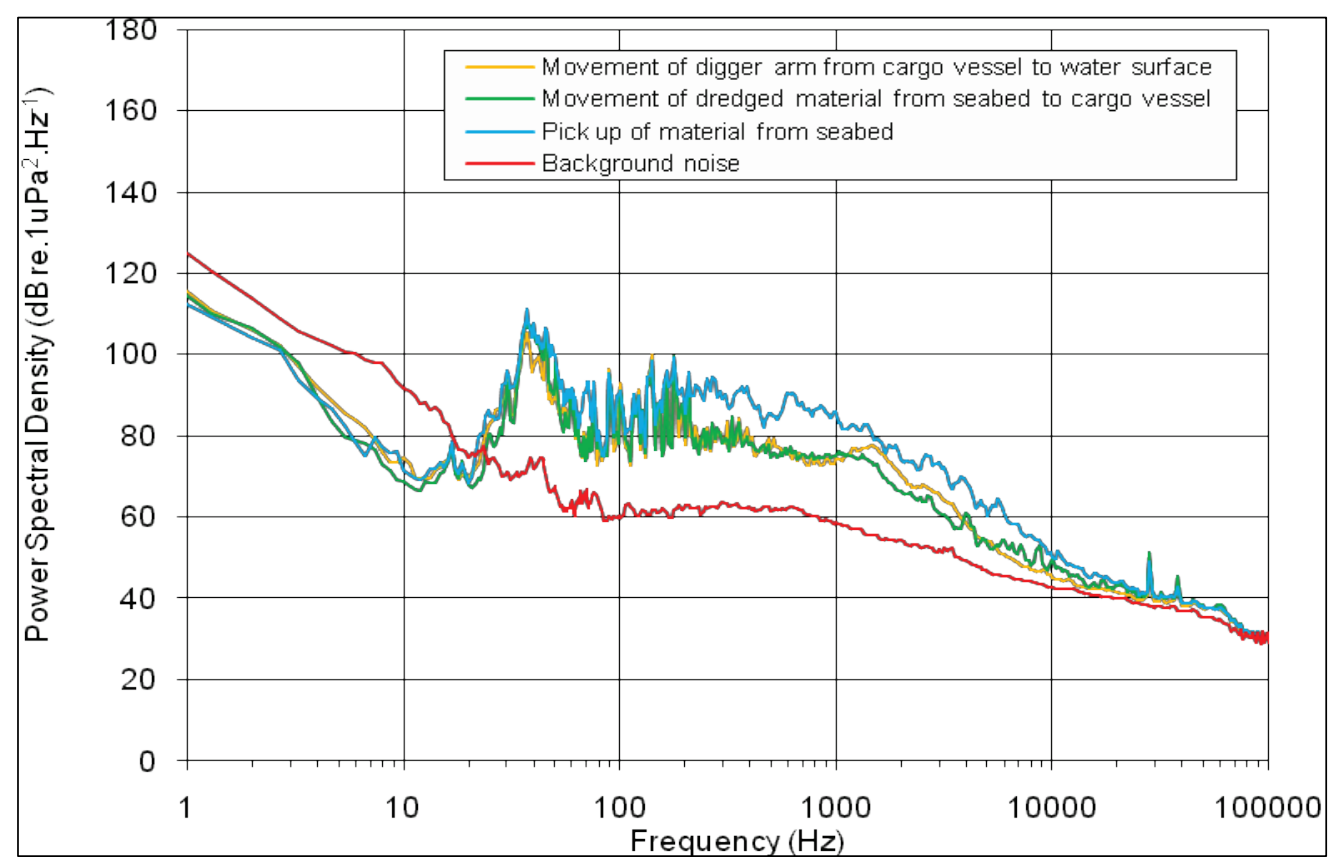

At $105 \mathrm{~m}$ from the BHD, the bucket grinding and scraping was still audible and reached a maximum SPL of $145 \mathrm{~dB}$ re $1 \mu \mathrm{Pa}$. More commonly, the underwater sound emanating from the BHD operations ranged from $132 \mathrm{~dB}$ re $1 \mu \mathrm{Pa}$ to $136 \mathrm{~dB}$ re $1 \mu \mathrm{Pa}$ (Nedwell et al. 2008). Based on a $10-\log (\mathrm{R} / 1 \mathrm{~m})$ scaling factor, source SPLs were estimated at $163 \mathrm{~dB}$ re $1 \mu \mathrm{Pa}$ at $1 \mathrm{~m}$.

Overall, Nedwell et al. (2008) observed that BHD activities increased the underwater sound relative to background sound levels at frequencies from about $20 \mathrm{~Hz}$ to approximately $20 \mathrm{kHz}$. A relatively continuous sound was generated by the dredge at the low frequency range from 20 to $80 \mathrm{~Hz}$, with peak spectral sound levels occurring between 35 and $45 \mathrm{~Hz}$ (Figure 11). These sounds were relatively consistent regardless of the dredging arm activity; therefore, they were likely a feature of the dredging generator systems.

\subsubsection{United Kingdom: Robinson et al. (2011)}

The MALSF published a study (Robinson et al. 2011) that provided data for the underwater sound levels generated by the seven TSHDs during marine aggregate (sand and gravel) excavation at three locations along the UK coast. Dredging (i.e., draghead on seabed, pump on, excavating aggregate, speed $1-2$ knots) and turning (i.e., draghead raised, pump on or off, state when turning at end of track) modes were assessed in water depths ranging from $27 \mathrm{~m}$ to $45 \mathrm{~m}$. 
Figure 12. Underwater sound output measured from seven TSHD in the UK fleet during typical operating conditions (taken from Robinson et al. 2011). Numbers in parentheses indicate study area where sounds were recorded along the UK coast.

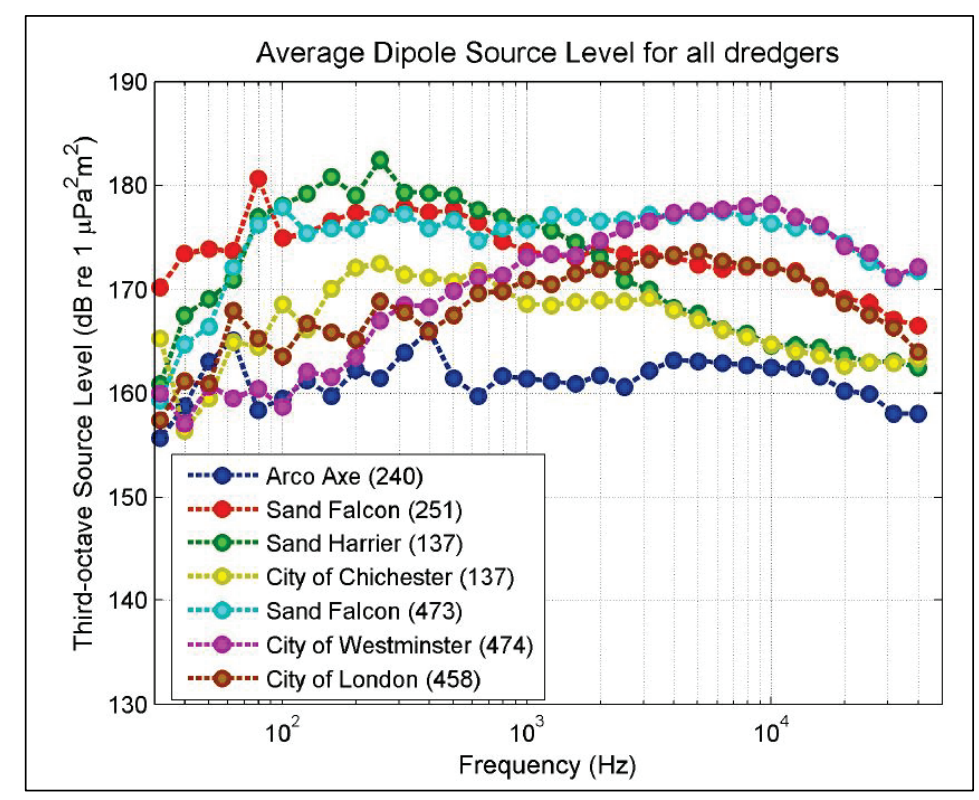

The results of the study indicated that the main energy of underwater sound originating from dredges were at frequencies less than $500 \mathrm{~Hz}$ (Figure 12) and were similar to those measured for cargo ships traveling at speeds reasonable for harbor transit (around 8-16 knots). Analysis of the data indicated that the primary source of higher frequency sounds $(>1,000 \mathrm{~Hz})$ were due to the abrasion of the aggregate material passing through the draghead, suction pipe, and pump (and possibly cavitation). Elevated broadband sound depended on the aggregate type being extracted, with coarse gravel generating greater SPLs than sand. Dredge transit sounds were not measured during this study.

\subsubsection{The Netherlands: Maasvlatke 2 studies}

The Port of Rotterdam began a major expansion beginning in 2008 to meet ever-increasing demands to accommodate larger cargo vessels. During the construction of Maasvlatke 2 expansion, several dredges (i.e., TSHD) were monitored and underwater sound during operations were measured (de Jong et al. 2010; Heinis et al. 2013).

During the Port of Rotterdam expansion, de Jong et al. (2010) measured underwater sound produced by several TSHD. Underwater sound was measured for dredging, transit, pumping, and discharge of sediment, 
which consisted mostly of sand. The authors developed a sound propagation model for shallow water areas and provided an estimate of the dipole source level spectra covering a wide frequency band. Dipole source levels of underwater sound accounts for the interactions of the direct and surface reflected sound propagation paths.

The results indicated that the greatest SPLs were recorded for large dredges during transit (at speeds up to 16 knots). The activity of dredging sand yielded source levels typically less than those for dredges in transit (Figure 13). Similarly, the activities of pumping and rainbowing (i.e., aerial discharge of dredged material as a fountain; in this case, while stationary) resulted in source levels similar to those recorded when dredging sand. Sand dumping produced the lowest SPLs, but the authors attributed this to the absence of cavitation sound from the propellers and bow thrusters which dominated all other measured dredging activities. The frequency range was typically between $500 \mathrm{~Hz}$ and $10 \mathrm{kHz}$. Broadband sound characteristics greater than $100 \mathrm{~Hz}$ were similar across dredging activities except sand dumping. The average dredging sounds measured among TSHD during operations were strikingly similar (Figure 14). In the 50 to $1000 \mathrm{~Hz}$ frequency range, TSHD SPLs ranged from 160 to $186 \mathrm{~dB}$ re $1 \mathrm{mPa}-\mathrm{m}$ in $1 / 3$ octave band (Figure 14). Overall, the authors indicated that cavitation sounds from propellers and bow thrusters were the main sound sources, especially during dredging and pumping (de Jong et al. 2010). 
Figure 13. Dipole source level ( $\mathrm{dB}$ re $1 \mu \mathrm{Pa}^{2} \mathrm{~m}^{2}$ ) in third octave bands (maximum of all measurements for each activity) for TSHD in transit, and while dredging, dumping, pumping, and rainbowing (from de Jong et al. 2010 (actually copied from Ainslie et al. 2012)).

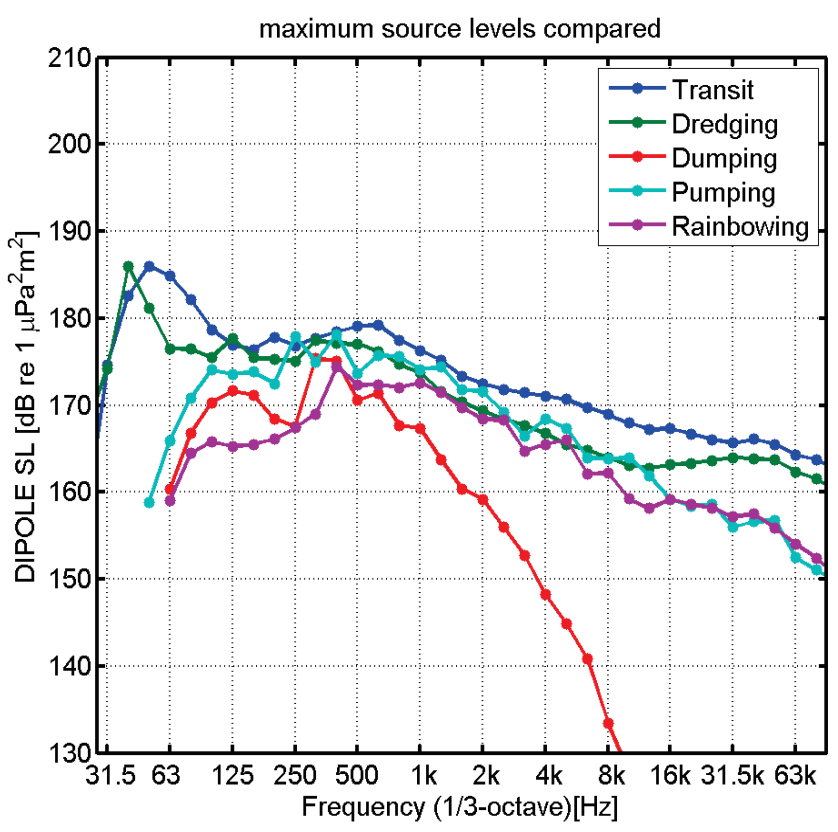

Figure 14. Comparison of dipole source level (dB re $\left.1 \mathrm{mPa}^{2} \mathrm{~m}^{2}\right)$ in $1 / 3$ octave bands of 6 TSHD (from de Jong et al. 2010).

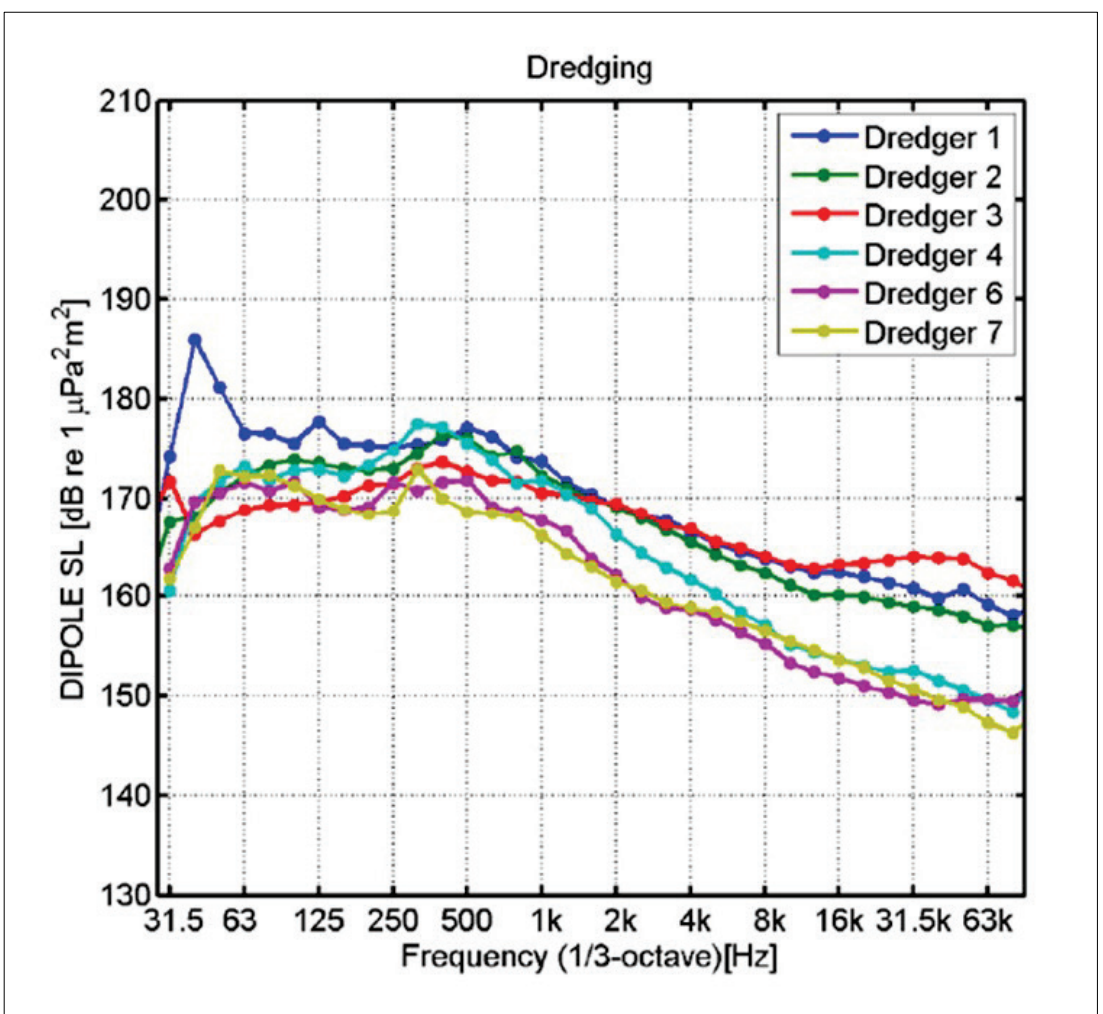




\subsubsection{United States: Dickerson et al. (2001)}

A study (Dickerson et al. 2001) was performed to characterize underwater sounds of a GD operation. Underwater sound was monitored for GD operations in Cook Inlet, Alaska, where the GD Viking was used to deepen the navigation channel and the GD Crystal Gayle was used to dredge the port docks. The GD operations were described as a repetitive sequence of sounds, with the sounds repeated on approximately 1 minute (min) intervals with periodic interruptions due to barge maneuvering and maintenance activities. SPLs (dB re $1 \mu$ Pa RMS) were recorded for six GD sound events measured at a distance of $150 \mathrm{~m}$ (Table 4 ).

Table 4. SPLs (dB re $1 \mu \mathrm{Pa}$ RMS) recorded for six GD sound events measured at a distance of $150 \mathrm{~m}$.

\begin{tabular}{|l|c|c|l|}
\hline $\begin{array}{l}\text { Dredge } \\
\text { activity }\end{array}$ & $\begin{array}{c}\text { SPL at } 150 \mathrm{~m} \\
(\mathrm{~dB} \text { re } \mu \mathrm{Pa} \mathrm{RMS})\end{array}$ & $\begin{array}{c}\text { Peak } \\
\text { frequency } \\
(\mathrm{Hz})\end{array}$ & Comment \\
\hline $\begin{array}{l}\text { Bucket striking } \\
\text { channel bottom }\end{array}$ & 124 & 162.8 & - \\
\hline Bucket digging & 113.2 & 40.4 & for coarse sediment and/or gravel \\
\hline Bucket closing & 99.2 & 316.3 & lowest underwater sound during dredge cycle \\
\hline Winch in/out & 116.6 & 34.9 & - \\
\hline $\begin{array}{l}\text { Dumping } \\
\text { material into barge }\end{array}$ & 108.6 & 82.1 & $\begin{array}{l}\text { sounds were dependent on volume of material in } \\
\text { barge, as more material was placed in barge, } \\
\text { SPLs were often less due to loss of transmission } \\
\text { through material and hull }\end{array}$ \\
\hline $\begin{array}{l}\text { Emptying barge at } \\
\text { placement site }\end{array}$ & 108.7 & 45.8 & - \\
\hline
\end{tabular}

As a basis for comparison, ambient sound measurements taken in a location away from the influence of dredging activities yielded peak ambient sound at $73.2 \mathrm{~dB}$ (relative $\mathrm{dB} \mathrm{RMS}$ ) at a peak frequency of $57.8 \mathrm{~Hz}$. In general, ambient sound averaged $60 \mathrm{~dB}$ at frequencies less than $100 \mathrm{~Hz}$ and about $50 \mathrm{~dB}$ level at frequencies ranging from $100 \mathrm{~Hz}$ to $1 \mathrm{kHz}$.

Underwater sounds produced from GD operations were quite variable, depending on the phase of the operation. Underwater sounds produced during GD operations in decreasing order of sounds produced were bucket striking the channel bottom, winch motor, bucket digging, bucket closing, and dumping material in a hopper barge. The buckets striking the channel bottom were dependent on substrate type, as buckets striking coarse sediments produced more sound than strikes in unconsolidated muds. Sounds produced during bucket closing events were variable and not always audible. Sound produced from dumping material into the hopper barge attenuated most rapidly with increasing distance from the sound source, 
with no audible sounds detected beyond $1,200 \mathrm{~m}$. The authors reported that SPLs (relative dB RMS) diminished from 15 to $30 \mathrm{~dB}$ at $150 \mathrm{~m}$ and $5,500 \mathrm{~m}$ distance from the dredge source. All dredging-related sounds were not detectable beyond $5.5 \mathrm{~km}$, with the exception of the bucket striking the channel bottom, which was slightly above background at $7 \mathrm{~km}$.

\subsubsection{United States: Clarke et al. (2002)}

Clark et al. (2002) characterized underwater sounds generated by GD, CSD, and TSHD operations. The 1,500 hp GD Viking (10 yd $3\left(8.4 \mathrm{~m}^{3}\right)$ bucket) was monitored while dredging coarse sand and gravel in Cook Inlet, Alaska, during the deepening of the entrance channel to the Port of Anchorage. The CSD James B, a 10,000 hp dredge with a 24-inch (0.6 m) discharge pipe diameter (Lake Michigan Contractors Dredge), was monitored during channel maintenance in Mississippi Sound, Mississippi. The TSHD Stuyvesant (Bean Stuyvesant), a 15,000 hp dredge with an $11,140 \mathrm{yd}^{3}\left(9,314 \mathrm{~m}^{3}\right)$ capacity, was monitored during maintenance and subsequent transport of dredged material to an offshore placement site in upper Mobile Bay, Alabama.

The authors found that the intensity, periodicity, and spectra of sounds produced differed substantially between the three dredges studied.

Consistent with sounds observed by Dickerson et al. (2001), GDs produce a repetitive sequence of sounds generated by winches, bucket impact with the substrate, bucket closing, and bucket emptying. Sounds from the CSD generated more continuous sound produced as the cutterhead rotated in bottom sediment. TSHD sounds were produced from two continuous sources (engine and propeller sounds), and sounds from the draghead contacting sediments. The authors noted that underwater sounds produced by dredges are dependent on several factors, including substrate type, geomorphology of the waterway, site-specific hydrodynamic conditions, equipment maintenance status, and skill of the dredge plant operator.

The authors reported sound attenuation over distance when the GD's bucket struck the channel bottom. A reduction of $30 \mathrm{~dB}$ re $1 \mu \mathrm{Pa}-\mathrm{m}$ occurred between the $150 \mathrm{~m}$ (124.01 dB re $1 \mu \mathrm{Pa}-\mathrm{m}$; peak frequency $162.9 \mathrm{~Hz}$ ) and 5,000 $\mathrm{m}$ distance from the dredge $(94.97 \mathrm{~dB}$ re $1 \mathrm{mPa}-\mathrm{m}$; peak frequency $72.7 \mathrm{~Hz}$ ). The authors detected only faintly audible sounds at $7 \mathrm{~km}$ from the sound source. 


\subsubsection{United States: Reine et al. (2012a)}

Reine et al. (2012a; also reported in Reine et al. 2014a) characterized sounds produced by the dredge New York, a 3,434-hp BHD (Great Lakes Dredge and Dock) during removal of coarse gravel-sized rock in New York/New Jersey Harbor as part of a channel deepening project. The authors also monitored ambient sounds in several locations in the harbor unrelated to dredging operations.

Most of underwater sounds recorded during operation of the BHD were of low frequency, generally in the range of $130 \mathrm{~Hz}$ to $1.25 \mathrm{kHz}$. The lowest frequency sounds $(<200 \mathrm{~Hz}$ ) were associated with spud walking; the highest frequencies $(1.25 \mathrm{kHz})$ were associated with raising or lowering the spuds during movement or anchoring. The most intense sounds were when the bucket was drawn backwards to fill with material, which produced grinding and scraping sounds and when the spuds were raised and lowered. Source levels for the bucket were $179 \mathrm{~dB}$ re $1 \mu \mathrm{Pa}$ at $1 \mathrm{~m}$. Source levels were less when spuds were raised and lowered (176 dB re $1 \mu \mathrm{Pa}$ at $1 \mathrm{~m}$ ) and during spud walking (172 $\mathrm{dB}$ re $1 \mu \mathrm{Pa}$ at $1 \mathrm{~m}$ ).

The authors also reported source levels for four other sound events during BHD activities, all with similar source levels. These sound sources included popping sounds (SPL $=167.1 \mathrm{~dB}$ re $1 \mu \mathrm{Pa}$ at $1 \mathrm{~m}$ ), engine/generator sounds $(\mathrm{SPL}=167 \mathrm{~dB}$ re $1 \mu \mathrm{Pa}$ at $1 \mathrm{~m})$, barge loading sounds $(\mathrm{SPL}=166 \mathrm{~dB}$ re $1 \mu \mathrm{Pa}$ at $1 \mathrm{~m}$ ), and hydraulic ram sounds (SPL of $164 \mathrm{~dB}$ re $1 \mu \mathrm{Pa}$ at $1 \mathrm{~m}$ ).

A plot of ambient sound measurements (e.g., wind, waves, tidal flows, precipitation, and traffic sound from fishing and commercial shipping vessels) recorded at 11 locations in the harbor indicated a range from 97 to $131 \mathrm{~dB}$ re $1 \mu \mathrm{Pa}$ RMS (mean $=117 \mathrm{~dB}$ re $1 \mu \mathrm{Pa})$. The use of spuds, bottom grabs, and spud walking exceeded the maximum ambient SPL by $45 \mathrm{~dB}$, $48 \mathrm{~dB}$, and $41 \mathrm{~dB}$, respectively. The SPL levels for popping, engine/generator, barge loading, and hydraulic ram sound sources exceeded maximum ambient SPLs by 33 to $36 \mathrm{~dB}$ re $1 \mu \mathrm{Pa}$ at $1 \mathrm{~m}$.

The source range for the BHD New York for all sound sources measured was 164 to $179 \mathrm{~dB}$ re $1 \mu \mathrm{Pa}$ at $1 \mathrm{~m}$. Similarly, in the only other BHD sound reported in the literature, the Manu Peeka had a measured sound source of $163 \mathrm{~dB}$ re $1 \mu \mathrm{Pa}$ at $1 \mathrm{~m}$ (Nedwell et al. 2008). Both reported BHD SPLs were slightly less when compared to source levels reported for CSD (168- 
$178 \mathrm{~dB}$ re $1 \mu \mathrm{Pa}$ at $1 \mathrm{~m}$; Greene 1987$)$ and TSHD (190 dB re $1 \mu \mathrm{Pa}$ at $1 \mathrm{~m}$ ) reported by Nedwell et al. (2008).

\subsubsection{United States: Reine et al. (2012b)}

Reine et al. (2012b) reported the results of underwater sound monitoring during the fracturing of limestone rock in New York/New Jersey Harbor as part of a channel deepening project. The resultant fractured material was removed by a BHD as described in Reine et al. (2012a) and Reine et al. (2014a). The CSD Florida (Great Lakes Dredge and Dock) had suction and discharge diameters of $940 \mathrm{~mm}$ and $914 \mathrm{~mm}$, respectively, and used a 3,000 hp Esco 54D $3.3 \mathrm{~m}$ diameter (diam) cutter rotating at $26 \mathrm{rpm}$. The total installed power was $25,400 \mathrm{hp}$, of which $10,000 \mathrm{hp}$ operated the main pump.

Most of the underwater sounds produced by the CSD Florida were relatively continuous and at a low frequency-generally less than $1000 \mathrm{~Hz}-$ occurring most frequently in the $800 \mathrm{~Hz}, 1,000 \mathrm{~Hz}$, and $2,500 \mathrm{~Hz} 1 / 3$-octave bands. The CSD rock-fracturing source level ranged between 170 and $175 \mathrm{~dB}$ re $1 \mu \mathrm{Pa}$ at $1 \mathrm{~m}$, with sound levels decreasing with increasing distance from the dredge. The farthest distance the authors detected sound was about $800 \mathrm{~m}$. Using a fitted regression (15LogR), the authors back-calculated SPL as loss attributable to practical spreading and $175 \mathrm{~dB}$ as a source level, estimating the SPL would diminish to $132 \mathrm{~dB}$ at a distance of $800 \mathrm{~m}$ from the dredge, approximating the maximum (131 dB) ambient value (see Reine et al. 2012a; previous section).

Figure 15 plots SPL versus distance during monitoring of the dredge Florida operations, signifying the variation recorded in SPL at distance and depth. SPL differed by as much as 10 to $15 \mathrm{~dB}$ at distances of less than $200 \mathrm{~m}$, but typically this variance decreased to less than $4 \mathrm{~dB}$ with increasing distance from the dredge. Overall, the authors observed considerable variability in SPL measured at specific distances, a fact that they attributed to distance from the sound source, orientation related to the dredge, position of the Florida swinging laterally, and to the noncontinuous sediment removal process. 
Figure 15. Underwater sound results for $1 / 3$ octave (SPL in dB re $1 \mu \mathrm{Pa}$ ) RMS versus distance from the dredge source $(m)$ (from Reine et al. 2012b).

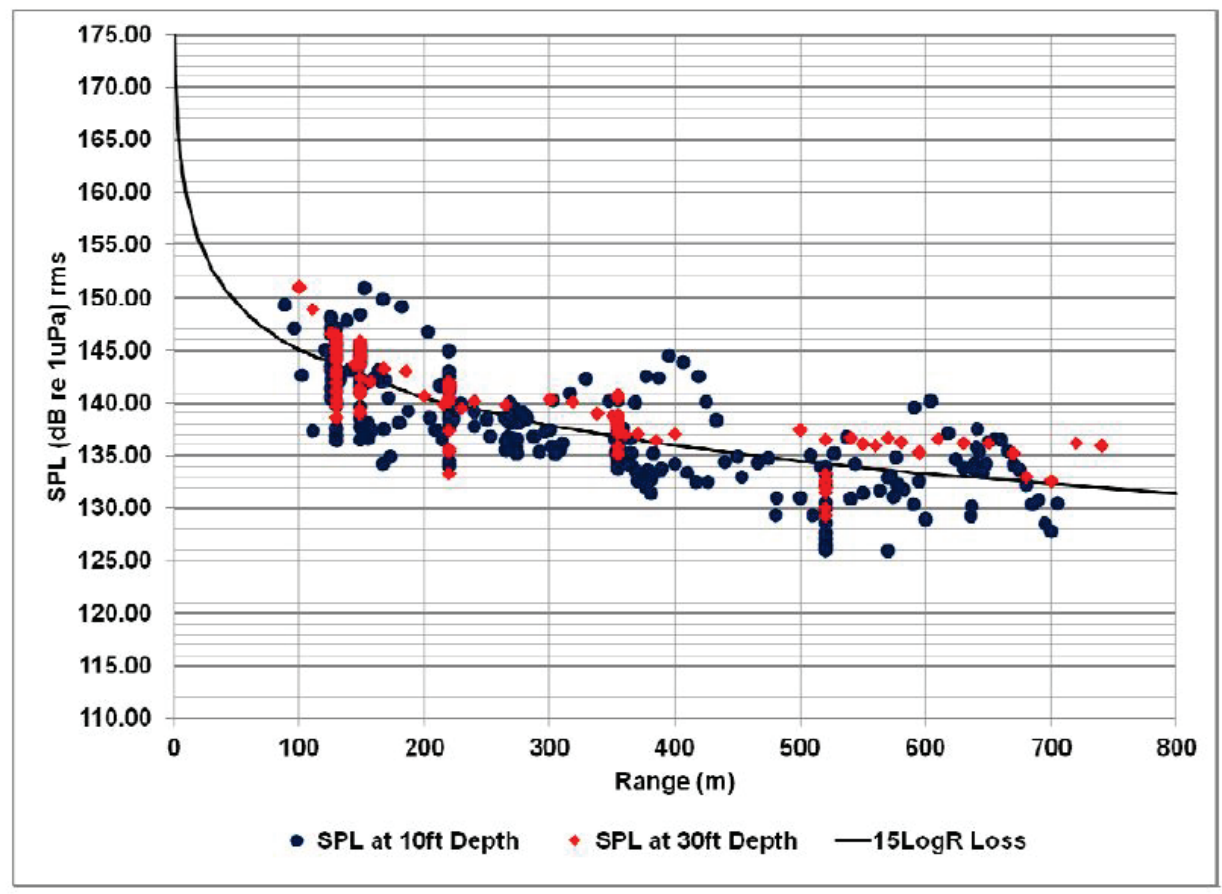

\subsubsection{United States: Reine et al. (2014b)}

Underwater sounds were characterized for three TSHD during sand excavation from an offshore borrow area and during transfer of the sediment at the placement site at Wallops Island, Virginia (Reine et al. 2014b). Sound sources related to TSHD operations were excavation, pump-out of material, pump-out of clear water during pipe flushing, transit to the borrow site (hopper empty) and transit to the pump-out stations (hopper loaded). Of the three TSHD monitored, the dredge Liberty Island is larger and more powerful than the smaller Padre Island and Dodge Island. The propulsion power (kW) for the Liberty Island was 2.3 times greater than the Padre Island and 3.3 times greater than the Dodge Island. In transit, the dredge Liberty Island transited at 12 knots, the Dodge Island at 11 knots, and the Padre Island at 10 knots.

Source Levels (dB re $1 \mu \mathrm{Pa}$ at $1 \mathrm{~m}, \mathrm{RMS}$ ) back-calculated by the authors using fitted regression (15.788LogR) ranged from $161.3 \mathrm{~dB}$ to $176.7 \mathrm{~dB}$ re $1 \mu \mathrm{Pa}$ at $1 \mathrm{~m}$ RMS. The highest SL were produced by the Dredge Liberty Island, which had nearly twice the installed power $(12,300 \mathrm{~kW})$ than the dredges Padre Island and Dodge Island (each with installed power of approximately 7,000 $\mathrm{kW}$ ). Transit produced the highest SL regardless of whether the hopper was empty or full. 
At $50 \mathrm{~m}$ from the source-the closest distance monitored by the authorsresults from the $1 / 3$-octave analysis for all three dredges and activities combined resulted in an overall SPL of $147.7 \mathrm{~dB}$ (Figure 16). Sediment removal produced the most underwater sound ( $151 \mathrm{~dB})$, followed closely by transition from transit to digging ( $150 \mathrm{~dB})$. The TSHD activities producing the least sound were transition from pump-out to transit and pump-out of seawater during flushing of dredge pipes. SPLs (1/3-octave) averaged 138 to $139 \mathrm{~dB}$, roughly $12-15 \mathrm{~dB}$ less than during sediment removal. On a $1 / 3$ octave basis, the greatest sounds produced by the three TSHD monitored were less than $500 \mathrm{~Hz}$ (Figure 16).

Figure 16. 1/3 octave analysis for the three TSHD and dredging activities events combined (from Reine et al. 2014b). Scale at right is the range $(\mathrm{m})$ from the source.

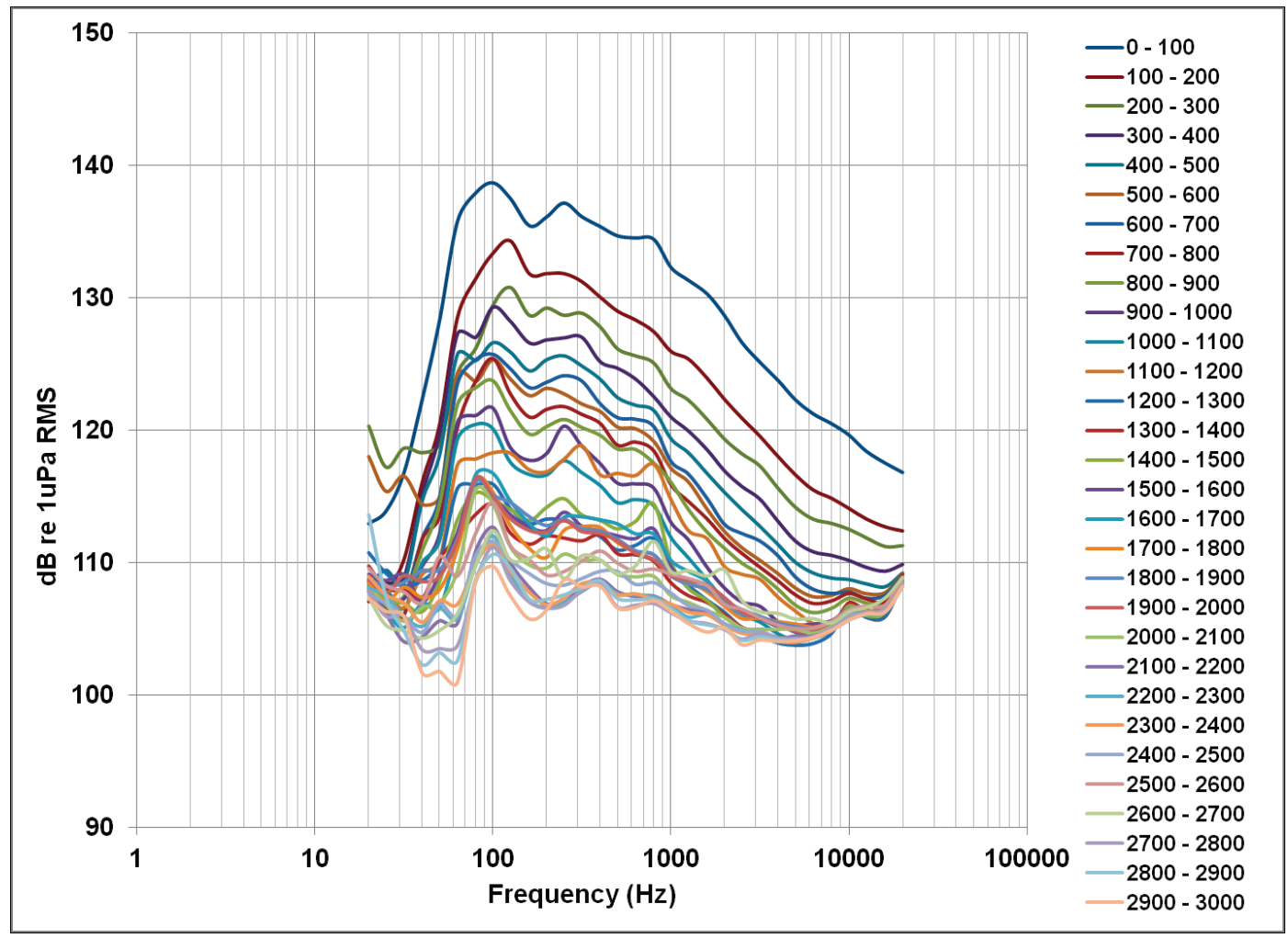

The authors also measured ambient underwater sound (absent of dredging activities) at four locations (inshore, offshore, borrow area, and pump-out stations) at two water depths ( 3 and $6 \mathrm{~m}$ ) and for wind speeds ranging from Beaufort 1 (1-2 knots) to Beaufort 4 (11-15 knots). Combining measurements across all sampling days, sites, water depths, and weather conditions yielded an ambient SPL of $117 \mathrm{~dB}$ re $1 \mu \mathrm{Pa}$ and a $1 / 3$ octave SPL of $121 \mathrm{~dB}$. The two activities producing the most underwater sound (sediment removal at $151 \mathrm{~dB}$ ) and transition from transit to digging 
(150 dB) exceeded ambient level by about 29-30 dB. Attenuation to ambient was dependent on the sound source, but at a $2.5 \mathrm{~km}$ distance from the dredge, underwater sounds generated by all three dredges for all TSHD activities had reduced to ambient levels.

\subsubsection{United States: Reine and Dickerson (2014)}

Reine and Dickerson (2014) monitored underwater sounds generated by the CSD Veracious (Vortex Marine) during maintenance dredging in the Stockton Deepwater Ship Channel, California. The total power of the Veracious operating the main pumps (1,00o hp) was used to pump dredged material through a 16 inch (in.) ( $0.4 \mathrm{~m}$ ) pipeline to an upland confined placement facility.

Most of the underwater sounds produced by Veracious were of relatively low frequency $(<1,000 \mathrm{~Hz})$. Source level, determined by the authors via curvilinear regression, ranged from $151 \mathrm{~dB}$ (upstream, bow) to $157 \mathrm{~dB}$ (downstream, astern) re $1 \mu \mathrm{Pa}$ at $1 \mathrm{~m}$. An average SL of $153 \mathrm{~dB}$ re $1 \mu \mathrm{Pa}$ at $1 \mathrm{~m}$ was determined for all data combined.

The authors reported data for ambient sound from eight locations in the Port Stockton navigation channel study area in the absence of dredging activities. The authors reported a 5oth percentile SPL of the ambient data at $118 \mathrm{~dB}$. This value incorporated generator sound (from moored ships) and port activity sounds, but did not include underwater sound generated from vessels transiting the study area. The average SL of $153 \mathrm{~dB}$ re $1 \mu \mathrm{Pa}$ at $1 \mathrm{~m}$ for all dredging activities was $35 \mathrm{~dB}$ greater than the 5oth percentile ambient SPL (118 dB).

\subsection{Blasting}

Overall, blasting is not routinely required in navigational dredge operations. In some cases, however, bottom substrate hardness or geotechnical characteristics inhibit the ability to dredge navigation channels using hydraulic or mechanical methods. In these situations, underwater blasting may be necessary to fragment the substrate prior to dredging. The energy distribution from an underwater explosion is categorized into two phases: pressure (shock) wave $(>200 \mathrm{~Hz})$ and bubble pulse (<200 Hz; Baker 2008; Normandeau 2012). In addition to wave propagation in the water column, ground vibrations following blasts are important exposure characteristics. Underwater explosions detonated 
freely in the water column (e.g., on a rock surface) produce substantially greater shock waves (up to 10 times greater) as compared to explosives used in boreholes, which are designed to minimize propagation of pressure waves in the water column and potentially lessen effects on aquatic biota (Hempen et al. 2007; IADC 2016). Therefore, the ecological risks associated with charges detonated in confined boreholes will be fundamentally different as compared to open-water blasts.

Acoustical characteristics monitored in terms of "peak" SPLs from underwater blasting using confined boreholes in shallow water (i.e., $10 \mathrm{~m}$ ) were approximately $220 \mathrm{~dB}$ re $1 \mu \mathrm{Pa}$ at $1 \mathrm{~m}$ from source, decreasing to $180 \mathrm{~dB}$ re $1 \mu \mathrm{Pa}$ at 1,000 $\mathrm{m}$ distance from source (Hall 2010). Important components of blasting that influence pressure wave propagation (e.g., SPL, pounds per second inch (psi), etc.) and ground vibrations include the quantity and size of charges, characteristic of rock, borehole placement, water depth, and firing sequence (IADC 2016). Few studies were found monitoring blasting events during dredging activities; these are discussed below. It should be noted that reported metrics related to blasting (e.g., psi, ground particle motion $(\mathrm{mm} / \mathrm{s})$ ) make comparisons across studies challenging.

Carlson et al. (2011) monitored underwater rock blasting in a 1-mile section of the Columbia River during the 2011 navigation expansion project. For the widening and deepening of the channel, blasting was used in conjunction with dredging to remove approximately $300,000 \mathrm{~m}^{3}$ of basalt rock formations. The study monitored 99 blast events over approximately four months. Charges were confined to boreholes with stemming (i.e., boreholes back-filled with pea gravel). Blast events resulted in very complex underwater sound, which was influenced by the array of blast charges and sequence of blasts. Underwater blast pressures measured in kilopascals, $\mathrm{kPa}$ (where $\mathrm{k}=1,000$ ), in the immediate vicinity of the blasting zone ranged from $28 \mathrm{kPa}$ to $164 \mathrm{kPa}$ ( 4 to $24 \mathrm{psi}$ ). During the blasting events, detailed surveys of fish were conducted to evaluate potential adverse effects (discussed in more detail in Section 5.2).

Hempen et al. (2007) recorded underwater blast pressures during a Miami Harbor Channel Deepening project. Blast charges were confined in boreholes with stemming (i.e., boreholes back-filled with aggregate material). Maximum pressure following blasting was approximately $30 \mathrm{psi}$. Maximum recorded pressures generally did not clearly correlate with charge 
weight. This was likely the case due to the other factors influencing the pressure wave (e.g., firing sequence, borehole depth and confinement, etc.). The range of pressures recorded (from confined holes) ranged from 10 to 90 psi. Overall, this study was one of the first to confirm in the field that detonations in open water produce higher amplitudes and more rapidly oscillating shock waves as compared to rock removal (borehole) blasts.

Tripathy and Shirke (2015) monitored 36 blast events during drilling and blasting of rock associated with the dredging and deepening of a port in Mumbai, India. Underwater drilling, blasting, and dredging was used to remove approximately 25,000 $\mathrm{m}^{3}$ of basalt rock. Due to the proximity of the blasting to historical and culturally significant structures near the port, ground vibrations following blasts were monitored. "Safe" levels of ground particle motion were based on existing recommendations for historical structures. During the 36 blast events, ground vibrations were $<0.25 \mathrm{~mm} / \mathrm{s}$, below the threshold of vibrations levels ( $>1 \mathrm{~mm} / \mathrm{s}$ ) estimated to be protective of structural damage. The Tripathy and Shirke (2015) study confirmed that use of boreholes and delayed detonations substantially reduced the effects of underwater shock waves and shock wave propagation as compared to open-water blasting.

\subsection{Summary}

Underwater sound produced by hydraulic and mechanical dredge operations in the U.S. and Europe has been studied for several decades (Table 5; Figure 17). Acoustical characteristics related to the dredge activity can be categorized as excavation, transiting, and placement. Primary sources of sound from dredging are commonly machinery, propulsion, and excavation of substrate (e.g., aggregate). Cavitation sounds from propellers and pumps were the primary source of the highest continuous SPLS reported. Dredging activities producing the lowest SPLs generally included sand depositing, depositing in a scow or hopper, and bucket closing on the channel bottom. Overall, source level SPLs associated with dredging operations commonly range from approximately $\sim 100$ to $190 \mathrm{~dB}$ (RMS) re $1 \mu \mathrm{PA}$ at $1 \mathrm{~m}$. In general, SPLs from dredging activities are similar to levels reported for underwater sound associated with commercial shipping (Figure 17). It should be noted that the acoustical characteristics are often summarized as single maximum recorded values near the dredge (i.e., $1 \mathrm{~m}$ from source). Additionally, a single sound event (e.g., propeller cavitation) can skew the calculated SPLs (RMS) and may not provide an accurate representation of the dredging operation. 
Figure 17. Summary of underwater SPLs by dredging type: cutter suction dredge (CSD); trailing suction hopper dredge (TSHD); grab dredge (GD); and backhoe dredge (BHD). Source Level data from Table 5.

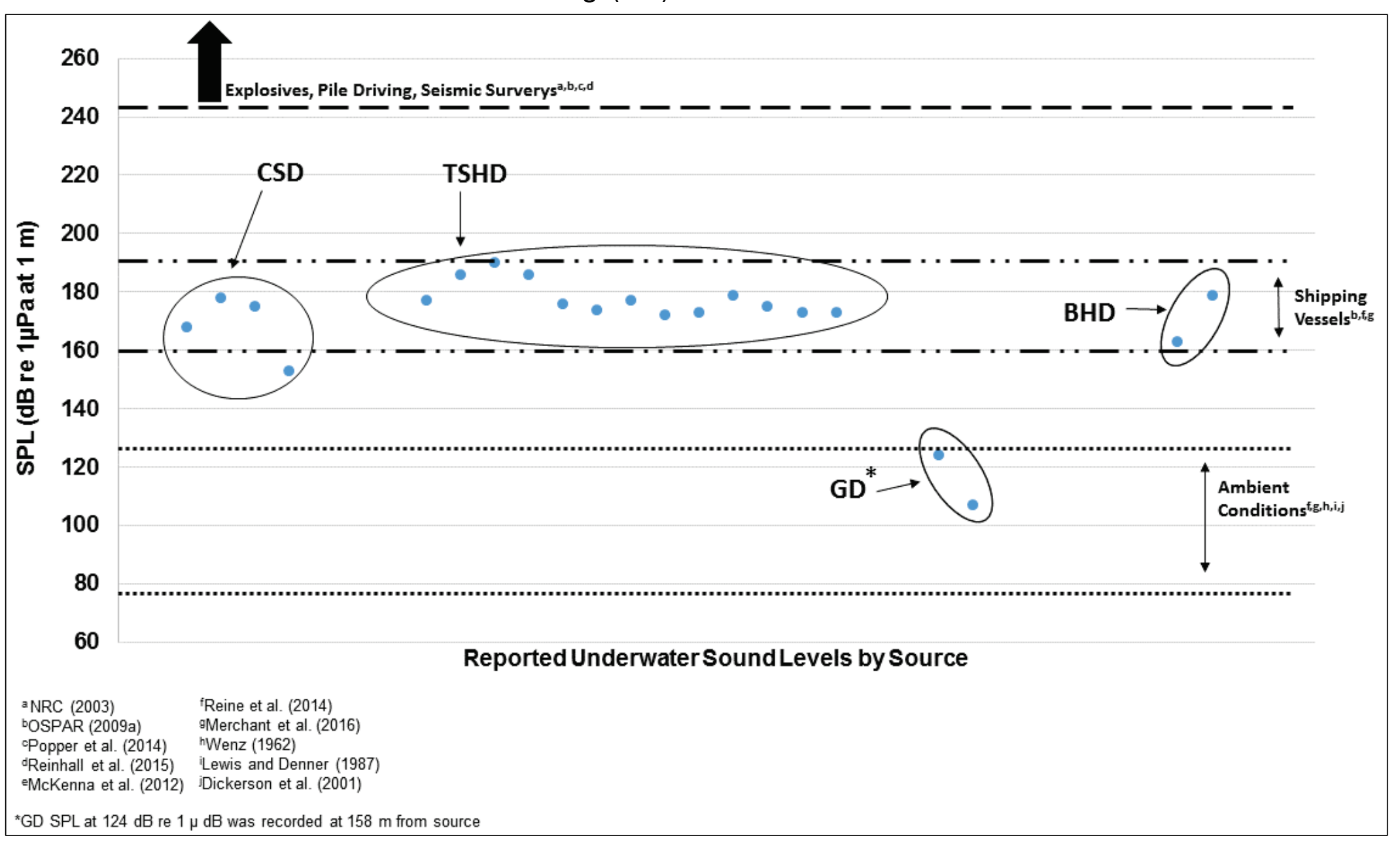


Table 5. Summary of underwater sound measurements by dredging type.

\begin{tabular}{|c|c|c|c|c|c|c|c|}
\hline $\begin{array}{l}\text { Dredger } \\
\text { type }\end{array}$ & Reference & Ship name & $\begin{array}{c}\text { Installed } \\
\text { power (kW) }\end{array}$ & $\begin{array}{l}\text { Dredger size } \\
\text { indicator }\end{array}$ & $\begin{array}{l}\text { Sound pressure } \\
\text { level }\end{array}$ & $\begin{array}{l}\text { Peak spectral level (dB } \\
\text { re } 1 \mu \mathrm{Pa} / \mathrm{Hz} \text { ) }\end{array}$ & $\begin{array}{l}\text { 1/3 Octave receive } \\
\text { levels (dB re } 1 \mu \mathrm{Pa} \text { ) }\end{array}$ \\
\hline CSD & Greene $1987^{a}$ & $\begin{array}{l}\text { Beaver } \\
\text { Mackenzie }\end{array}$ & $\begin{array}{l}1,100- \\
1,300\end{array}$ & $\begin{array}{c}\text { Transfer rate: } \\
100,000 \mathrm{~m}^{3} / \text { day }\end{array}$ & $\begin{array}{l}168 \mathrm{~dB} \text { re } 1 \mu \mathrm{PA}-\mathrm{m} \\
\text { in } 1 / 3 \text { Octave at } 80 \\
\mathrm{~Hz}{ }^{\mathrm{a}}\end{array}$ & $122 \mathrm{~dB}(120 \mathrm{~Hz}, 190 \mathrm{~m})$ & $\begin{array}{l}128 \mathrm{~dB}(80 \mathrm{~Hz}, \\
200 \mathrm{~m})\end{array}$ \\
\hline CSD & Greene 1987a & Aquarius & 12,889 & $\begin{array}{c}\text { Transfer rate: } \\
100,000 \mathrm{~m}^{3} / \text { day }\end{array}$ & $\begin{array}{l}178 \mathrm{~dB} \text { re } 1 \mu \mathrm{PA}-\mathrm{m} \\
\text { in } 1 / 3 \text { Octave at } \\
125 \mathrm{Hza}\end{array}$ & $122 \mathrm{~dB}(200 \mathrm{~Hz}, 200 \mathrm{~m})$ & $\begin{array}{l}134 \mathrm{~dB}(160 \mathrm{~Hz} \\
125 \mathrm{~Hz})\end{array}$ \\
\hline CSD & Clarke et al. 2002 & James B* & 6,300 & $\begin{array}{c}\text { 10,000 hp with a 24" } \\
\text { discharge pipe }\end{array}$ & - & $\begin{array}{l}112 \mathrm{~dB}(105 \mathrm{~Hz},< \\
500 \mathrm{~m})\end{array}$ & - \\
\hline CSD & Reine et al. $2012^{b}$ & Florida* & 25,400 & $\begin{array}{c}10,000 \text { hp with a } \\
130 " \text { cutter }\end{array}$ & $175 \mathrm{~dB}$ re $1 \mu \mathrm{Pa}-\mathrm{m}$ & - & - \\
\hline CSD & $\begin{array}{l}\text { Reine and Dickerson } \\
2014\end{array}$ & Veracious* & 1,000 & - & $153 \mathrm{~dB}$ re $1 \mu \mathrm{Pa}-\mathrm{m}$ & - & - \\
\hline TSHD & Greene $1987^{a}$ & Cornelis Zanen & 12,064 & Capacity $8,000 \mathrm{~m}^{3}$ & $142 \mathrm{~dB}($ at $930 \mathrm{~m}$ ) & $125 \mathrm{~dB}(175 \mathrm{~Hz}, 930 \mathrm{~m})$ & - \\
\hline TSHD & Greene $1987^{a}$ & $\begin{array}{l}\text { Geophotes X } \\
\text { (Inai Selasih) }\end{array}$ & 15,384 & Capacity $8,000 \mathrm{~m}^{3}$ & $139 \mathrm{~dB}$ (at $430 \mathrm{~m}$ ) & $125 \mathrm{~dB}(100 \mathrm{~Hz}, 430 \mathrm{~m})$ & $\begin{array}{l}147 \mathrm{~dB}(80 \mathrm{~Hz}, \\
500 \mathrm{~m})\end{array}$ \\
\hline TSHD & Greene $1987^{a}$ & W.D. Gateway & 13,870 & Capacity $12,000 \mathrm{~m}^{3}$ & $131 \mathrm{~dB}$ (at $1.5 \mathrm{~km}$ ) & $131 \mathrm{~dB}(350 \mathrm{~Hz}, 1.5 \mathrm{kM})$ & - \\
\hline TSHD & Clarke et al. 2002 & Stuyvesant* & 15,000 & Capacity 9,314 m³ & - & $142 \mathrm{~dB}(105 \mathrm{~Hz},>40 \mathrm{~m})$ & - \\
\hline TSHD & Defra 2003 & Acro Adur & 1,100 & Capacity $2,890 \mathrm{~m}^{3}$ & - & $122 \mathrm{~dB}(320 \mathrm{~Hz}, 50 \mathrm{~m})$ & - \\
\hline TSHD & Gerstein et al. 2006 & Columbia & 2,800 & - & $177 \mathrm{~dB}$ re $1 \mu \mathrm{Pa}-\mathrm{m}$ & - & - \\
\hline TSHD & Parvin et al. $2008^{c}$ & \begin{tabular}{|l|} 
The City of \\
Westminster
\end{tabular} & $2 \times 1,950$ & Capacity $2,700 \mathrm{~m}^{3}$ & $186 \mathrm{~dB}$ re $1 \mu \mathrm{Pa}-\mathrm{m}$ & $125 \mathrm{~dB}(80 \mathrm{~Hz}, 251 \mathrm{~m})$ & $\begin{array}{l}126 \mathrm{~dB}(31.5 \mathrm{~Hz} \& \\
100 \mathrm{~Hz}, 514 \mathrm{~m})\end{array}$ \\
\hline TSHD & Nedwell et al. 2008d & - & - & - & $190 \mathrm{~dB}$ re $1 \mu \mathrm{Pa}-\mathrm{m}$ & - & - \\
\hline TSHD & de Jong et al. 2010e,f & Dredger \#1 & $\begin{array}{l}8,000- \\
30,000\end{array}$ & $\begin{array}{c}\text { Capacity } 3,000- \\
20,000 \mathrm{~m}^{3}\end{array}$ & $\begin{array}{l}186 \mathrm{~dB} \text { re } 1 \mu \mathrm{Pa}-\mathrm{m} \\
\text { in } 1 / 3 \text { Octave at } 45 \\
\mathrm{~Hz}\end{array}$ & - & - \\
\hline TSHD & de Jong et al. 2010e & Dredger \#2 & $\begin{array}{l}8,000- \\
30,000\end{array}$ & $\begin{array}{l}\text { Capacity } 3,000- \\
20,000 \mathrm{~m}^{3}\end{array}$ & $\begin{array}{l}176 \mathrm{~dB} \text { re } 1 \mu \mathrm{Pa}-\mathrm{m} \\
\text { in } 1 / 3 \text { Octave at } \\
500 \mathrm{~Hz}\end{array}$ & - & - \\
\hline
\end{tabular}




\begin{tabular}{|c|c|c|c|c|c|c|c|}
\hline $\begin{array}{l}\text { Dredger } \\
\text { type }\end{array}$ & Reference & Ship name & $\begin{array}{c}\text { Installed } \\
\text { power (kW) }\end{array}$ & $\begin{array}{l}\text { Dredger size } \\
\text { indicator }\end{array}$ & $\begin{array}{l}\text { Sound pressure } \\
\text { level }\end{array}$ & $\begin{array}{l}\text { Peak spectral level (dB } \\
\text { re } 1 \mu \mathrm{Pa} / \mathrm{Hz} \text { ) }\end{array}$ & $\begin{array}{l}\text { 1/3 Octave receive } \\
\text { levels }(\mathrm{dB} \text { re } 1 \mu \mathrm{Pa})\end{array}$ \\
\hline TSHD & de Jong et al. $2010 \mathrm{e}$ & Dredger \#3 & $\begin{array}{l}8,000- \\
30,000\end{array}$ & $\begin{array}{c}\text { Capacity } 3,000- \\
20,000 \mathrm{~m}^{3}\end{array}$ & $\begin{array}{l}174 \mathrm{~dB} \text { re } 1 \mu \mathrm{Pa}-\mathrm{m} \\
\text { in } 1 / 3 \text { Octave at } \\
350 \mathrm{~Hz}\end{array}$ & - & - \\
\hline TSHD & de Jong et al. 2010 e & Dredger \#4 & $\begin{array}{l}8,000- \\
30,000\end{array}$ & $\begin{array}{c}\text { Capacity } 3,000- \\
20,000 \mathrm{~m}^{3}\end{array}$ & $\begin{array}{l}177 \mathrm{~dB} \text { re } 1 \mu \mathrm{Pa}-\mathrm{m} \\
\text { in } 1 / 3 \text { Octave at } \\
300 \mathrm{~Hz}\end{array}$ & - & - \\
\hline TSHD & de Jong et al. $2010 \mathrm{e}$ & Dredger \#6 & $\begin{array}{l}8,000- \\
30,000\end{array}$ & $\begin{array}{l}\text { Capacity } 3,000- \\
20,000 \mathrm{~m}^{3}\end{array}$ & $\begin{array}{l}172 \mathrm{~dB} \text { re } 1 \mu \mathrm{Pa}-\mathrm{m} \\
\text { in } 1 / 3 \text { Octave at } 63 \\
\mathrm{~Hz}\end{array}$ & - & - \\
\hline TSHD & de Jong et al. 2010 e & Dredger \#7 & $\begin{array}{l}8,000- \\
30,000\end{array}$ & $\begin{array}{c}\text { Capacity } 3,000- \\
20,000 \mathrm{~m}^{3}\end{array}$ & $\begin{array}{l}173 \mathrm{~dB} \text { re } 1 \mu \mathrm{Pa}-\mathrm{m} \\
\text { in } 1 / 3 \text { Octave at } 45 \\
\mathrm{~Hz}\end{array}$ & - & - \\
\hline TSHD & Robinson et al. 2011 & Sand Harrier & 3,824 & Capacity $2,700 \mathrm{~m}^{3}$ & - & - & $181(159 \mathrm{~Hz}, 137 \mathrm{~m})$ \\
\hline TSHD & Robinson et al. 2011 & Sand Falcon & $2 \times 2,460$ & Capacity $4,832 \mathrm{~m}^{3}$ & - & - & $180(80$ Hz, 251 m) \\
\hline TSHD & Robinson et al. 2011 & Arco Axe & 2,940 & Capacity $2,890 \mathrm{~m}^{3}$ & - & - & $166(398 \mathrm{~Hz}, 240 \mathrm{~m})$ \\
\hline TSHD & Robinson et al. 2011 & $\begin{array}{l}\text { City of } \\
\text { Chichester }\end{array}$ & 2,720 & Capacity $1,418 \mathrm{~m}^{3}$ & - & - & $173(251 \mathrm{~Hz}, 137 \mathrm{~m})$ \\
\hline TSHD & Robinson et al. 2011 & City of London & 4,080 & Capacity $2,652 \mathrm{~m}^{3}$ & - & - & $\begin{array}{l}174(5,012 \mathrm{~Hz}, \\
458 \mathrm{~m})\end{array}$ \\
\hline TSHD & Robinson et al. 2011 & $\begin{array}{l}\text { City of } \\
\text { Westminster }\end{array}$ & 4,080 & Capacity $2,999 \mathrm{~m}^{3}$ & - & - & $\begin{array}{l}178(1,000 \mathrm{~Hz}, \\
474 \mathrm{~m})\end{array}$ \\
\hline TSHD & Reine et al. $2014 \mathrm{~s}$ & Liberty Island* & 12,353 & Capacity 5,003 m³ & $179 \mathrm{~dB}$ re $1 \mu \mathrm{Pa}-\mathrm{m}$ & - & - \\
\hline TSHD & Reine et al. 2014g & Dodge Island* & 6,972 & Capacity $2,754 \mathrm{~m}^{3}$ & $175 \mathrm{~dB}$ re $1 \mu \mathrm{Pa}-\mathrm{m}$ & - & \\
\hline TSHD & Reine et al. $2014 \mathrm{~g}$ & Padre Island* & 7,006 & Capacity $2,754 \mathrm{~m}^{3}$ & $173 \mathrm{~dB}$ re $1 \mu \mathrm{Pa}-\mathrm{m}$ & - & - \\
\hline TSHD & Reine et al. 2014g,i & Atchafalaya* & 2,209 & Capacity $2,300 \mathrm{~m}^{3}$ & $173 \mathrm{~dB}$ re $1 \mu \mathrm{Pa}-\mathrm{m}$ & - & \\
\hline GD & $\begin{array}{l}\text { Dickerson et al. } 2001 \\
\text { and Clarke et al. } 2002\end{array}$ & Viking* & 1,500 & $10 \mathrm{~m}^{3}$ bucket & - & $\begin{array}{l}124 \mathrm{~dB} \text { re } 1 \mu \mathrm{Pa}(162.8 \\
\mathrm{Hz}, 158 \mathrm{~m})\end{array}$ & - \\
\hline
\end{tabular}




\begin{tabular}{|c|c|c|c|c|c|c|c|}
\hline $\begin{array}{l}\text { Dredger } \\
\text { type }\end{array}$ & Reference & Ship name & $\begin{array}{c}\text { Installed } \\
\text { power (kW) }\end{array}$ & $\begin{array}{l}\text { Dredger size } \\
\text { indicator }\end{array}$ & $\begin{array}{l}\text { Sound pressure } \\
\text { level }\end{array}$ & $\begin{array}{l}\text { Peak spectral level (dB } \\
\text { re } 1 \mu \mathrm{Pa} / \mathrm{Hz} \text { ) }\end{array}$ & $\begin{array}{l}\text { 1/3 Octave receive } \\
\text { levels (dB re } 1 \mu \mathrm{Pa} \text { ) }\end{array}$ \\
\hline GD & Dickerson et al. 2001 & Crystal Gayle* & - & - & - & $\begin{array}{l}107 \mathrm{~dB} \text { re } 1 \mu \mathrm{Pa}-\mathrm{m} \text { at } \\
91.5 \mathrm{~Hz}\end{array}$ & - \\
\hline BHD & Nedwell et al. 2008 & Manu Peeka & 1,515 & $14 m^{3}$ bucket & $163 \mathrm{~dB}$ re $1 \mu \mathrm{Pa}-\mathrm{me}$ & - & - \\
\hline BHD & Reine et al. $2012^{b, c}$ & New York* & 3,434 & $18 \mathrm{~m}^{3}$ bucket & $179 \mathrm{~dB}$ re $1 \mu \mathrm{Pa}-\mathrm{m}$ & - & - \\
\hline
\end{tabular}

Dashes indicate data not reported; Asterisks by ship name indicate USACE sponsored study

aAcoustic data presented in the original Greene (1987) publication were presented as received levels and spectra and were reprocessed to source levels and $1 / 3$ octave spectra in Richardson et al. (1995)

bReine et al. (2012a,b; 2014) used a $15.778 \log (R / 1 \mathrm{~m})$ to back-calculate source levels

cReported in Reine et al. (2014)

dNedwell et al. (2008) estimated TSHD source level based on spherical spreading (10 log (R/1 m)) based on measures $200 \mathrm{~m}$ from source.

ede Jong et al. (2010). SPLs sourced from figure 5.8 (p 38); units express as dB re $1 \mu \mathrm{Pa}^{2} \mathrm{~m}^{2}$ are the same as "dB re $1 \mu \mathrm{Pa}$ at $1 \mathrm{~m} "$

fde Jong et al. (2010) reports that the highest dB measured (186 dB) occurring at low frequency was likely due to propeller cavitation.

gReine et al. (2014) data sourced from Table 23 (p. 75) of technical report. SL based on a 15.778LogR obtained from fitted regression.

nNedwell et al. (2008) used scaling factor of $10 \log (R / 1 \mathrm{~m})$ to back-calculate source level.

iReine et al. (2014) references the TSHD (Atchafalya) reported as an average of SPLs measured. 
Dredging-induced underwater sounds are temporally and spatially dynamic, and dependent on site-specific activities and conditions. In general, dredge-related sounds are mostly continuous and non-impulsive sounds. The duration of underwater sounds depends on the type of dredge operation. Hydraulic dredges generate continuous sounds as the cutterhead rotates on the channel bottom or when the draghead contacts the sediment. There are also continuous sounds from vessel propulsion (engine and propeller). Mechanical dredge work occurs in regular intervals (discontinuous) and is repeated (cyclic) often. Sounds originate from winches and derrick movements, machinery and propulsion, and digging.

The type of material dredged (e.g., rock, gravel, sand, mud) affects the frequency of underwater sounds. Dredging sounds are predominantly lower frequency, with reported peak spectral levels below $500 \mathrm{~Hz}$ (Table 5). Underwater sounds produced by dredges and the radiated distance are dependent on several factors, including substrate type, geomorphology of the waterway, site-specific hydrodynamic conditions, equipment maintenance, and dredge operator skill. It is anticipated that within dredge types, larger dredges have higher SPLs as compared to smaller dredges. However, based on the currently available dredge sound data (Table 5), there were no apparent relationships associated with installed power and underwater SPLs within dredge types. 


\section{Review of Underwater Sound Effects}

Sound is an important sensory function for many marine organisms (Hawkins 2008; OSPAR 2009b). Marine mammals, fish, and invertebrates have special mechanisms for emitting and detecting underwater sound (Popper 2003; OSPAR 2009b). Underwater sound is biologically important for communication, orientation, predator avoidance, and foraging (OSPAR 2009b). It is recognized that sound emanating from anthropogenic sources may have a diverse range of physiological and behavioral effects on marine biota (Southall et al. 2007; Popper et al. 2014), and there is a growing international focus to better understand these interactions (Popper and Hastings 2009). Only recently (past few decades) has the field of study developed investigating the potential effects associating underwater sound from industrial activities to various marine taxa (Figure 18; Williams et al. 2015).

Aquatic Noise Trust (organized by Arthur et al.) has held four conferences on anthropogenic underwater sound research since 2007. The most recent of these was the 4th International Conference on the Effects of Noise on Aquatic Life held in Dublin, July 2016. Papers presented at previous conferences were published as extended abstracts in a variety of forums, including as a Special Issue in the journal Bioacoustics (Hawkins 2008; Volume 17, Nos. 103); a book titled The Effects of Noise on Aquatic Life (published in a special issue of Advances in Experimental Medicine and Biology 730, DOI 10.1007/978-1-4419-7311-5_5 (2012)); and a third book titled The Effects of Noise on Aquatic Life II (Popper and Hawkins 2016).

In addition, a publically available library database for research related to underwater sound is supported by E\&P Sound and Marine Life Program under the direction of the International Association of Oil and Gas Producers (IOGP). The online database provides access to project reports, peer-reviewed publications, factsheets, and content from IOGP-funded research and can be found at http://www.soundandmarinelife.org.

This section discusses effects on marine biota from natural and anthropogenic sound sources in the aquatic environment. This review is meant to be strategic, focusing on literature that will provide insight to potential risks associated with underwater sound emanating from dredging operations. The goal of this literature review was to include underwater sounds from natural and anthropogenic sources that span 
from lower intensity (non-impulsive) to higher intensity (impulsive) sounds. This "span" of sound exposures was used to provide context for source levels (SPLs) and frequencies emanating from dredging operations (typically lower intensity non-impulsive sounds). Additionally, the intent was to include literature that reported biological responses to sound that spans from sub-lethal to lethal responses, in efforts to provide context for potential risks associated with the acoustical characteristics of dredging. It should be noted that there should be caution when directly comparing across studies, due to the lack of standardized underwater sound measurement techniques and methods for measuring biological responses (Thomsen et al. 2016; Erbe et al. 2016).

Figure 18. The proportion of underwater sound publications across sources by decade (top) and proportion of publications across taxa by decade (from Williams et al. 2015). Note: The proportion of papers is based on a bibliometric analysis of published ocean sound research from 1940 to 2015 covering 576 unique records (Williams et al. 2015).

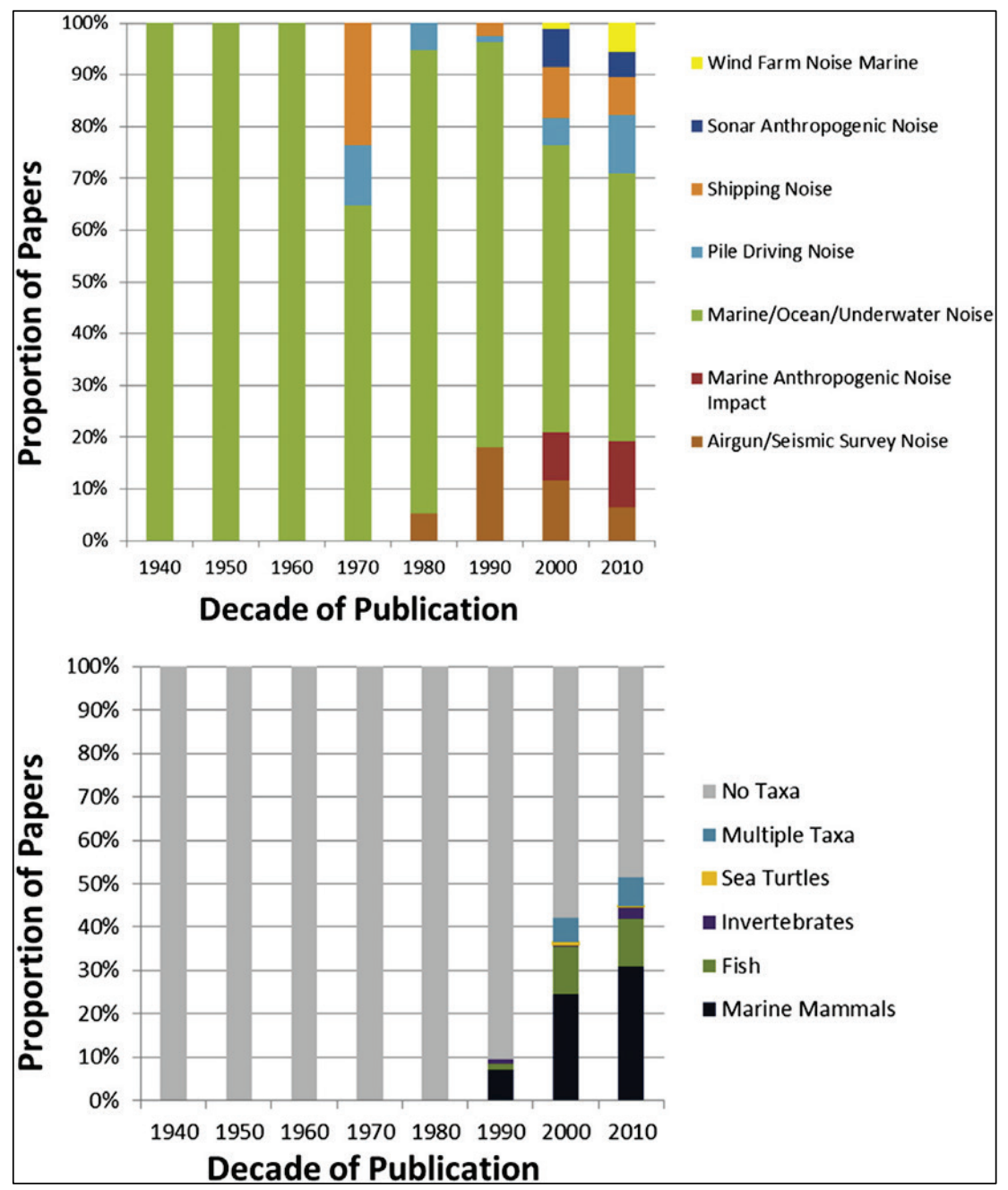




\subsection{Effects overview}

A key principle to understanding and predicting adverse effects from underwater sound is to develop exposure-response relationships of underwater sound for environmentally relevant organisms (Boyd et al. 2008; Thomsen et al. 2016). Reported effects to marine biota following exposures to anthropogenic sounds (e.g., pile driving, sonar, and shipping) range from lethal to sub-lethal (behavioral effects). The spectrum of species responses to underwater sound is generally described by direct injury, effects on hearing, masking, and behavioral responses (Figure 19).

Figure 19. Theoretical zones of influence around a sound source (based on Richardson et al. 1995).

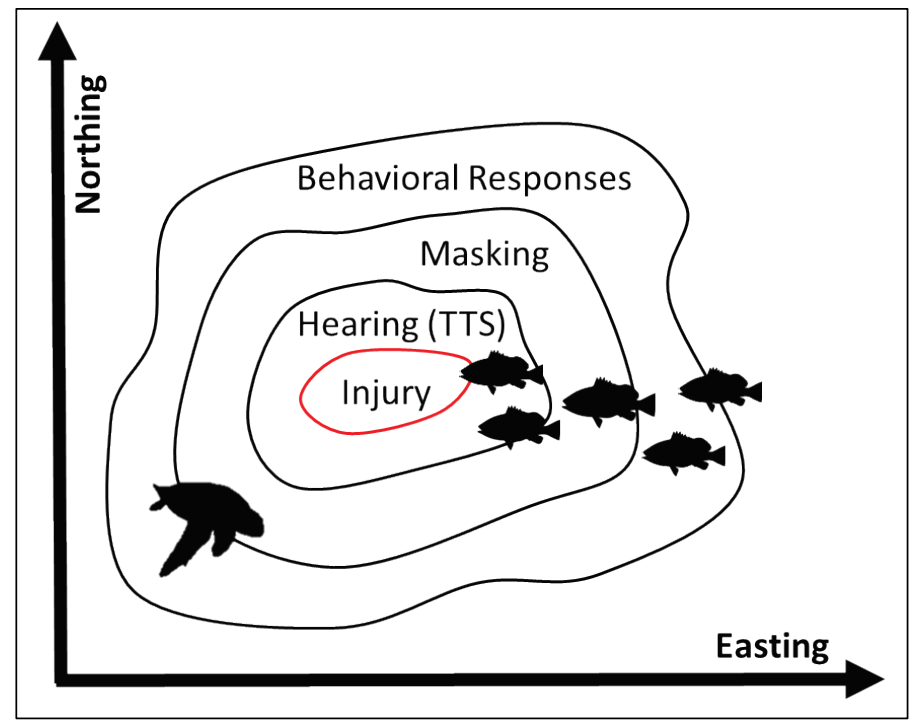

Based on the characteristics of underwater sound associated with various dredging operations, there is general consensus that there is not a significant risk of mortality or permanent injury to marine biota when dredging bottom substrates (Todd et al. 2015). The effects of underwater sound emanating from dredging operations are anticipated to have masking effects or alter behavioral responses (Hawkins et al. 2015). Dredging operations and other anthropogenic sounds (e.g., shipping vessels) can produce lower-frequency sounds (20 to 1,000 Hz) that overlap the detectable frequency range of marine organisms. A notable exception is during blasting activities when rock and other hard substrata need to be removed in ship channels to ensure navigation safety. These higher intensity sounds have a rapid rise time and can cause direct injury and auditory effects due to the high level of sound pressure (e.g., 270-280 
dB zero to peak) and propagation of shock waves (Richardson et al. 1995; OSPAR 2009a).

Common types of species responses to underwater sound and response metrics are briefly described below.

\subsubsection{Death and injury}

Direct injury and tissue trauma are typically limited to high amplitude impulsive sounds generated from explosions, impact pile driving, and seismic airguns (OSPAR 2009a). For example, explosions have the highest peak levels of anthropogenic sounds with a rapid rise-time. Explosions also produce shock waves, which propagate differently than acoustical waves (Richardson et al. 1995). Shock waves can cause direct mechanical damage due to the force of impact. In general, gas-containing organs (e.g., swim bladders, gastrointestinal tract, and lungs) are especially susceptible to damage. Boundary layers of tissues, where tissues of different densities intersect, are also susceptible to damage from impulsive sounds (Richardson et al. 1995). The auditory system is particularly susceptible to rapid pressure fluxes due to its adaptation to respond to pressure changes. Also, rapid changes in pressure can cause barotrauma in fishes (Popper et al. 2014). Barotrauma is damage to tissues or organs from blood gasses that come out of solution, or gas volumes expanding and contracting rapidly in tissues (e.g., swim bladders) causing damage or rupture (Popper et al. 2014).

\subsubsection{Effects on hearing}

Sound effects on hearing can be permanent or temporary, affecting the auditory structure (e.g., hair cells of the inner ear), nerve fibers, or other tissue structures in the auditory pathway of exposed fish and marine mammals. Permanent threshold shifts (PTS) occur when there is a permanent loss of the hearing sensory function (OSPAR 2009a). Additionally, short-term reduction in hearing known as temporary threshold shifts (TTS) are commonly used as a metric for determining auditory impairment (Erbe 2011). The degree of PTS and TTS is a function of the auditory exposure (e.g., pressure level, duration, rise time; Erbe 2011). 
In general, onset of TTS follows a predictive exposure-response relationship (Weilgart 2007; Finneran 2008). The following are general observations of TTS reported by Finneran (2008):

- Degree of TTS will generally increase with exposure SPL and duration.

- Short durations of sounds require greater SPLs to induce the same level of TTS compared to sounds of longer duration.

- SPLs or duration of exposure alone are poor predictors of TTS.

- Recovery is an important consideration for TTS.

- It appears that recovery period occurs faster for larger auditory threshold shifts, and slower for smaller shifts.

The majority of mammal and fish auditory threshold shifts are measured based on behavioral studies (training mammals to respond to "audible" tones) or electrophisologically derived data using auditory-evoked potentials (AEP) measures. Discrepancies between behavioral and AEP auditory methods have been identified, with AEP-derived TTS observed at 20-40 dB higher than behaviorally derived TTS (Finneran 2008; NMFS 2016).

Both fish and marine mammals can recover from TTS, with recovery times to "baseline" occurring on the order of minutes to days (Popper et al. 2005; Lucke et al. 2009; Kastelein et al. 2008, 2012, 2017a). Although PTS and TTS are useful metrics to determine auditory injury, there is uncertainty as to the environmental relevance of measurable auditory shifts to overall animal fitness and survival (Tougaard et al. 2016).

\subsubsection{Masking}

Masking is an animal's diminished ability to detect relevant sounds against background due to increased ambient sound (Southall et al. 2007). This may affect the organism's ability to orient, navigate, and select habitat. Masking may be particularly important for soniferous fish (soundproducing fish; e.g., cods, croakers, groupers) that produce sounds associated with spawning behavior, aggregating behavior, and orientation (Hawkins et al. 2015). In marine mammals, masking can affect communication networks between individuals of a social group or between groups (Janik 2005; Clark et al. 2009). Masking is "biologically significant" when there is a measureable decrease in animal fitness (e.g., growth, reproduction; Carr and Erbe 2008). 
It should be noted that organisms can compensate for background sounds using a number of different mechanisms. These compensation mechanisms can be as simple as timing vocalizations to minimize overlap or waiting for the interfering sound to subside (Clark et al. 2009). An organism may also increase the level of vocalization above the interfering noise, which is known as the "Lombard Effect." The Lombard Effect is an automatic and involuntary change in the vocalization intensity in the presence of background sound needed to maintain a constant signal-tonoise ratio. This effect has been confirmed with marine mammals and fish (Scheifele et al. 2005; Holt and Johnston 2014; Neenan et al. 2016). It should be noted that although masking is often referenced as an important effects endpoint in regard to underwater sound, there are significant information gaps on the masking effects of anthropogenic sounds to marine organisms (Hawkins et al. 2015; Hawkins and Popper 2016).

\subsubsection{Behavioral effects}

Recent studies investigating behavioral effects from underwater sound have primarily focused on startle responses and avoidance (Everley et al. 2016; Hawkins and Popper 2016). Behavioral responses to sound could be significant to an individual animal when it interferes with normal behavior or activity, or affects growth, survival, or reproduction (NRC, 2005). It is critical to link behavioral responses to "vital" population level responses (e.g., survival, reproduction, growth) to understand and predict population changes (Boyd et al. 2008).

\subsubsection{Population-level effects on fitness and survival}

Population-level effects to marine biota following anthropogenic sounds have not been well studied (Popper et al. 2014). Predictive models for marine mammals have been developed; however, these models have not been validated (NRC 2005). A severe limitation for modeling efforts are the lack of robust sound exposure-response data. For marine mammals, Population Consequences of Acoustic Disturbance (PCAD) model (NRC 2005) was developed to estimate changes in population growth rates and ecosystem dynamics, through the effects of acoustic disturbance on individual fitness and fecundity (CEFAS 2015). To date, the use of this model has been limited due to the lack of empirical data to derive model parameters (CEFAS 2015; Hawkins and Popper 2017). 


\subsection{Effects on fish}

In general, fish have a lower sound frequency detection range as compared to marine mammals. Fish can detect frequency ranges between 30 to $1,000 \mathrm{~Hz}$ (Erbe 2011), and some fish can even detect infrasound ( $<20 \mathrm{~Hz}$; e.g., Clupeid spp.) and ultrasound ( $>20,000 \mathrm{~Hz}$; e.g., Atlantic herring; Normandeau Associates 2012). More commonly, the 100 to $400 \mathrm{~Hz}$ frequencies are detected by a majority of fish studied (Offutt 1974; Yan 2001; Codarin et al., 2009; Parmentier et al. 2011). In general, this means that high-frequency $(>10,000 \mathrm{~Hz})$ sounds (e.g., sonar) are not expected to overlap with hearing frequencies of most fish species (Slabbekoorn 2016). Fish appear to be particularly well adapted to detecting lower frequency sounds $(<1,000 \mathrm{~Hz})$, like those emanating from shipping or dredging operations. To date, less than 100 fish species have audiograms of hearing thresholds that overlap with shipping vessel frequencies (Neenan et al. 2016). Although only a small percentage $(<1 \%)$ of the total fish species $(>30,000)$ have been part of bioacoustics investigations (Erbe 2011), these studies are improving our understanding of the potential risk to fish exposed to underwater sound.

SPLs are an important metric when considering the interaction with airfilled cavities (i.e., swim bladders) (Slabbekoorn 2016). However, fish are also sensitive to the particle motion of sound detected by auditory hair cells (OSPAR 2009a). A topic of future study that was identified at a World Organization of Dredging Association (WODA) workshop hosted in 2015 "Workshop on Underwater Sounds" included using particle motion as a metric for addressing underwater sound exposure to fish, as compared to the more commonly expressed sound pressure $(\mathrm{dB})$ descriptions. In comparison to hydrophones, the use of underwater particle motion detectors is a relatively new method because only recently has the technology become commercially available (Nedelec et al. 2016). Therefore, particle motion data are not commonly reported as acoustic measures describing anthropogenic sounds, but they are likely to become an important component for evaluating effects on fish (Hawkins and Popper 2017).

\subsubsection{Direct injury}

Sound sources causing direct injury or mortality to fish are generally limited to high-intensity impulsive sounds. Explosions and pile driving sound effects on fishes have resulted in barotrauma and include 
immediate lethality, rupturing of swim bladders, hemorrhaging of various organs and tissue, and swim bladder deflation (Popper et al. 2014; Casper et al. 2016). In general, smaller body size and presence of swim bladders make fish more susceptible to impulsive sounds like blasting or pile driving (Yelverton et al. 1975; Richardson et al. 1995; Popper et al. 2014). To date, direct mortality has not been documented or observed to occur in association with dredging sounds, with the exception of underwater blasting of rock formations in navigation channels (Carlson et al. 2011).

Carlson et al. (2011) monitored underwater rock blasting in a 1-mile section of the Columbia River during a widening and deepening project. Blasting was conducted over a 4-month time period, with a total of nine blasting events monitored. Underwater blast pressure ranged from $28 \mathrm{kPa}$ to $164 \mathrm{kPa}$ ( 4 to $24 \mathrm{psi}$ ). During blasting events, native fish species in the affected area of the reach were monitored. Additionally, caged juvenile salmonids were placed near the blasts to provide additional data for estimating mortality. Based on the field observations and mortality estimations, there was no observed or predicted mortality for adult salmon or Eulachon species of fish. Over the four-month monitoring period, the total "take" was three dead sturgeon recovered following the 99 blasting events.

In field experiments, Govoni et al. (2008) measured the responses of juvenile and adult spot (Leiostomus xanthurus) and pinfish (Lagodon rhomboides) to underwater explosions. Following explosions, spot were more sensitive to shockwaves as compared to pinfish. Differences in fish responses were attributed to anatomical differences of the swim bladder. Results indicated that the recently transformed juveniles were the most sensitive to shock waves. For larval and early juvenile fish, 50\% mortality occurred at impulse pressures ranging from 5.3 to 8.9 Pa-s for pinfish and spot, respectively (Govoni et al. 2008).

Casper et al. (2016) empirically derived injury thresholds (barotrauma and onset of TTS) to impulsive sounds through laboratory experiments. Six species were used in the experiments, including juvenile Chinook salmon (Oncorhynchus tshawytscha), lake sturgeon (Acipenser fluvecens), Nile tilapia (Oreochromis niloticus; Cichlidae), Mozambique tilapia (Oreochromis mossambicus; Cichlidae), hogchoker (Trinectes maculates; Achiridae), and hybrid striped bass (white bass Morone chryspos x striped bass Morone saxatilis; Moronidae). The results indicated that fish with swim bladders (e.g., salmon) had onset of injury at SELcum of $210 \mathrm{~dB}$ re 
$1 \mu \mathrm{Pa}^{2} \mathrm{~s}$. Major conclusions from this study included that barotrauma effects were not observed in species without swim bladders (e.g., hogchokers), onset of damage to auditory damage were substantially higher than barotrauma injuries, and barotrauma effects did not occur until the SELcum were substantially above interim regulations (Casper et al. 2016).

\subsubsection{Effects on hearing}

Fish auditory sensitivities to underwater sound can be categorized into hearing generalists and hearing specialists. Hearing generalists have a narrow frequency bandwidth of auditory detection and have lower sensitivities to SPLs (e.g., Gadidae (cod); Salmonidae (salmon); Chapman and Hawkins 1973; Hawkins and Johnstone 1978; OSPAR 2009a; Popper and Hastings 2009). In contrast, hearing specialists have anatomical structures (e.g., connections between inner ear structures and swim bladders) that increase the hearing frequency thresholds as compared to generalists. Examples of hearing specialists include Otophysi (e.g., catfish), Clupeiformes (e.g., herrings and sardines), Sciaenids (e.g., drums and croakers), and Holocentrids (e.g., squirrelfishes) (Popper and Hastings 2009).

Fish can regenerate lost or damaged sensory cells of the ear (Smith 2016); therefore, permanent hearing loss or permanent threshold shifts (PTS) are unlikely to occur. In contrast, the adverse effect endpoint of concern in fish is the temporary loss of hearing, referred to as a temporary threshold shifts (TTS). One method for experimentally testing temporary hearing loss in fish following sound exposure is directly measuring the density of hair cells in the inner ear and estimating and performing hearing tests by recording auditory-evoked potentials (AEPs). AEP methods use electrodes non-invasively attached to the head, where electrophysiological responses to sounds are measured. Measuring AEPs takes a considerable amount of time and specialized equipment, and therefore is relatively challenging to perform (Smith 2016). Fish TTS have been measured from non-impulsive sounds (dredging, shipping, and simulated playback sounds ("white noise”) and impulsive sounds (e.g., pile driving, and seismic airguns). Auditory effects to fish exposed to anthropogenic underwater sounds are discussed below by sound source. 


\subsubsection{Dredging}

No studies were found where underwater sound effects of dredging were directly measured for fish. However, several studies have made comparisons from measured dredging or shipping sounds to Fisheries Hydroacoustics Working Group (FHWG) exposure criteria or literaturederived effect levels in efforts to estimate potential injury risk.

Heinis et al. (2013) measured underwater sound of shipping and dredging activities (TSHD) during the expansion of the Port of Rotterdam in the Netherlands. Although behavioral effects of fish were not measured, Heninis et al. (2013) compared the measured underwater acoustics of dredging sounds to fish TTS criteria developed by FHWG (Oestman et al. 2009; Table 6) for pile-driving noises. Following dredging operations, $24 \mathrm{hr}$ SELcum of 182 and $186 \mathrm{~dB}$ re $1 \mu \mathrm{Pa}^{2} \mathrm{~s}$ were estimated for regular shipping activity and regular shipping with dredging, respectively. Heinis et al. (2013) estimated that dredging operations from TSHDs in the port of Rotterdam expansion project exposed smaller fish $(<2$ gram $)$ to sound levels slightly exceeding the fish TTS criteria of $183 \mathrm{~dB}$ re $1 \mu \mathrm{Pa}^{2} \mathrm{~s}$. However, the authors estimated that larger fish $(>2 \mathrm{~g}$ ) were not at risk for auditory injury following exposures from shipping and dredging sounds.

Nedwell et al. (2008) measured BHD and TSHD sound in Southhampton, UK, waters and calculated sound exposures above "hearing thresholds" (denoted $\mathrm{dBht}$ ) for Atlantic salmon (Salmo salar). Underwater sound above $50 \mathrm{dBht}$ were used as behavioral disturbance thresholds for salmon. Measurements during operations indicated that the highest sound levels were when the excavator was in contact with the seafloor. BHD sound levels were above $50 \mathrm{dBht}$ in the immediate $(<15 \mathrm{~m})$ vicinity of the operation, but declined below "behavioral" thresholds at distances greater than $15 \mathrm{~m}$. For TSHD noises, it was estimated that sound levels greater than $50 \mathrm{dBht}$ were limited to a distance within $50 \mathrm{~m}$ from the source.

In the UK, underwater sound generated by a TSHD Acro Adur was monitored to estimate the potential dredging-related sounds to fish (Department for Environment, Food and Rural Affairs (DEFRA) 2003). Underwater sound was measured when the draghead was in contact with the seafloor and the seawater and fine dredged material was overflowing from the screening spillways. Underwater sound levels at $50 \mathrm{~m}$ from the dredge (hopper capacity of 2,980 m3) were $117 \mathrm{~dB}$ (at $200 \mathrm{~Hz}$ ) and $122 \mathrm{~dB}$ at $320 \mathrm{~Hz}$. The authors estimated the potential dredging-related sound 
effects to fish based on comparisons of measured underwater sounds to literature derived auditory threshold effects. Based on these comparisons, it was concluded that fish (Clupeidae (e.g., herring, shads, sardines) and flat fish (e.g., plaice and dab)) were not at risk to suffer auditory injury.

\subsubsection{Shipping}

Liu et al. (2013) conducted laboratory experiments to measure effects of playback sounds from a 2,00o-horsepower (hp) containership on the onset of TTS of Chinese suckers (Myxocyprinus asiaticus). The maximum instantaneous SPL measured from the containership at a distance of $25 \mathrm{~m}$ was $142.8 \mathrm{~dB}$ re $1 \mu \mathrm{Pa}$. TTS was estimated using AEP methods, with durations of exposure of 1, 2, 4, 8, and 24 hours. After 24 hours of sound playback exposures, measurable auditory threshold shifts (TTS) were measured at all frequencies tested $(100-3,000 \mathrm{~Hz})$. Following the sound exposures, fish hearing recovered to baseline within 96 hours.

\subsubsection{Broadband "white noise"}

Smith et al. (2006) investigated the regenerative capabilities of the inner ear of fish following exposures to sound. The study measured the relationship between hair cell damage and physiological changes in auditory responses following noise exposures. Smith et al. (2006) exposed goldfish (Carassius auratus; hearing specialist) to "white noise" at $170 \mathrm{~dB}$ re $1 \mu \mathrm{Pa}$ RMS for 48 hours in a bandwidth ranging from $0.1 \mathrm{kHz}$ to $10 \mathrm{kHz}$ in laboratory experiments. Following exposures, fish had a mean temporary threshold shift (TTS) of $16 \mathrm{~dB}$ averaged across all frequencies, in addition to statistically significant hair cell loss as compared to untreated control. Following sound exposures, fish were allowed to recover for one week. During the recovery period, both hair cell regrowth and TTS were observed to recover to baseline. Hair cells regenerated at a linear rate following noise exposures. Hair cell loss was $85 \%$ immediately following sound exposures. After seven days of recovery, hair cell loss decreased to $\sim 47 \%$. With hair cell regeneration, functional hearing also increased (i.e., TTS decreased). TTS decreased from $16 \mathrm{~dB}$ (immediately following exposures) to $4 \mathrm{~dB}$ at 7 days' exposure (Smith et al. 2006; Smith 2016). This study demonstrated the onset of inner ear damage to noise exposures and the regenerative responses of the hair cells and functional hearing during the recovery period. 
Amoser and Ladich (2003) measured auditory shifts of two hearing specialist (goldfish (Carassius auratus) and catfish (Pimelodus pictus)) exposed to broadband "white-noise" measurements in laboratory experiments. To discern potential effects of sound duration to the onset of hearing loss, the study was conducted using 12- and 24-hour exposure durations. Hearing effects were determined using auditory brainstem responses (ABR), and recovery was measured after 3, 7, and 14 days. Following exposures to broadband white noise at SPLs of $158 \mathrm{~dB}$ re $1 \mu \mathrm{Pa}$, a significant loss of hearing was observed for both species with a loss of up to $26 \mathrm{~dB}$ in goldfish and $32 \mathrm{~dB}$ in catfish. The duration of sound exposure had no apparent effect on extent of hearing loss, with no differences in hearing sensitivities following 12- and 24-hour exposure durations. Both fish species recovered from hearing loss post-exposures, with recovery occurring within 3 days for goldfish and 14 days for catfish (Amoser and Ladich 2003).

Using these data (i.e., Amoser and Ladich 2003 and Smith et al. 2006), Popper et al. (2014) proposed fish sound exposure criteria for shipping and continuous sounds (Table 6).

Table 6. Shipping and continuous sounds exposure guidelines for fish (reported in Popper et al. 2014).

\begin{tabular}{|c|c|c|}
\hline Response & Type of Fish & Exposure Level \\
\hline Recoverable injury & $\begin{array}{c}\text { Swim bladder involved in hearing } \\
\text { (primarily pressure detection) }\end{array}$ & $\begin{array}{c}170 \mathrm{~dB} \text { re } 1 \mu \mathrm{Pa} \text { RMS for } \\
48 \mathrm{~h}^{\mathrm{a}}\end{array}$ \\
\hline TTS & $\begin{array}{c}\text { Swim bladder involved in hearing } \\
\text { (primarily pressure detection) }\end{array}$ & $\begin{array}{c}158 \mathrm{~dB} \text { re } 1 \mu \mathrm{Pa} \text { RMS for } \\
12 \mathrm{~h}^{\mathrm{b}}\end{array}$ \\
\hline
\end{tabular}

aDerived from Smith et al. (2006) regarding exposures of goldfish (Carassius auratus) to broadband "white noise"

berived from Amoser and Ladich (2003) for TTS onset for goldfish (Carassius auratus) and catfish (Pimelodus pictus) exposed to broadband "white noise"

\subsubsection{Seismic Airgun Exposures}

Popper et al. (2005) examined the onset of TTS in fish species following sound exposures from a seismic airgun array. The study was conducted in the Mackenzie River Delta, where fish were held in cages and exposed to five or 20 seismic airgun shots. TTS shifts were quantified using auditory brainstem responses (ABRs) for three fish (northern pike (Esox lucius); broad whitefish (Coregonus nasus); and lake chub (Couesius plumbeus)). The study was designed to mimic a single pass of an airgun array used for river seismic surveys. Sound exposures had an average SEL of $177 \mathrm{~dB}$ re 
$1 \mu \mathrm{Pa}^{2} \mathrm{~s}$, for durations of $40 \mathrm{~s}$. The greatest TTS were observed at $20 \mathrm{~dB}$ (at $400 \mathrm{~Hz}$ ) and $35 \mathrm{~dB}$ (at $400 \mathrm{~Hz}$ ) in northern pike and lake chub, respectively. No apparent hearing effects were observed for broad whitefish following airgun exposures. Hearing loss recovery occurred within 18 and 24 hours for the lake chub and northern pike, respectively. Based on the conservative nature of the experimental design, the authors concluded that the fish species evaluated were not likely to be adversely impacted by a seismic airgun survey.

Popper et al. (2014) estimated seismic airgun acoustic criteria for fish based on effects data derived from Halvorson et al. (2011; 2012a, b) and Popper et al. (2005) (Table 7).

Table 7. Seismic airgun exposure guidelines for fish (reported in Popper et al. 2014). Mortality and recoverable injury data based on Halvorson et al. (2011, 2012a, b); TTS impairment based on Popper et al. (2005).

\begin{tabular}{|c|l|l|}
\hline \multicolumn{1}{|c|}{ Response } & \multicolumn{1}{|c|}{ Type of Fish } & \multicolumn{1}{c|}{ Exposure Level } \\
\hline \multirow{5}{*}{ Recoverable Injury } & $\begin{array}{l}\text { No swim bladder } \\
\text { (particle motion detection) }\end{array}$ & $>216 \mathrm{~dB} \mathrm{SEL}_{\text {cum }}$ or $>213 \mathrm{~dB}$ peak \\
\cline { 2 - 3 } & $\begin{array}{l}\text { Swim bladder not involved in hearing } \\
\text { (particle motion detection) }\end{array}$ & $>203 \mathrm{~dB}$ SELcum or $>207 \mathrm{~dB}$ peak \\
\cline { 2 - 3 } & $\begin{array}{l}\text { Swim bladder involved in hearing } \\
\text { (primarily pressure detection) }\end{array}$ & $>203 \mathrm{~dB} \mathrm{SEL}_{\text {cum }}$ or $>207 \mathrm{~dB}$ peak \\
\hline \multirow{2}{*}{ TTS } & $\begin{array}{l}\text { No swim bladder } \\
\text { (particle motion detection) }\end{array}$ & $>>186 \mathrm{~dB} \mathrm{SEL}_{\text {cum }}$ \\
\cline { 2 - 3 } & $\begin{array}{l}\text { Swim bladder not involved in hearing } \\
\text { (particle motion detection) }\end{array}$ & $>>186 \mathrm{~dB} \mathrm{SEL}_{\text {cum }}$ \\
\cline { 2 - 3 } & $\begin{array}{l}\text { Swim bladder involved in hearing } \\
\text { (primarily pressure detection) }\end{array}$ & $186 \mathrm{~dB} \mathrm{SEL}_{\text {cum }}$ \\
\hline
\end{tabular}

Notes: peak and RMS sound pressure level dB re $1 \mu \mathrm{Pa}$; SEL dB re $1 \mathrm{mPa}^{2} \mathrm{~s}$

\subsubsection{Pile driving}

Auditory effects criteria for fish have been developed for estimating onset of injury from impulsive (pile-driving) sounds. Carlson et al. (2007) provided sound exposure criteria for fish during pile-driving activities on a sliding scale corresponding to fish mass (between 0.5 and $200 \mathrm{~g}$; for nonauditory tissue damage; Table 8 ). Effects criteria were based on nonauditory tissue damage, auditory tissue damage, and TTS. Due to the nature of pile-driving sounds, the criteria was broken down by peak SEL and cumulative SEL. Cumulative SELs are calculated based on Hastings and Popper (2005; Equation 3) 


$$
S E L_{\text {cum }}=10 \log (\# \text { pile strikes })+\text { single strike SEL }
$$

Table 8. Carlson et al. (2007) recommended interim sound exposure criteria for fish.

\begin{tabular}{|c|c|c|c|c|}
\hline Response & Hearing Type & Peak SEL & SELcum & Application Notes \\
\hline \multirow{3}{*}{$\begin{array}{l}\text { Auditory } \\
\text { tissue } \\
\text { damage (hair } \\
\text { cells) }\end{array}$} & generalist & $>206$ & $>213$ & $\begin{array}{c}\text { Accumulation of SEL should } \\
\text { not be reinitiated if SELcum } \\
\text { is }>213 \mathrm{~dB}\end{array}$ \\
\hline & generalist & $>206$ & $>189$ & \multirow{2}{*}{$\begin{array}{l}\text { After an 18-hour non- } \\
\text { exposure period, reset } \\
\text { accumulation of SELs }\end{array}$} \\
\hline & specialist & $>205$ & $>185$ & \\
\hline \multirow{2}{*}{ TTS } & generalist & 207 & 185 & \multirow{2}{*}{$\begin{array}{l}\text { After an 18-hour non- } \\
\text { exposure period, reset } \\
\text { accumulation of SELs }\end{array}$} \\
\hline & specialist & 205 & 183 & \\
\hline
\end{tabular}

The Fisheries Hydroacoustic Working Group (FHWG) revisited the criteria and simplified them based on fish size (estimating the smallest fish likely to be encountered in the field is $2 \mathrm{~g}$ ). The FHWG, which is composed of representatives from NOAA, USFWS, DFG, and the USACE met in 2008 to further discuss injury thresholds. Following the meeting, the agreed-upon criteria for injury to fish from pile-driving activities were proposed (as reported in Oestman et al. 2009; Table 9):

Table 9. Fisheries Hydroacoustic Working Group (FHWG) recommended interim sound exposure criteria for fish (reported in Oestman et al. 2009).

\begin{tabular}{|l|c|}
\hline Interim Criteria for Injury & Agreement in Principle \\
\hline Peak & $206 \mathrm{~dB}$ (all size of fish) \\
\hline \multirow{2}{*}{ SELcum } & $187 \mathrm{~dB}-$ fish $\geq 2 \mathrm{~g}$ \\
\cline { 2 - 2 } & $183 \mathrm{~dB}-$ fish $<2 \mathrm{~g}$ \\
\hline
\end{tabular}

More recently, Popper et al. (2014) estimated pile-driving acoustic criteria for fish based on effects data derived from Halvorson et al. (2011; 2012a, b) and Popper et al. (2005) (Table 10). 
Table 10. Pile-driving exposure guidelines for fish (reported in Popper et al. 2014). Mortality and recoverable injury data based on Halvorson et al. (2011; 2012a, b); TTS impairment based on Popper et al. (2005).

\begin{tabular}{|c|c|c|}
\hline Response & Type of Fish & Exposure Level \\
\hline \multirow{3}{*}{$\begin{array}{l}\text { Recoverable } \\
\text { Injury }\end{array}$} & $\begin{array}{l}\text { No swim bladder } \\
\text { (particle motion detection) }\end{array}$ & $>216 \mathrm{~dB}$ SEL $L_{\text {cum }}$ or $>213 \mathrm{~dB}$ peak \\
\hline & $\begin{array}{l}\text { Swim bladder not involved in hearing } \\
\text { (particle motion detection) }\end{array}$ & $>203$ dB SEL cum or >207 dB peak \\
\hline & $\begin{array}{l}\text { Swim bladder involved in hearing } \\
\text { (primarily pressure detection) }\end{array}$ & $>203$ dB SEL $L_{\text {cum }}$ or >207 dB peak \\
\hline \multirow{3}{*}{ TTS } & $\begin{array}{l}\text { No swim bladder } \\
\text { (particle motion detection) }\end{array}$ & >>186 dB SEL \\
\hline & $\begin{array}{l}\text { Swim bladder not involved in hearing } \\
\text { (particle motion detection) }\end{array}$ & >>186 dB SEL \\
\hline & $\begin{array}{l}\text { Swim bladder involved in hearing } \\
\text { (primarily pressure detection) }\end{array}$ & $186 \mathrm{~dB}$ SEL cum \\
\hline
\end{tabular}

Notes: peak and RMS sound pressure level dB re $1 \mu \mathrm{Pa}$; SEL dB re $1 \mathrm{mPa}^{2} \mathrm{~S}$

\subsubsection{Masking}

No studies were found that measuring masking to fish communication related to dredging-induced sounds. However, Codarin et al. (2009) conducted laboratory sounds using boating sound playbacks to investigate the potential impact of the communication of three vocal fish species (Mediterranean damselfish (Chromis chromis), brown meagre (Sciaena umbra), red-mouthed goby (Gobis cruentatus)). Playback audio of ambient sounds and boating sounds from an 8.5-m-long $163 \mathrm{hp}$ diesel craft were used with acoustic frequency main energy below 1,00o $\mathrm{Hz}$, and a source SPL of $142.3 \mathrm{~dB}$ re $1 \mu \mathrm{PA}$ at $1 \mathrm{~m}$. Results indicated that vessel sounds could impact the communication of fish, interfering with the detection of conspecific sounds (Codarin et al. 2009).

\subsubsection{Behavioral effects}

There are a few field studies available that estimate the avoidance behavior of "free swimming" fish to anthropogenic sounds. There are a number of challenges in discerning differences in behavioral responses for free swimming fish. Such challenges include "weak" biological responses to stimuli and absence of protocols for standardizing observational methods. Determining the "normal" variance of behavior is challenging due to the multivariate and intrinsic nature of organisms' behavioral changes in time and space (Erbe et al. 2016). 
Simpson et al. (2015) investigated the behavioral impacts to juvenile European eels (Anguilla anguilla) to simulated shipping sound playbacks in laboratory and open-water experiments. Eels exposed to playbacks of shipping sounds at approximately $153 \mathrm{~dB}$ re $1 \mu \mathrm{Pa}$ at $1 \mathrm{~m}$ had slower startle responses to ambush predators, diminished spatial performance, and elevated ventilations and metabolic rates (stress indicators) as compared to control individuals. These results showed underwater sound effects of shipping-affected physiological and behavioral endpoints.

Jung and Swearer (2011) conducted a field study to determine the potential behavioral avoidance of larval fish (multiple species) exposed to recorded playbacks of underwater sounds emitted from recreational boat traffic. The study was conducted in open water where fish were held in experimental traps and exposed to the playback sounds. Received levels were $107 \mathrm{~dB}$ re $1 \mu \mathrm{Pa}$ RMS (boat only) and $111 \mathrm{~dB}$ re $1 \mu \mathrm{Pa} \mathrm{RMS} \mathrm{(boat} \mathrm{and}$ ambient noise). The results indicated no significant differences among the boat playback traps or control in terms of abundance or diversity of larval fish. This study concluded that recreational boating sounds were not expected to have an adverse effect on recruitment of larval fish.

In addition, a few studies have demonstrated measurable changes in biometric stress responses following shipping sound playbacks to fish. Wysocki et al. (2006) measured increased cortisol secretion in three species of fish (carp (Cyprinus carpio)), gudgeon (Gobio gobio), and European perch (Perca fluviatilis)) following exposure to shipping playback sounds at SPLs of $153 \mathrm{~dB}$ re $1 \mu \mathrm{Pa}$ at a duration of $30 \mathrm{~min}$. Also, Celi et al. (2016) measured increases in a number of biometric stress indices of gilthead seabream (Sparus aurata) following ten-day exposures to shipping sound playback as compared to a control.

In the most comprehensive study found, Kastelein et al. (2008) tested startle responses of fish species in laboratory exposures to determine threshold effect levels. Fish were exposed to pure tones at frequencies ranging from 0.1 to $64 \mathrm{kHz}$, and "reaction thresholds" were estimated when $50 \%$ or more of the population reacted to the stimulus. In general, this study demonstrated that reactions to underwater sounds vary by frequency and are dependent on the auditory thresholds of fish species. The following general observations were made by the authors:

- Sea bass (Dicentrarchus labrax) had a 50\% reaction during exposures of SPLs ranging from 100 to $160 \mathrm{~dB}$ re $1 \mu \mathrm{Pa}$ at frequency bands 
between 0.1 and $0.7 \mathrm{kHz}$. Startle responses are 0-30 dB above reported hearing thresholds.

- Atlantic herring (Clupea harengus; a hearing "specialist") had a 50\% reaction during exposures of SPLs ranging from 160 to $180 \mathrm{~dB}$ re $1 \mu \mathrm{Pa}$ at a narrow frequency band of $4 \mathrm{kHz}$. The startle responses were $\sim 30 \mathrm{~dB}$ above auditory hearing thresholds.

- Pollack (Pollachius pollachius) response threshold levels were not achievable based on the study design. It is likely that response thresholds were $>180 \mathrm{~dB}$ (the maximum SPL achievable in the experimental design).

- Horse mackerel (Trachurus trachurus) had a 50\% reaction during exposures of SPLs ranging from 100 to 170 SPL (dB re $1 \mu \mathrm{Pa}$ ) at frequencies between 0.1 and $2 \mathrm{kHz}$.

- Pout (Trisopterus luscus) had a 50\% reaction at SPLs ranging from 100 to $140 \mathrm{~dB}$ re $1 \mu \mathrm{Pa}$ at frequencies between 0.1 and $0.25 \mathrm{kHz}$.

More recently, Kastelein et al. (2017b) conducted a laboratory-scale study to discern the acoustic dose-behavior response relationship in sea bass (Dicentrarchus labrax) following exposures to pile-driving sound playbacks. Initial behavioral responses, in terms of swim speed and direction, were monitored in addition to sustained responses, which included changes in school cohesion, swimming depth, and speed. Results indicated that the 50\% initial response (i.e., sudden, short-lived changes in swim behavior) threshold occurred at SEL (expressed as a "single strike") of 131 and $141 \mathrm{~dB}$ re $1 \mu \mathrm{Pa}^{2} \mathrm{~s}$ for small (31 centimeters [cm]) and large $(44 \mathrm{~cm})$ fish, respectively. This study found no evidence of any sustained responses to sound exposures, indicating that longer-term behavioral responses are unlikely within the range of exposures measured in this study (SEL 122 to $158 \mathrm{~dB} \mathrm{~dB}$ re $1 \mu \mathrm{Pa}^{2} \mathrm{~s}$; Kastelein et al. 2017b).

\subsubsection{Fish Effects Summary}

To date, the authors are unaware of any studies that have directly measured effects of underwater dredging sounds on fish species. A few studies have estimated effects on fish by comparing sounds from fielddredging operations to literature-derived TTS effects criteria. The currently available effects data from anthropogenic sources indicate that dredging-induced sounds do not pose a significant risk to direct injury or mortality in juvenile or adult fish. Mortality of fish following exposures to anthropogenic sounds is generally limited to high-intensity impulsive sounds (e.g., explosions, pile driving, airguns; Table 11). 
Table 11. Overview of effects of underwater sound on fish species from anthropogenic sources.

\begin{tabular}{|c|c|c|c|c|c|}
\hline \multirow[b]{2}{*}{ Source } & Exposure Level & \multirow[b]{2}{*}{$\begin{array}{l}\text { Frequency } \\
\quad(\mathrm{kHz})\end{array}$} & \multirow[b]{2}{*}{ Species (life stage) } & \multirow[b]{2}{*}{ Effect } & \multirow[b]{2}{*}{ Reference } \\
\hline & $\begin{array}{l}\text { SELcum (dB re } 1 \mu \mathrm{PA}^{2} \mathrm{~s} \text { ), } \\
\text { unless otherwise noted }\end{array}$ & & & & \\
\hline Explosion & 234 (SPL zero-to-peak) & NR & Spot, pinfish (late larvae) & Lethal effects & Govoni et al. 2008 \\
\hline \multirow{2}{*}{ Seismic airgun } & 220-242 (SPL zero-to-peak) & NR & $\begin{array}{l}\text { Cod, saithe, herring, turbot, plaice } \\
\text { (eggs and larvae) }\end{array}$ & $\begin{array}{l}\text { Injuries and lethal effects in some } \\
\text { species }\end{array}$ & Booman et al. 1996 \\
\hline & $\begin{array}{l}180 \text { (mean SEL); } 207 \text { (peak } \\
\text { SPL) }\end{array}$ & $<0.04$ & $\begin{array}{l}\text { Northern pike, lake chub, broad } \\
\text { whitefish (adult and YOY) }\end{array}$ & $\begin{array}{l}\text { TTS (pike and chub), TTS recovery } \\
\text { within } 24 \mathrm{~h}\end{array}$ & Popper et al. 2005 \\
\hline \multirow{3}{*}{ Pile driving } & 217 & NR & Chinook salmon (juveniles) & $\begin{array}{l}\text { No mortality; onset of injury with } \\
\text { evidence of recovery }\end{array}$ & Casper et al. 2012 \\
\hline & 210 & $<1$ & Chinook salmon (juveniles) & Onset of injurya & Halvorsen et al. $2012 \mathrm{~b}$ \\
\hline & 207 & NR & Lake sturgeon, Nile tilapia (juveniles) & Onset of injurya & Halverson et al. $2012 a$ \\
\hline \multirow{3}{*}{ Dredging } & $\begin{array}{l}190 \text { (SPL dB re } 1 \mu \mathrm{Pa} \text { RMS; } \\
\text { TSHD) }\end{array}$ & 0.08 to 1 & Atlantic salmon & no significant behavioral effects & Nedwell et al. 2008 \\
\hline & $\begin{array}{l}163 \text { (SPL dB re } 1 \mu \mathrm{Pa} \text { RMS; } \\
\text { BHD) }\end{array}$ & 0.08 to 1 & Atlantic salmon & no significant behavioral effects & Nedwell et al. 2008 \\
\hline & $\begin{array}{l}117-122(\mathrm{SPL} d B \text { re } 1 \mu \mathrm{Pa} \\
\text { at } 50 \mathrm{~m})\end{array}$ & $\mid<1$ & Clupeidae and flat fish & no auditory injury risk & DEFRA 2003 \\
\hline $\begin{array}{c}\text { Shipping + } \\
\text { Dredging }\end{array}$ & 186 (24 h exposure) & 0.5 to 10 & ND (modeled fish exposure) & \begin{tabular}{|l} 
Exceeded TTS risk threshold for fish < \\
$2 \mathrm{~g}^{\mathrm{b}}$
\end{tabular} & Heinis et al. 2013 \\
\hline Shipping & 182 (24 h exposure) & 0.5 to 10 & ND (modeled fish exposure) & $\begin{array}{l}\text { Did not exceed TTS risk threshold for } \\
\text { fish }>2 g^{b}\end{array}$ & Heinis et al. 2013 \\
\hline \multirow{3}{*}{$\begin{array}{l}\text { Simulated } \\
\text { playback }\end{array}$} & 170 (dB re $1 \mu \mathrm{Pa} \mathrm{RMS}$ ) & 0.1 to 10 & Goldfish (adult) & $\begin{array}{l}\text { TTS; inner ear hair cell loss; TTS } \\
\text { recovery within } 8 \mathrm{dc}\end{array}$ & Smith et al. 2006 \\
\hline & $\begin{array}{l}\sim 150 \mathrm{~dB}(\mathrm{SPL} d \mathrm{db} \text { re } 1 \mu \mathrm{Pa} ; \\
\text { nine month duration) }\end{array}$ & 0.1 to 5 & Rainbow trout (life cycle) & No hearing loss detected & Wysocki et al. 2007 \\
\hline & 137-147 (SPL dB re $1 \mu \mathrm{Pa})$ & 0.16 to 0.5 & Herring (adult) & $\begin{array}{l}\text { No differences in fish behavior (school } \\
\text { size, rise time) }\end{array}$ & Handegard et al. 2016 \\
\hline \multicolumn{5}{|c|}{ aThreshold for which tissue injury (hematomas or organ hemorrhaging) developed } & YOY = young of year \\
\hline \multirow{3}{*}{\multicolumn{5}{|c|}{$\begin{array}{l}\mathrm{b} T \mathrm{TS} \text { risk thresholds for fish }<2 \mathrm{~g}=183 \mathrm{~dB} \text { re } 1 \mu \mathrm{Pa}^{2} \mathrm{~s} \text {; TTS risk thresholds for }>2 \mathrm{~g}=187 \mathrm{~dB} \text { re } 1 \mu \mathrm{Pa}^{2} \mathrm{~s} \text { (origi } \\
\mathrm{c} 8 \mathrm{~d} \text { post-exposures TTS recovery to baseline was observed; correlating with inner ear hair cell density recovery } \\
\text { Note: Booman et al. (1996) data cited as reported in Bolle et al. (2016) }\end{array}$}} & $\begin{array}{l}\text { RMS = root mean } \\
\text { square }\end{array}$ \\
\hline & & & & & $N R=$ not reported \\
\hline & & & & & \\
\hline
\end{tabular}


Of the few studies available that evaluated sub-lethal effects of dredginginduced sounds (i.e., DEFRA 2003; Nedwell et al. 2008; Heinis et al. 2013), there was no evidence of risk for auditory injury (TTS) or behavioral effects for larger-bodied fish ( $>2 \mathrm{~g}$ ). In terms of adverse effects to smaller-bodied fish, Heinis et al. (2013) estimated based on "worst case" scenario that smaller-bodied fish $(>2 \mathrm{~g})$ were at risk in the immediate vicinity of the sound source $(<20 \mathrm{~m})$. In terms of masking and behavioral responses, lower-frequency sounds $(<1,000 \mathrm{~Hz})$ emanating from shipping and dredging are of particular interest due to the overlap of hearing detection of many fish species.

\subsection{Effects on marine mammals}

The published literature on the effects of underwater sound on marine mammals is more extensive than that for fish (William et al. 2015). This trend is likely based on the regulatory focus of larger charismatic marine mammals (e.g., whales, seals, dolphins). Many of the controlled experiments conducted on marine mammals were tonal or playback sounds. Only a few studies were found that estimated effects of dredgingrelated sounds on marine mammals (Richardson et al. 1990; Gilmartin 2003; Gerstein et al. 2006; Hoffman 2010; Heinis et al. 2013).

As reported in the literature, the effects of underwater sound on marine mammals range from direct mortality, auditory, and non-auditory physiological effects, masking, and behavioral responses (Erbe 2011). Field surveys collected synoptically with naval sonar exercises, seismic surveys, and pile-driving activities provide sound exposure data for potential adverse effects to marine mammals (Foote et al. 2004; Tougaard et al. 2009; Brandt et al. 2011; Tyack et al. 2011; Dahne et al. 2013). In addition, controlled laboratory experiments have also been conducted investigating threshold levels of auditory effects from sound playbacks (Finneran et al. 2002; Kastelein et al. 2012, 2013a,b). The NOAA NMFS's 2016 technical guidance is an additional resource that provides a comprehensive review and study of peer-reviewed literature and government reports on the impacts of underwater sound on marine mammals (discussed further in Section 7).

There are numerous marine mammals for which auditory sensitivities and vocalization patterns overlap sounds generated by anthropogenic activities (see Appendix A for more information). Echolocating marine mammals (e.g., dolphins and porpoises) have acute hearing and may be particularly sensitive to lower frequency sounds (Kats 2009). In general, available sound 
effect data are limited to Pinnipeds (e.g., seals, sea lions), and Odontocetes (e.g., dolphins, whales), with limited data available for Sirenians (manatees).

\subsubsection{Direct injury}

High intensity sounds (e.g., explosions, sonar) have been linked to mortality in a variety of marine mammal species (Koper and Plön 2012). Reports of direct injury to underwater explosions are typically anecdotal observations, with very few instances of reported details regarding the acoustical characteristics or shock waves associated with exposures. Near a site that had conducted repeated offshore blasting (with explosives up to $5000 \mathrm{~kg}$ ), two humpback whales were found with mechanical injuries to the ears-ruptured tissues, which eventually lead to death (Ketten 1995).

Indirect injury attributed to high-intensity sounds include the rapid dive or rise time of marine mammals, which can lead to embolism (gas bubbles in bloodstream) causing damage to tissues and organs. Mass stranding of cetaceans (e.g., whales, dolphins, porpoises) following military sonar operations have been well documented, where recovered animals had evidence of hemorrhaging of internal organ or tissues (Koper and Plön 2012). Todd et al. (2015) conducted a literature review of the impacts of marine dredging activities on marine mammals. Key findings from this review estimated that it is unlikely that dredging-related sounds would physiologically damage marine mammal auditory systems; however, there may be risk associated with masking and behavioral disturbances. Todd et al. (2015) indicated that, based on overlap of baleen whale communications at low frequencies, they might be at higher risk to dredging-related sounds. With the exception of underwater blasting of rock formations to widen or deepened a navigation channels, direct injury leading to mortality in marine mammals has not been documented in association with navigation dredging projects (Todd et al. 2015).

\subsubsection{Effects on hearing}

\subsubsection{Dredging}

To date, there are no studies that have directly measured hearing loss (PTS or TTS) in mammals in relation to dredging sounds. However, a single study was conducted in 2013 that measured the acoustic signatures during 
shipping and dredging activities and related those to existing auditory effects thresholds (i.e., Southall et al. 2007).

Heinis et al. (2013) measured underwater sounds of shipping and TSHD dredging activities during the expansion of the Port of Rotterdam in the Netherlands. Sound measures were modeled and compared to PTS and TTS auditory thresholds (i.e., Southall et al. 2007). Measured SPLs for 24-hour exposures were $186.6 \mathrm{~dB}$ re $1 \mu \mathrm{Pa}^{2} \mathrm{~s}$. Sound exposures were weighted for swim behavior of harbor porpoises and seals in relation to the sound sources. Estimated 24-hour exposures for harbor porpoises and seals were 180.5 and $182.4 \mathrm{~dB}$ re $1 \mu \mathrm{Pa}^{2} \mathrm{~s}$, respectively. Exposures were compared against conservative thresholds developed by Southall et al. (2007) for PTS and TTS risk for harbor porpoises and harbor seals. Using a worst-case scenario assumption of swimming behavior of marine mammals, Heinis et al. (2013) estimated that less than 0.1\% of harbor porpoises and seals were exposed to the risk of TTS during dredging activities of the Rotterdam expansion project.

\subsubsection{Tonal frequencies}

The U.S. Navy Marine Mammal Program (MMP) has conducted TTS experiments using marine mammals (i.e., bottlenose dolphins and belugas; Finneran 2008). TTS were estimated based on behavioral responses to sound exposures (trained to vocalize when hearing test tones) and auditory-evoked potentials (AEPs). Major findings from these studies were the following:

- Extent of TTS generally increases with exposure SPL and duration; however, these alone are poor predictors for TTS.

- Onset of TTS from "steady-state" sounds up to 16 sec can be predicted using an equal energy relationship.

- Dolphins with onset of behaviorally measured TTS up to $33 \mathrm{~dB}$ have completely recovered after several days.

- Differences among TTS measured behaviorally and electrophysiologically (AEPs) were dramatically different, whereas TTS measured using AEPs were always larger.

Data derived from these studies are in part the basis for the development of auditory exposure guidelines (PTS and TTS; Southall et al. 2007; NOAA et al. 2016). TTS criterion is generally accepted as an appropriate metric for estimating auditory injury and establishing exposure limits due to the 
relative sensitivity of mammals' inner ear to sound exposures (Southall et al. 2007) and the ability to reliably measure TTS in captive marine mammals (Tougaard et al. 2009).

The initial effort for developing underwater sound exposure criteria for mammals was proposed by Southall et al. (2007), which relied on the available exposure-response data and calculated auditory frequencyweighted threshold functions to develop TTS and PTS criteria. Since then, a number of studies that improved knowledge about the effects of underwater sound sources (Finneran 2015; Erbe et al. 2016) resulted in a new comprehensive study of the current state of the science and the acoustic thresholds to inform revised NOAA (July 2016) technical guidance. NOAA (2016) marine mammal effects guidelines are discussed in greater detail in Section 7. Studies investigating the auditory effects for mammals from specific anthropogenic sound sources are discussed below.

\subsubsection{Seismic airgun}

There are a number of studies that have experimentally tested the auditory shifts of marine mammals to impulsive seismic airgun exposures. TTS shifts in marine mammals are measured using either behavioral (trained response) or electrophysiological methods (i.e., auditory-evoked potentials).

Finneran et al. (2002) exposed bottlenose dolphins (Tursiops truncates) and white whales (Delphinapterus leucas) to single pulses from seismic airguns in laboratory experiments. Temporary shifts in masked hearing thresholds (MTTS) were estimated using behavioral responses, and defined as $6 \mathrm{~dB}$ increase or larger shift from baseline. Following a single pulse of $186 \mathrm{~dB}$ re $1 \mu \mathrm{Pa}^{2} \mathrm{~s}$ at $400 \mathrm{~Hz}$ frequencies, threshold shifts of $7 \mathrm{~dB}$ were observed in the white whale. Auditory recovery was observed within $2 \mathrm{~dB}$ to baseline (pre-exposure thresholds) within 4 min post-exposure. The bottlenose dolphin did not have any measureable shift in auditory thresholds at the highest exposure conditions tested ( $188 \mathrm{~dB}$ re $\left.1 \mu \mathrm{Pa}^{2} \mathrm{~s}\right)$.

In another laboratory study using bottlenose dolphins (Tursiops truncates), Schlundt et al. (2016) measured shifts in auditory thresholds following exposures of 10 pulses from seismic airguns. Auditory shifts were estimated using behavioral methods only, due to the inconclusive results from attempted AEP methods. After cumulative SEL exposures of 189-195 dB re $1 \mu \mathrm{Pa}^{2} \mathrm{~S}$ (212 dB re $1 \mu \mathrm{Pa}$ (peak-to-peak)), there were no measureable TTS in any of the individuals used. However, behavioral responses were measured 
in two of the individuals that exhibited an "anticipatory" response to the airgun exposures. These results suggest that the auditory responses of dolphins may be less sensitive than previously predicted.

Lucke et al. (2009) measured TTS in harbor porpoises (Phocoena phocoena) following a single impulse exposure from a seismic airgun in a laboratory study. Auditory shifts were estimated using electrophysiological methods and TTS onset was defined as differences of twice the standard deviation from average hearing threshold or a $6 \mathrm{~dB}$ from baseline (Southall et al. 2007). At an SEL of $165.5 \mathrm{~dB}$ re $1 \mu \mathrm{Pa}^{2} \mathrm{~s}$, porpoises had a $9.1 \mathrm{~dB}$ TTS. Within 3 hours of the initial exposure, TTS decreased by $2.9 \mathrm{~dB}$, with full recovery to baseline estimated to occur within 12 to 55 hours. Similarly, Kastelein et al. (2017a) observed onset of $\sim 4$ dB TTS in harbor porpoises after exposures to multiple airgun shots (10 to 20) with sound exposures of SELcum 188 to $191 \mathrm{~dB}$ re $1 \mu \mathrm{Pa}^{2}$ s. Porpoise TTS recovery was observed within $12 \mathrm{~min}$ post exposure (Kastelein et al. 2017a). Overall, these studies demonstrate that mammal TTS onset can occur from impulsive sounds, and auditory recovery to pre-exposure conditions have been observed within minutes to days.

\subsubsection{Masking}

A few studies were identified that estimated the influence of low-frequency continuous sounds from shipping and dredging operations to communication or auditory masking of marine mammals (manatee and whales). Gerstein et al. (2006) estimated zones of auditory masking to manatee during TSHD operations in the St. Johns River in Jacksonville, FL. The primary goal was to discern whether manatees had an increased risk of vessel strikes due to the underwater sound of dredging activities. Masking was defined by the critical ratio of manatee's auditory sensitivities, ambient noise conditions, acoustical characteristics of TSHD, and speed of approaching vessels. It should be noted that no behavioral parameters were assessed during the study because no manatees were observed in the study area prior to, during, or after operations. The major sources of underwater sound that were relatively continuous included cavitation from dredge propellers, draghead vacuuming, and the submerged slurry pump out pipeline. Sound pressures levels measured during operations ranged from 169 to $177 \mathrm{~dB}$ re $1 \mu \mathrm{Pa}$ at $1 \mathrm{~m}$. Gerstein et al. (2006) estimated that TSHD acoustical properties created zones of auditory masking in the vicinity of the operations; the zones may increase the probability of vessel strikes. Zones of masking for manatee were estimated to be $512 \mathrm{~m}$ and 4,096 $\mathrm{m}$ from the 
dredge, for boats approaching at speeds of 5 and 24 miles per hour (mph), respectively. This study empirically demonstrated the potential masking zones that could increase the risks associated with manatee boat strikes.

More recently, Clark et al. (2009) investigated the acoustic masking influence of shipping sound on singing fin (Balaenoptera physalus), singing humpback (Megoptera novaeangliae), and calling right (Eubalaena glacialis) whale species. The purpose of the study was to provide an analytical approach to address the challenges with quantifying masking effects in a dynamic acoustical communication space. To demonstrate the approach, the authors used a combination of modeling and analytical techniques for estimating the overlap of shipping sound and the target whales' communication space. The resultant modeling provided signal-to-noise ratios (SNR) for estimating the amount for which sound reduces the ability of a receiving animal to discern other biological underwater sounds. Of the three species evaluated, it was determined that the North Atlantic right whale was compromised by sound from commercial shipping traffic (Clark et al. 2009). This study was one of the first to define parameters to address the spatial and temporal aspects of quantifying masking effects from shipping sounds.

\subsubsection{Behavioral effects}

There are numerous behavioral responses observed for marine mammals such as humpback whales, porpoises, and seals exposed to anthropogenic sounds. Generally, studies investigating behavioral responses to sound are anecdotal field observations that offer limited data for understanding exposure response relationships. Behavioral responses to sound include avoidance, startle responses, swim direction and speed, dive duration, surfacing duration and interval, respiration (blow rate), movement towards or away from sound, or changes in acoustic vocalization behavior (Erbe 2011). Reports of marine mammal behavioral responses near dredging activities are discussed below.

\subsubsection{Dredging}

Hoffman (2010) investigated the potential adverse effects of dredging on a threated whale species near Cook Inlet, Alaska. USACE annually dredges approximately 1.6 million $\mathrm{m}^{3}$ of material from the Port of Anchorage near the head of Cook Inlet (Hoffman 2010). Beluga whales are listed as threatened under the Endangered Species Act (ESA); therefore, a 
biological assessment was conducted that focused on the potential impacts of dredging on Beluga whales. Whales were often observed within a few meters of cargo ships and dredges at the Port of Anchorage; however, it was unclear if whales were tolerating the underwater sound or had become habituated to it. The hearing frequencies of beluga whales are best between 10 and $100 \mathrm{kHz}$, which is typically above the lower frequency ranges associated with dredging and shipping (Hoffman 2010; Appendix C). Based on a biological impact analysis, it was concluded that dredging and placement did not adversely affect beluga whales.

In a comprehensive 2-year study by Richardson et al. (1990), behavioral reactions of bowhead whales were observed near dredging and drilling operations in the Canadian Beaufort Sea. In addition to observational data collected during active operations, open-water experiments were conducted using sound playbacks of underwater sounds associated with drillships and dredge sounds (Richardson et al. 1990).

Richardson et al. (1990) conducted observational studies during active dredging operations and behavioral data were recorded. Occasionally, bowhead whales were observed near $<5 \mathrm{~km}$ dredging operations. The closest recorded whale activity during operations was at a distance of $0.8 \mathrm{~km}$ from the suction dredge Beaver Mackenzie. During one dredging operation, two groups of bowhead whales were observed at $13 \mathrm{~km}$ from hopper dredges unloading, with corresponding received sound levels estimated at $115-117 \mathrm{~dB}$ re $1 \mu \mathrm{Pa}$ in the $20-1000 \mathrm{~Hz}$ frequency band (authors did not estimate based on SEL; i.e., duration of sound exposure unknown). These bowheads engaged in normal activities during this time. Even when the dredge began to approach and unload, there was no apparent change in behavior and no orientation away from the dredge.

Richardson et al. (1990) also conducted open-water playback exposures of recorded sounds of drill ships and dredges. The underwater sound exposures were 30-40 min durations, repeated seven times. Following playback sounds, behavioral characteristics of bowhead whales that were measured included call rates, feeding, and surfacing cycles. Peak source levels of playback experiments ranged from 155 to $164 \mathrm{~dB}$ re $1 \mu \mathrm{Pa}$ at $1 \mathrm{~m}$ (broadband). Estimated received levels of low-frequency sounds (20$1,000 \mathrm{~Hz}$ ) to the farthest whales during the experimental periods ranged from $94 \mathrm{~dB}$ to $122 \mathrm{~dB}$ re $1 \mu \mathrm{Pa}$. In general, there was no one behavioral variable that was consistently altered during playback experiments. 
Overall, bowheads tended to orient and move away during playbacks. During one playback experiment, feeding ceased and whales moved away from sound source. Sometimes the duration of surfacing and number of blows were reduced; however, there was no evidence of alterations of call types, intervals between respirations, frequencies of turns, or dive behavior following playback sounds.

Overall findings of this study were that there was broad overlap between received sound levels to which bowheads did and did not respond to sound playbacks; however, approximately $50 \%$ of bowheads reacted when received underwater sound level was $115 \mathrm{~dB}$ re $1 \mu \mathrm{Pa}$ in the $20-1,000 \mathrm{~Hz}$ frequency band. This corresponded to approximately 20 to $30 \mathrm{~dB}$ above ambient sound conditions. In terms of zones of influence around dredges, the following observations were made:

- Dredging sounds were estimated to be above background at $15 \mathrm{~km}$ from dredge.

- The audible zone (based on signal-to-noise ratios) was estimated to be $29 \mathrm{~km}$ from dredge source.

- The radii of responsiveness (eliciting a behavioral response) were estimated to be $4.6 \mathrm{~km}$ (broadband) and $2.8 \mathrm{~km} \mathrm{(1/3} \mathrm{octave} \mathrm{band)} \mathrm{from}$ the dredge.

Gilmartin (2003) observed behaviors of Hawaiian monk seals (Monachus schauinslandi) during grab dredging operations in early 1990 at Tern Island at French Frigate Shoals, Hawaii. Seals transiting the area during dredging did not appear startled or adversely affected, with no observable change in swim speed or direction. Pirotta et al. (2013) observed avoidance behavior of bottlenose dolphins during dredging activities in the Aberdeen Harbor (Scotland). It was also determined that dolphins responded to high levels of boat traffic. It should be noted that dredging often occurs in areas with other sources of anthropogenic sounds (e.g., shipping); therefore, it can be challenging to attribute field-observed effects directly to dredging activities (Todd et al., 2015).

\subsubsection{Marine mammals effects summary}

As compared to other taxa, marine mammals have been more extensively studied in terms of responses to underwater sound. Auditory injury has been observed for impulsive (pile driving, seismic surveys) and continuous sounds (broadband sound playbacks; Table 12). Common metrics of 
sound-related injury are described by PTS or TTS. The TTS criterion is generally accepted as a reliable metric for estimating sound-related injury and has been used for establishing exposure limits due to the relative sensitivity of the inner ear of mammals to sound exposures (Southall et al. 2007) and the ability to reliably measure TTS in captive marine mammals (Tougaard et al. 2009).

In terms of mammal responses to dredging-induced sounds, there are limited data directly measuring the onset of auditory injury. Based on the data available for mammal responses to other anthropogenic underwater sounds, risks associated with dredging are likely limited to masking and behavioral effects (Thomsen et al. 2016). Only a single study to date has estimated the onset of PTS and TTS from dredging sounds (Heinis et al. 2013). During the expansion of the Port of Rotterdam, long-term monitoring of TSHD and shipping sounds were used to estimate the potential risks for harbor porpoises and seals using exposure modeling. Results from this study did not indicate that harbor porpoises or seals would exceed PTS or TTS thresholds during dredging operations (Heinis et al. 2013).

In terms of behavioral responses to dredging activities observed in the field, whales and seals had no adverse reactions or avoidance behavior near active dredging operations. Following playback sounds from dredging activities, bowhead whales sometimes exhibited avoidance or altered feeding behaviors (Richardson et al. 1990). A 1-year field study evaluating avoidance behavior in harbor porpoises revealed that there may be shortterm avoidance of areas near dredging activity; however, these effects were short-term and porpoises return to the areas after the dredging activity was completed (Diederichs et al. 2010). Based on observational studies, pinnipeds (seals) did not exhibit avoidance or altered behavior near dredging activities (Gilmartin 2003). There is some evidence that sirenians (manatee) may be susceptible to low-frequency sounds masking boating sounds (Gerstein et al. 2006). 
Table 12. Overview of effects of underwater sound on mammal species from anthropogenic sources.

\begin{tabular}{|c|c|c|c|c|c|}
\hline \multirow[b]{2}{*}{ Source } & Exposure Level & \multirow[b]{2}{*}{$\begin{array}{l}\text { Frequency } \\
\quad(\mathrm{kHz})\end{array}$} & \multirow[b]{2}{*}{ Species } & \multirow[b]{2}{*}{ Effect } & \multirow[b]{2}{*}{ Reference } \\
\hline & $\begin{array}{l}\text { SELcum (dB re } 1 \mu \mathrm{Pa}^{2} \mathrm{~S} \text { ), } \\
\text { unless otherwise noted }\end{array}$ & & & & \\
\hline \multirow{4}{*}{ Seismic airgun } & $\begin{array}{l}186 \mathrm{~dB} \text { re } 1 \mu \mathrm{Pa}^{2} \mathrm{~s} ; 226(\mathrm{SPL} \\
\text { peak-to-peak) }\end{array}$ & 0.4 and 30 & White whale (adult) & 7 and $6 \mathrm{~dB}$ MTTSa & Finneran et al. 2002 \\
\hline & $\begin{array}{l}188 \mathrm{~dB} \text { re } 1 \mu \mathrm{Pa}^{2} \mathrm{~s} ; 226(\mathrm{SPL} \\
\text { peak-to-peak) }\end{array}$ & $0.4,4$, and 30 & Bottlenose dolphin (adult) & No observable MTTS & Finneran et al. 2002 \\
\hline & $\begin{array}{l}\text { 189-195; 193-209 (SPL peak-to- } \\
\text { peak) }\end{array}$ & NR & Atlantic bottlenose dolphin (adult) & No observable TSS & Schlundt et al. 2016 \\
\hline & 165.5 & 0.5 to 20 & Yangtze finless porpoise & $9.1 \mathrm{~dB}$ MTTS, with recoveryb & Lucke et al. 2009 \\
\hline \multirow{2}{*}{$\begin{array}{l}\text { Sound playback } \\
\text { ("white noise") }\end{array}$} & $\begin{array}{l}163 \text { (SPL; } 60 \text { min continuous } \\
\text { exposure) }\end{array}$ & $\sim 4$ & Harbor seal & $44 \mathrm{~dB}$ TSS, with recoveryc & Kastelein et al. 2013a \\
\hline & $151-190$ & $\sim 4$ & Bottlenose dolphin & 15 dB TSS, with recoveryd & Kastelein et al. 2012 \\
\hline Sonar & 142 (SPL dB re $1 \mu \mathrm{Pa}$ RMS) & 3.5 to 8 & Blainville's beaked whales & $\begin{array}{l}\text { echolocation alterations, } \\
\text { modified diving behavior }\end{array}$ & Tyack et al. 2011 \\
\hline \multirow{2}{*}{ Pile driving } & 194 & 0.08 to 0.2 & Harbor porpoise (field observations) & behavioral effects (avoidance) & Brandt et al. 2011 \\
\hline & $139-152$ & $\sim 0.25$ & Harbor porpoise (field observations) & behavioral effects (avoidance) & Dahne et al. 2013 \\
\hline \multirow{7}{*}{ Dredging } & 177 (SPL dB re $1 \mu \mathrm{Pa}$ RMS) & 0.1 to 10 & Modeled manatee masking zone & $\begin{array}{l}\text { 512-4,096 } \mathrm{m} \text { auditory masking } \\
\text { zone }\end{array}$ & Gerstein et al. 2006 \\
\hline & $\begin{array}{l}\text { 115-117 (SPL dB re } 1 \mu \mathrm{Pa} \\
\text { "received level") }\end{array}$ & 0.02 to 1 & Bowhead whales (field observations) & $\begin{array}{l}\text { no observable behavioral } \\
\text { response }\end{array}$ & Richardson et al. 1990 \\
\hline & $\begin{array}{l}\text { 94-122 (SPL dB re } 1 \mu \mathrm{Pa} \\
\text { "received level") }\end{array}$ & 0.02 to 1 & $\begin{array}{l}\text { Bowhead whales (dredging sound } \\
\text { playback) }\end{array}$ & $\begin{array}{l}\text { inconclusive behavioral } \\
\text { responses }\end{array}$ & Richardson et al. 1990 \\
\hline & NR & NR & $\begin{array}{l}\text { Hawaiian monk seals (field } \\
\text { observations) }\end{array}$ & no adverse behavioral response & Gilmartin 2003 \\
\hline & NR & NR & Beluga whales (impact assessment) & no adverse effects reported & Hoffman 2010 \\
\hline & NR & NR & $\begin{array}{l}\text { Bottlenose dolphins (field } \\
\text { observations) }\end{array}$ & avoidance behavior & Pirotta et al. 2013 \\
\hline & NR & NR & Harbor porpoise (field observation) & Short-term avoidance behavior & Diederichs et al. 2010 \\
\hline \multirow{2}{*}{$\begin{array}{l}\text { Shipping + } \\
\text { Dredging }\end{array}$} & 182 (24 hour exposure) & 0.5 to 10 & Modeled seal behavior (AQUARIUS) & $\begin{array}{l}\text { did not exceed TTS risk } \\
\text { thresholde }\end{array}$ & Heinis et al. 2013 \\
\hline & 180 (24 hour exposure) & 0.5 to 10 & $\begin{array}{l}\text { Modeled harbor porpoise behavior } \\
\text { (AQUARIUS) }\end{array}$ & did not exceed TTS risk thresholdf & Heinis et al. 2013 \\
\hline
\end{tabular}




\begin{tabular}{|c|c|c|c|c|c|}
\hline \multirow[b]{2}{*}{ Source } & Exposure Level & \multirow{2}{*}{$\begin{array}{l}\text { Frequency } \\
\quad(\mathrm{kHz})\end{array}$} & \multirow[b]{2}{*}{ Species } & \multirow[b]{2}{*}{ Effect } & \multirow[b]{2}{*}{ Reference } \\
\hline & $\begin{array}{l}\text { SEL } L_{\text {cum }}\left(\mathrm{dB} \text { re } 1 \mu \mathrm{Pa}^{2} \mathrm{~S}\right) \text {, } \\
\text { unless otherwise noted }\end{array}$ & & & & \\
\hline \multirow{4}{*}{ Shipping } & 176 (24 hour exposure) & 0.5 to 10 & Modeled seal behavior (AQUARIUS) & $\begin{array}{l}\text { did not exceed TTS risk } \\
\text { thresholde }\end{array}$ & Heinis et al. 2013 \\
\hline & 170 (24 hour exposure) & 0.5 to 10 & $\begin{array}{l}\text { Modeled harbor porpoise behavior } \\
\text { (AQUARIUS) }\end{array}$ & did not exceed TTS risk thresholdf & Heinis et al. 2013 \\
\hline & 117 (SPL dB re $1 \mu \mathrm{Pa}$ RMS) & NR & St. Lawrence river belugas & increased level of vocalizations & Scheifele et al. 2005 \\
\hline & $\begin{array}{l}\text { generalized comparisons to } \\
\text { shipping traffics }\end{array}$ & NR & Killer whales (adult) & increased duration of calls & Foote et al. 2004 \\
\hline
\end{tabular}

aHearing thresholds recovery occurred approximately 4 min postexposure

bEstimated recovery $<6 \mathrm{~dB}$ MTTS was $55 \mathrm{~h}$

cHearing recovered $4 \mathrm{~d}$ post-exposure

dEstimated recovery time varied between 4 and 96 min

eCalculated SEL values were below the TTS threshold values of 183 (seal; Southall 2007)

fCalculated SEL values were below the TTS threshold values of 195 (harbor porpoise; Southall 2007)

gAnalysis of whale behavior (duration of calls) with increased boat noise during 1973 and 2003.

$\mathrm{NR}=$ not reported

MTTS = masked hearing threshold 


\subsection{Effects on other marine species}

\subsubsection{Sea turtles}

Significant data gaps exist in terms of sea turtle responses to underwater sound. Willis (2016) reports that the vocalizations and best hearing frequencies for turtles are around 300-500 Hz. Only a few species having published audiograms (exceptions are loggerhead turtle (Caretta caretta); green turtle (Chelonia mydas); Kemp Ridley (Lepidochelys kempi); and red-eared slider (Trachemys scripta elegans) (Appendix A)). Preliminary data suggests sea turtles are somewhat resistant to high-intensity explosives, suggesting that sea turtles are also resistant to impulsive sounds (e.g., pile driving, seismic airguns; Ketten et al. 2005; Popper et al. 2014). One study evaluating sound exposures to turtles, Moein et al. (1994), investigated the potential adverse effects of seismic airgun deterrents to loggerhead sea turtles in an effort to minimize the turtles' activity around dredging operations. Following exposures to dB levels ranging from 175-176 (reference pressure not stated), sea turtles experienced slight shifts in auditory capabilities. Based on the lowerfrequency hearing range of turtles, there may be potential for behavioral or masking effects of lower-frequency anthropogenic sounds.

\subsubsection{Invertebrates}

Reponses of aquatic invertebrate species to underwater sound are discussed below and organized based on sound source. To date, the authors are unaware of any studies that have evaluated the effects of invertebrates following dredging-induced sounds.

\subsubsection{Shipping and low-frequency sounds}

Wale et al. (2013a) measured stress-related biomarkers (oxygen consumption rates) of shore crabs (Carcinus maenas) following single and repeated exposures of playbacks of ambient and shipping underwater sounds in controlled tank-based exposures. Sound playback exposures were 108-111 and 148-155 dB RMS for ambient ship sounds, respectively. Following repeated exposures to shipping sounds, shore crabs had an increase in oxygen consumption as compared to ambient sound playback exposures. In addition, heavier crabs had stronger responses to shipping sounds as compared to lighter crabs, indicating that there was a size dependency to the exposure-response relationship. 
In another behavioral study by Wale et al. (2013b) using similar experimental methods and the same sound exposure characteristics, behavioral responses in terms of foraging activity and antipredator responses following shipping playback sounds were measured. There were no measurable differences among the number of crabs finding a food source or time taken to find a food source; however, there were significantly more crabs distracted during feeding when exposed to shipping sounds as compared to ambient sounds. In terms of antipredator behavior in shore crab, crab exposed to shipping noise took significantly longer to return to shelter in the immediate aftermath of a simulated attack (Wale et al. 2013b).

In one of the most comprehensive studies reviewed, Sole et al. (2013) conducted controlled laboratory experiments using four cephalopod species (cuddlefish (Sepia officinalis), octopus (Octopus vulgaris), and squid (Lobigo vulgarus and Illex condientii)) exposed to low frequency sounds (50-400 Hz). Following sound exposures, the whole inner ear structure of the cephalopod's sensory organs (statocyst) were evaluated for apparent damage using scanning (SEM) and transmission (TEM) electron microscopy techniques. Peak sound exposure levels were $175 \mathrm{~dB}$ re $1 \mu \mathrm{Pa}$ at 1-s sweeps for a duration of 2 hour at a frequency of 50-400 Hz. Following exposures, sensory organs were examined and compared to untreated controls. Following sound exposures, there was observed statocyst damage (lesions, hair cell loss, etc.) in cephalopod species. The results from this study indicate that high-intensity, low-frequency sounds can damage sensory organs in cephalopod (i.e., squid, octopus, cuddlefish) species.

\subsubsection{Underwater explosions}

In general, invertebrates are less sensitive to pressure-related damage following underwater explosions as compared to many marine mammal species (Keevin and Hempen et al. 1997). This is likely related to the lack of gas-containing organs susceptible to mechanical injury in vertebrates. A number of studies have measured mortality of invertebrates (shellfish and $\mathrm{crab}$ ) as a function of distance from detonation sources of explosions. White shrimp near a blasting site using $33 \mathrm{~m}$ of $100 \mathrm{~g} / 33 \mathrm{~cm}$ of detonation cord had 30\% and o\% mortality at distances of 11 and $46 \mathrm{~m}$ from source, respectively (Linton et al. 1985 (cited in Keevin and Hempen 1997)). Anon (1948) (cited in Keevin and Hempen et al. (1997)) measured blue crab (Callinectes sapidus) mortality following blasts from $30 \mathrm{lb}$ of TNT. At distances of 8 and $46 \mathrm{~m}$ from blasts, blue crab mortality was $89 \%$ and $7 \%$, 
respectively. Lobsters (Panulirus interruptus) within 15-17 m of a blasting site using $9.1 \mathrm{~kg}$ of $60 \%$ petrogel had no mortality.

\subsubsection{Seismic surveys}

A few studies have investigated the potential influences of open-water seismic surveys to the catch yields of commercially relevant species of shellfish. Andriguetto-Filho et al. (2005) conducted a field investigation on the potential impact of seismic prospecting on shrimp fisheries (southern white shrimp (Litopenaeus schmitti); southern brown shrimp (Farfantepenaeus subtilis); and the Atlantic seabob (Xyphopenaeus kroyeri)) by comparisons of bottom trawl yields before and after the use of airguns. The airgun array produced peak SPLs of $196 \mathrm{~dB}$ re $1 \mu \mathrm{Pa}$ at $1 \mathrm{~m}$ shooting every $12 \mathrm{~s}$. Catch yields were compared from pre-seismic surveys and 12-36 hours post airgun arrays. The results indicated no measureable differences in ship trawl yields after seismic prospecting. Parry and Gason (2006) conducted a statistical analysis of historical commercial catch rates of rock lobster (Palinuvidae family) to measure the potential adverse effects associated with coinciding seismic surveys. Based on the analysis of catch rates and corresponding seismic surveys, there was no apparent relationship of lobster catch yields to seismic surveys.

In one of the first studies to investigate the effects of underwater sound on larval abnormalities, de Soto et al. (2013) measured the potential adverse effects of seismic pulses to scallop larvae development in controlled laboratory experiments. Playbacks of seismic pulses were conducted in bench-scale experiments with SPL exposures of 160-164 dB RMS re $1 \mu \mathrm{Pa}$, corresponding to a sound exposure level of 161-165 dB RMS re $1 \mu \mathrm{Pa}^{2} \mathrm{~s}$. Following noise exposures, scallop larvae had significant developmental delays and $46 \%$ developed body abnormalities.

\subsubsection{Broadband noise}

A few studies have been conducted evaluating the effects associated with the ambient "broadband" noise associated with the maintenance and rearing of marine animals. Lagardere (1982) and Regnault and Langardere (1983) compared the health of brown shrimp (Crangon crangon) in ambient rearing tank conditions compared to soundproofed tanks with $30 \mathrm{~dB}$ lower sounds. The results indicated that experimental tank environments with prevailing ambient sounds resulted in a significant 
reduction in growth and reproduction rates of the shrimp as compared to soundproofed tanks (Lagardere 1982; Regnault and Lagardere 1983).

\subsection{Effects summary}

Anthropogenic underwater sound effects range from direct mortality to a variety of non-lethal responses. Typically, mortality observed for marine biota to anthropogenic sound is limited to high-intensity impulsive sounds (e.g., explosions). With the exception of blasting events in navigation channels, sounds associated with dredging activities are not at sufficient intensities (SPLs) to pose risks of mortality or permanent injury (Boyd et al. 2008; Todd et al. 2015). Ecological risks associated with sounds from dredging activities are anticipated to be limited to non-lethal effects, which include auditory injury, masking, and behavioral responses (Boyd et al. 2008; Todd et al. 2015; Hawkins et al. 2015).

Auditory injury (in terms of PTS and TTS) has been observed for a number of mammal and fish species exposed to both impulsive and continuous underwater sounds. Common metrics of sound-related injury are described by PTS or TTS. The TTS criterion is generally accepted as a reliable metric for estimating sound-related injury and has been used for establishing exposure limits due to the relative sensitivity of the inner ear to sound exposures (Southall et al. 2007; Carlson et al. 2007; Oestman et al. 2009) and the ability to reliably measure TTS in captive organisms (Tougaard et al. 2009). To date, no auditory exposure-response data exist for dredging related sounds to aquatic organisms. Of the single study that estimated auditory risks of dredging operations by comparing sound metrics to existing auditory thresholds, there was no evidence of exceeding TTS risk thresholds for mammals or larger fish ( $>2 \mathrm{~g}$ ), and slight risk on TTS for small $(<2 \mathrm{~g})$ fish in the immediate vicinity $(<20 \mathrm{~m})$ of the sound source (Heinis et al. 2013).

In terms of behavioral responses to dredging operations, a few species of whales and seals have demonstrated no adverse responses or avoidance near dredging (Richardson et al. 1990; Hoffman et al. 2010). Following playback sounds from dredging activities, bowhead whales sometimes exhibited avoidance or altered feeding behaviors (Richardson et al. 1990). Based on observational studies, pinnipeds (e.g., seals) did not exhibit avoidance or altered behavior near dredging activities (Gilmartin 2003). There is some evidence that low-frequency sounds from dredging activities may mask approaching boating sounds to sirenians (manatee, etc.) 
(Gerstein et al. 2006). It should be noted that there is uncertainty as to the appropriateness of using sound metrics for predicting biological responses. To date, dredging sounds have been described using SPLS RMS; however, comparisons to effects thresholds are limited to peak SPLs (for impulsive sounds) or SELs (cumulative). 


\section{Managing Risks from Underwater Sound}

For dredging, there is a need to develop an appropriate risk-based framework to address the sound exposure of nearby biota to dredging sounds (e.g., excavation, transport, and placement). Accurate characterization of the acoustic exposure and biological responses is a critical step preceding risk management. A risk-based approach provides a systematic framework for characterizing exposures and biological responses to inform actions such as mitigation (Boyd et al. 2008; Thomsen et al. 2016; Merchant et al. 2017). A critical aspect of any successful underwater sound risk framework is to identify and mitigate appropriate ecological risks and to avoid managing ecologically insignificant risks that would pose unnecessary constraints and costs on dredging operations.

In general, mitigation techniques are implemented when risk management determined sound exposures are predicted to exceed threshold levels for one or more aquatic species occurring nearby (as defined by legislation, biological significance, or societal views) (Boyd et al. 2008). Based on management strategies used for other underwater sound sources (e.g., pile driving, drilling, shipping), there are a number of sound mitigation alternatives to consider. In general, the objective of these strategies is to alter the sound exposure to aquatic organisms through avoidance or minimization (Boyd et al. 2008).

\subsection{Avoidance}

\subsubsection{Exclusion zones}

Avoidance can be achieved by establishing "exclusion zones" surrounding a sound source (von Lüders and Gill 2008; ACCOBAMS 2013). These zones are intended to delineate distances from the sound source that pose risk to biological receptors and thereby exclude target organisms from those areas during operations. Exclusion zones are commonly established for high-intensity impulsive sounds (e.g., explosions, pile driving; ACCOBAMS 2013). Due to the complexity of sound propagation, exclusion zone dimensions are typically established using a combination of sound propagation modeling techniques and field monitoring (Greene and Blackwell 2008). 
The goal of an exclusion zone is to eliminate the source of the sound if organisms move within the zone (von Lüders and Gill 2008; NOAA 2016); therefore, a combination of visual and acoustic monitoring protocols can be used to observe biological activity within the zones. Dedicated marine mammal observers (MMO) or protected species observers (PSOs) can monitor zones prior to and during operations to provide real-time information (ACCOBAMS 2013; NOAA 2016). Additionally, passive acoustic monitoring systems can be used to detect the presence of vocally active species around exclusion zones, especially when visual observations by MMOs are impaired (i.e., during night and inclement weather, or due to submerged animals; Verfuss et al. 2018). If organisms are observed inside exclusion zones, operations are halted until the organisms have vacated the zone (NOAA 2016). Monitoring efforts are generally limited to larger animals that surface or more vocal species that can be readily detected using acoustic monitoring. There are ongoing efforts to broadly standardize MMO methods and qualifications (von Lüders and Gill 2008). In the United States, NOAA has provided a Technical Memorandum "National Standards for a Protected Species Observer and Data Management Program" to provide guidance to PSOs for standardizing methods (Baker et al. 2013). The level of effort and cost for establishing exclusion zones are largely dependent on the duration and location of dredging operations.

An experimental exclusion zone method applied to minimize biota exposures near the sound source is to implement "soft-starts" or "rampup" of high intensity sounds in an effort to provide time for biota to move away from the sound source prior to the production of full intensity sounds (ACCOBAMS 2013). However, ramp-ups have not been fully validated as effective means of deterring organisms; therefore, there are still questions about their utility in implementation (Convention on Biological Diversity (CBD) 2012).

\subsubsection{Biological deterrents}

To aid in minimizing biological impacts, there are also a number of tools and techniques that can be used to actively deter animals in an effort to minimize overlap with unwanted underwater sounds (OSPAR 2009a). Underwater biological deterrents have been used for a variety of applications to restrict animal movement. Commonly used methods include acoustic deterrent devices (ADDs), acoustic harassment devices (AHDs), visual deterrents (flashing lights), physical or electrical barriers 
(netting, electric field), and chemical deterrents (taste or smell deterrent) (NOAA 2015, 2016). These techniques have been effectively used to deter animals from pile-driving exclusion zones. Verfuss et al. (2016) reported that ADDs, such as pingers and seal scarers, effectively deter porpoises and seals from pile-driving exclusion zones in the UK. Limitations to biological deterrents include habituation, select number of target species, and animals may not respond if other "motivational" factors (e.g., food availability) are present (Verfuss et al. 2016).

\subsubsection{Spatial and temporal restrictions}

An effective management tool for mitigating the effects of underwater sound is establishing seasonal or spatial restrictions on operations (OSPAR 2009b; CBD 2012). Establishing "environmental windows" of operation are designed to eliminate sound exposures during periods where resident biota are at sensitive stages (e.g., breeding or spawning seasons; OSPAR 2009a; Todd et al. 2015). Some examples of seasonal restrictions include minimizing the overlap with susceptible activities such as mating, breeding, feeding, or migration. Spatial restrictions would include protecting ecologically sensitive areas (e.g., spawning sites, protected vegetation).

In the context of dredging operations, environmental windows are a common management practice that have been in use for decades to limit the environmental impacts of dredging (Reine et al. 1998; Suedel et al. 2008; Todd et al. 2015). Environmental windows for dredging operations are implemented for a variety of reasons to restrict environmental impacts for a variety of species and habitats. Although underwater sound has not been a primary driver for creating the existing temporal or spatial restrictions for dredging operations, the current restrictions likely provide concurrent mitigation of underwater sound. Clearly, there is a need to evaluate whether existing restrictions also provide mitigation of sounds associated with dredging.

\subsection{Minimization}

\subsubsection{Acoustic damping}

To date, the authors are unaware of any engineered acoustic damping techniques applied specifically for dredging operations. However, damping approaches have been developed to attenuate underwater sound from 
impulsive pile-driving and drilling sounds. These include enclosures (e.g., coffer dams, pile sleeves), air-bubble curtains, or engineered sound curtains (e.g., hydro sound dampers). A physical barrier can decrease sound by reflecting sound waves and impeding their path. Sound-damping materials that have demonstrated utility include air (coffer dams) or airfilled materials (e.g., foam sleeves; Nehls et al. 2007; ACCOBAMS 2013). Pile-driving field demonstration results indicate foam sleeves used on piles provided sound reduction by 10 and $20 \mathrm{~dB}$ at $1 \mathrm{kHz}$ and $10 \mathrm{kHz}$, respectively (Nehls et al. 2007).

Bubble curtains are another method of sound reduction that have been used for the attenuation of a variety of impulsive sounds (e.g., pile driving, drilling; ACCOBAMS 2013). Typically, bubble curtains release air bubbles at the seafloor and are allowed to rise and encapsulate the sound source. Bubble curtains inhibit sound transmission by scattering, dissipating, and absorbing sound waves by resonating vibrating air bubbles (Wursig et al. 2000; Nehls et al. 2007). In general, the sound attenuation efficiencies of air bubbles are a function of the uniform distribution of consistent air bubble shapes. However, in practice, achieving a uniform distribution of free air bubbles in water is challenging due to varying ambient hydrodynamic conditions. Larger air bubbles with lower resonate frequency are more efficient at attenuating lower-frequency sounds ( $<1 \mathrm{KHz})$, but are relatively unstable and challenging to produce (Kuhn et al. 2012). Therefore, air bubble curtains are typically more efficient at attenuating higher frequency sounds (400-6,400 Hz; Wursig et al. 2000). Wursig et al. (2000) observed a $3-5 \mathrm{~dB}$ sound reduction in overall broadband frequencies, and up to $20 \mathrm{~dB}$ in the 1.6-6.4 kHz bands. In general, technical limitations of effectively implementing bubble curtains include achieving effective distribution around the sound source, maintaining a consistent distribution of bubble sizes, and the lack of sound mitigation at lower-range frequencies $(<1 \mathrm{kHz})$ (Nehls et al. 2007; Kuhn et al. 2012).

Hydro sound dampers (HSDs) are an alternative method to bubble curtains. HSDs use small gas-filled bladders and robust polyethylene foam elements fixed to a fishnet "curtain" that surrounds a sound source. Measured sound reductions of 20-22 dB (broadband frequencies) HSDs have been achieved in wave flumes testing simulated pile-driving operations (Kuhn et al. 2012). Bruns et al. (2014) implemented HSDs during off-shore pile-driving construction activities to minimize the potential sound exposures to harbor porpoises and seals. During field 
demonstrations of HSD for off-shore pile driving, underwater sound reduction of up to $25 \mathrm{~dB}$ (SEL) was achieved (Bruns et al. 2014).

\subsubsection{Equipment design or retrofit}

Due to the recent focus on low-frequency sound generated by commercial shipping vessels, there is a growing international interest to incorporate sound reduction technology in ship design or retrofitting. The International Maritime Organization (IMO) (2014) released guidelines providing general sound reduction advice to ship designers, builders, and operators. Underwater sound from vessels is generally broken down into two main categories: propeller/thruster sound and machinery sound. Therefore, IMO design recommendations focused on three main areas that generate the majority of underwater sound: propellers, hull design, and onboard machinery. It should be recognized that the cost associated with equipment design and retrofit is strongly dependent on the ship design, operational parameters, and mandatory requirements that are ship and situation dependent (IMO 2014). In general, the cost of sound control treatment for a conventional marine vessel when incorporated into the design phase is approximately 1-3\% of the vessel cost (Fisher and Pettit 2014). Alternatively, retrofits to existing vessels can cost up to 10 times greater as compared to incorporating the treatment technology earlier in the design phase (Fisher and Pettit 2014).

Propeller design considerations for sound reduction focus on decreasing the extent of cavitation (formation of water vapor cavities caused by pressure changes as water moves across a propeller blade; IMO 2014). Cavitation can be reduced by increasing uniformity in flow conditions around the propeller/thruster (Spence 2007). Design alterations to propeller diameter, blade number, pitch, skew, and sections can optimize the propeller load and provide a greater probability of uniform water flow into the propellers and less cavitation (IMO 2014; Nolet 2017). In addition, vessel hull design can be optimized to make the wake field propagating into the propeller more homogeneous to decrease cavitation (IMO 2014). However, technical or geometrical constraints may limit the design options (IMO 2014).

Onboard machinery-predominantly the main drive systems-also contribute to the overall sound budget of commercial shipping operations. For typical commercial vessels, vibration from power generation and propulsion equipment are major contributors to underwater sound 
(Spence 2007). A large proportion of vessel drive systems are diesel or diesel-electric engines. Vibration-damping devices can be used to decrease the overall sound of diesel engines (Nolet 2017), with both resilient mounts and "floating decks" used to isolate machinery vibration from the vessel's hull. Even with relatively simple designs, damping devices can reduce sound by $20 \mathrm{~dB}$ at $200 \mathrm{~Hz}$ (Spence 2007). In general, diesel electric engines produce less underwater sound than diesel engines, and diesel generators can be more effectively isolated with vibration-isolation devices (Nolet 2017).

The opportunity for achieving the greatest reduction in underwater sound is incorporating structural designs that mitigate sound during the design of new vessels. Sound reduction modifications to existing ships may prove to be economically impractical (IMO 2014). Modifications to existing ships that have shown a meaningful reduction in underwater sound include design and installation of modified propellers, installation of wakeconditioning devices, and installation of air injection to propellers (in ballast condition; IMO 2014).

Prior to investing in modifications to ship design, sound reduction modifications should be based on credible methods to clearly identify the primary source(s) of sound. With an increasing implementation of sound reduction engineering, there are a few classification societies (e.g., American Bureau of Shipping (ABS), Det Norske Veritas, Bureau Veritas) working with stakeholders establishing sound reduction classification systems to assist shipbuilders and operators in decision-making (Nolet 2017). Current gaps of information for implementing sound reduction technologies include lack of neutral testing facilities to validate manufacturing claims, relationship of sound reduction alterations to ship efficacy, and validation studies before and after sound control modifications are installed (ACCOBAMS 2013; Nolet 2017).

Examples exist in the navigation industry of organizations that have shown initiative to implement sound mitigation technology into ship design. For example, the Port of Vancouver recently established sound mitigation efforts associated with port activity (Brown 2016). The port authority established long-term sound-monitoring goals and identified specific mitigation efforts for underwater sound, including recognizing the use of "green vessel technology," changes to operational activities of 
vessels, recognition of certification programs for quiet vessels, and developing sound criteria for vessels entering the port (Brown 2016).

\subsubsection{Equipment operation and maintenance}

Alterations in operation and maintenance of existing equipment can also decrease underwater sound levels. For example, speed reduction is effective in decreasing sound for vessels equipped with fixed-pitch propellers and can be further decreased if the vessel drops below cavitation inception speeds (IMO 2014; Nolet 2017). For vessels with controllable pitch propellers, optimum combinations of shaft speed and propeller pitch can be used to decrease cavitation and sound (IMO 2014).

Cleaning propellers and underwater hull surfaces can also reduce underwater sound from commercial vessels. These maintenance activities decrease roughness and turbulence, thereby decreasing cavitation and vessel sound (IMO 2014). Additionally, onboard machinery is another source of vibration, and some consideration should be given to the selection, layout, and optimization that may contribute to reducing underwater sound (IMO 2014). An example layout may include "decoupling" equipment from the water surface to minimize underwater sound (Wursig et al. 2000). In terms of dredging-specific equipment, adequate maintenance of a dredge plant, including lubrication and repair of winches, generators, and propulsion components, could potentially mitigate underwater sound (WODA 2013). In relation to mitigating techniques for hopper dredges, Gerstein et al. (2006) suggested insulating and elevating the slurry pipeline (eliminating the contact with water) and minimizing the number and distance of transects from pump stations.

\subsubsection{Reduction in operation power levels}

Minimization of sound levels could be achieved by reducing the duration of a dredging or shipping activity or by limiting the number of times a system (e.g., propulsion) emits sound. Additionally, planning to use the lowest practical source of power to achieve the task could reduce sound levels (ACCOBAMS 2013). In the context of dredging, there would be a need to evaluate the relationship with operational power levels and underwater sound levels prior to altering operations to weigh cost versus benefit. 


\subsubsection{Alternate technologies}

Using alternative technologies or strategies that have decreased sound risks may also be identified to achieve the same operational goals. This could include the strategic selection of "quieter" equipment or vessels for operation.

\subsection{Summary}

Techniques for mitigating underwater sound can be informed by a riskbased approach (Boyd et al. 2008; Thomsen et al. 2016). For simplicity, mitigation strategies that can alter the risks associated with underwater sound can be categorized into avoidance and minimization techniques. Avoidance includes the creation of exclusion zones or spatial or temporal restrictions (windows) to limit animal exposures. Minimization measures involve the deployment of biological deterrents and acoustic damping devices to minimize sound at the source. Retrofits and modifications to existing commercial vessels and improved designs of new vessels may offer the best prospects for reducing underwater sound produced by commercial vessels, including dredges. Sound minimization techniques used in practice include, for example, the reduction in power and use of alternative technologies to reduce sound at the source.

A critical aspect of any successful underwater sound risk framework is to identify and mitigate appropriate ecological risks and to avoid managing ecologically insignificant risks that would pose unnecessary constraints and costs on operations. If mitigation technologies are necessary to manage risks for dredging-induced sound, cost of implementation should be weighed against risk reduction to ensure practical and cost-efficient approaches are selected (i.e., cost versus benefit comparisons). 


\section{NOAA NMFS Marine Mammal Acoustic Technical Guidance}

\subsection{Overview}

In July 2016, NOAA NMFS released the new technical guidance document for assessing the effects of anthropogenic sound on marine mammal hearing (NMFS 2016). Prior to this document, NMFS relied on generic acoustic threshold studies to assess the auditory impacts on marine mammals. In the 1990s, the Permanent Threshold Shift (PTS) for cetaceans was set at RMS SPL $180 \mathrm{~dB}$ and RMS SPL $190 \mathrm{~dB}$ for pinnipeds (NOAA 1998; HESS 1999). Due to lack of sound effects data at the time, NMFS set conservative and generic thresholds as single points of reference that could not account for the varied noise sources and hearing sensitivities of marine mammals. Since then, more comprehensive data sets for underwater sound effects on marine mammals have become available (Southall et al. 2007; Finneran 2015; Erbe et al. 2016). The improved understanding of acoustic thresholds allowed for a better evaluation of anthropogenic sound effects on marine mammals (Finneran and Jenkins 2012; NOAA 2014). The resulting information required a new comprehensive study of the current state of the science and the acoustic thresholds that were deemed sufficient to develop revised technical guidance.

The NMFS's 2016 technical guidance is a comprehensive review and study of peer-reviewed literature and government reports on the impacts of underwater sound on marine mammals. The technical guidance relied heavily upon the Finneran (2016) technical report "Auditory Weighting Functions and TTS/PTS Exposure Functions for Marine Mammals Exposed to Underwater Noise," which updated the underwater acoustic thresholds for TTS and PTS in marine mammals only. From the Finneran (2016) study, the NMFS updated the acoustic thresholds to a new standard to estimate PTS onset from all sound sources and use it to determine estimates for TTS from underwater impulsive and non-impulsive sounds. The NMFS 2016 acoustic thresholds are more complex than previous thresholds, but are more representative of the current scientific knowledge with regard to marine mammal hearing thresholds and potential responses to underwater sounds.

The purpose of the technical guidance was to provide NMFS analysts, managers, other action proponents and stakeholders (including other 
federal agencies) the most current information for determining how their underwater activities are going to result in auditory impacts to marine mammals from acoustic exposure. Because of differences between the new weighting factors and single reference point values, the NMFS acknowledges that the approach provided makes general or direct comparisons between the updated acoustic thresholds and previous thresholds difficult. Also, NMFS acknowledges the new marine mammal weighting functions and SELcum metrics may be difficult to implement in practice. For this reason, NMFS developed a set of tools to incorporate these new metrics (this is addressed in Appendix D of the technical guidance and User Spreadsheet, both of which can be found at http://www.nmfs.noaa.gov/pr/acoustics/guidelines.htm).

The technical guidance is not meant to represent the entirety of an effects analysis, but rather provide an additional tool to evaluate the adverse effects of underwater sound for marine mammals (NMFS 2016). Other sources of information that should be considered for a comprehensive risk assessment include behavioral impact thresholds, auditory masking assessments, and effects at the population level. NMFS indicates the technical guidance can be used as one line of evidence in the assessment of the proposed action and for input into the findings required by NOAA under relevant statutes (NMFS 2016).

\subsection{Background information}

NOAA was tasked to provide

“...technical guidance for assessing the effects of underwater anthropogenic (human-made) sound on the hearing of marine mammal species under the jurisdiction of the National Marine Fisheries Service (NMFS) and was completed in collaboration with the National Ocean Service (NOS), Office of National Marine Sanctuaries. Specifically, it (the technical guidance document) identifies the received levels, or acoustic thresholds, at which individual marine mammals are predicted to experience changes in their hearing sensitivity (either temporary or permanent) for acute, incidental exposure to underwater anthropogenic sound sources."

This guidance was published in July 2016 (NMFS 2016). 
This technical guidance used the newly available scientific information and provided a method for acoustic thresholds for onset of TTS and PTS in marine mammals. This guidance updated the methods used by NMFS and provided a framework to evaluate PTS onset caused by man-made impulsive and non-impulsive sound sources. The NMFS guidance focused on five marine mammal groups under NMFS jurisdiction (low- (LF): mid(MF), and high- (HF) frequency cetaceans, and otariid (OW) and phocid (PW) pinnipeds). The technical guidance does not include sirenians or manatees; however, Finneran (2016) included the sirenians group.

Animals are not equally sensitive to sound at all frequencies; therefore, auditory weighting functions are used. For each marine mammal group, a frequency-dependent weighting function and threshold for TTS and PTS were derived from currently available data on the hearing abilities of and the noise effect on these groups (Figure 20). The parameters needed to calculate the weighting function amplitudes are displayed in Table 13.

Figure 20. Weighting functions for all species groups from "Auditory weighting functions and TTS/PTS exposure functions for marine mammals exposed to underwater noise" (from NOAA Technical Memorandum NMFS-OPR-55 July 2016 Appendix A).

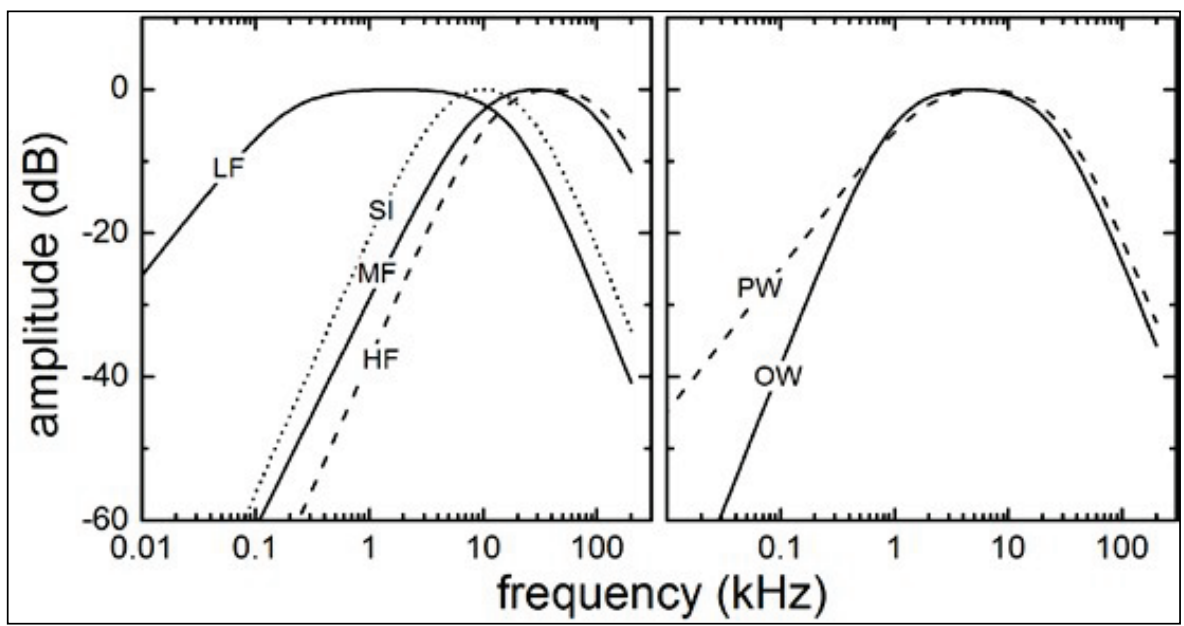


Table 13. Summary of weighting function parameters and TTS/PTS thresholds. SEL thresholds are in $\mathrm{dB} \mathrm{re} 1 \mu \mathrm{Pa}^{2} \mathrm{~S}$ and peak SPL thresholds are in dB re $1 \mu \mathrm{Pa}$ (from NOAA Technical Memorandum NMFS-OPR-55 July 2016 Appendix A).

\begin{tabular}{|c|c|c|c|c|c|c|c|c|c|c|c|}
\hline \multirow{2}{*}{\multicolumn{2}{|c|}{$W(f)=C+10 \log _{10}$}} & \multicolumn{3}{|c|}{$\left(f / f_{1}\right)^{2 a}$} & & \multicolumn{2}{|c|}{ Non-impulsive } & \multicolumn{4}{|c|}{ Impulse } \\
\hline & & \multicolumn{3}{|c|}{$\left[1+\left(f / f_{1}\right)^{2}\right]^{a}\left[1+\left(f / f_{2}\right)^{2}\right]$} & & \multirow{2}{*}{$\begin{array}{c}\begin{array}{c}\text { TSS } \\
\text { threshold }\end{array} \\
\text { SEL }\end{array}$} & \multirow{2}{*}{$\begin{array}{c}\begin{array}{c}\text { PTS } \\
\text { threshold }\end{array} \\
\text { SEL }\end{array}$} & \multicolumn{2}{|c|}{$\begin{array}{c}\text { TTS } \\
\text { threshold }\end{array}$} & \multicolumn{2}{|c|}{$\begin{array}{c}\text { PTS } \\
\text { threshold }\end{array}$} \\
\hline Group & $a$ & $b$ & $f 1$ & $f 2$ & C & & & SEL & $\begin{array}{c}\text { peak SPL } \\
\text { (unweighted) }\end{array}$ & SEL & $\begin{array}{c}\text { peak SPL } \\
\text { (unweighted) }\end{array}$ \\
\hline LF & 1 & 2 & 0.20 & 19 & 0.13 & 179 & 199 & 168 & 213 & 183 & 219 \\
\hline MF & 1.6 & 2 & 8.8 & 110 & 1.20 & 178 & 198 & 170 & 224 & 185 & 230 \\
\hline $\mathrm{HF}$ & 1.8 & 2 & 12 & 140 & 1.36 & 153 & 173 & 140 & 196 & 155 & 202 \\
\hline SI & 1.8 & 2 & 4.3 & 25 & 2.62 & 186 & 206 & 175 & 220 & 190 & 226 \\
\hline OW & 2 & 2 & 0.94 & 25 & 0.64 & 199 & 219 & 188 & 226 & 203 & 232 \\
\hline PW & 1 & 2 & 1.9 & 30 & 0.75 & 181 & 201 & 170 & 212 & 185 & 218 \\
\hline
\end{tabular}

Each group of marine mammals had frequency-dependent weighting functions and numeric thresholds for TTS and PTS onset, which was determined from the available data. The auditory weighting functions are based on a generic band-pass filter described by Equation 4:

$$
W(f)=C+10 \log _{10}\left\{\frac{\left(f / f_{1}\right)^{2 a}}{\left[1+\left(f / f_{1}\right)^{2}\right]^{a}\left[1+\left(f / f_{2}\right)^{2}\right]^{b}}\right\}
$$

where, $W(f)$ is the weighting function amplitude (in $\mathrm{dB}$ ) at the frequency $f$ (in $\mathrm{kHz}$ ). The shape of the filter is defined by the parameters $\mathrm{C}, f_{1}, f_{2}$, a, and $b$ :

$C=$ weighting function gain $(\mathrm{dB})$. The value of " $C$ " defines the vertical position of the curve. Changing the value of $C$ shifts the function up/down. The value of $C$ is often chosen to set the maximum amplitude of $W$ to o dB (i.e., the value of $C$ does not necessarily equal the peak amplitude of the curve).

$f_{1}=$ low-frequency cutoff $(\mathrm{kHz})$. The value of " $f 1$ " defines the lower limit of the filter pass-band; i.e., the lower frequency at which the weighting function amplitude begins to decline or "roll-off" from the flat, central portion of the curve. The specific 
amplitude at $f 1$ depends on the value of $a$. Decreasing $f 1$ will enlarge the pass-band of the function (the flat, central portion of the curve).

$f_{2}=$ high-frequency cutoff $(\mathrm{kHz})$. The value of " $f_{2}$ " defines the upper limit of the filter pass-band; i.e., the upper frequency at which the weighting function amplitude begins to roll off from the flat, central portion of the curve. The amplitude at $f_{2}$ depends on the value of $b$. Increasing $f 2$ will enlarge the passband of the function.

$a=$ low-frequency exponent (dimensionless). The value of " $a$ " defines the rate at which the weighting function amplitude declines with frequency at the lower frequencies. As frequency decreases, the change in weighting function amplitude becomes linear with the logarithm of frequency, with a slope of $20 a \mathrm{~dB} /$ decade. Larger values of $a$ result in lower amplitudes at $f 1$ and steeper roll-offs at frequencies below $f 1$.

$b=$ high-frequency exponent (dimensionless). The value of " $b$ " defines the rate at which the weighting function amplitude declines with frequency at the upper frequencies. As frequency increases, the change in weighting function amplitude becomes linear with the logarithm of frequency, with a slope of $-20 b \mathrm{~dB} /$ decade. Larger values of $b$ result in lower amplitudes at $f 2$ and steeper roll-offs at frequencies above $f 2$.

\subsection{Technical guidelines for marine mammals}

For the development of PTS and TTS thresholds, NMFS divided sound sources into two categories: impulsive and non-impulsive. The NOAA technical guidance used the following definitions:

- Impulsive: produce sounds that are typically transient, brief (less than $1 \mathrm{~s}$ ), broadband, and consist of high-peak sound pressure with rapid rise time and rapid decay (ANSI 1986; National Institute for Occupational Safety and Health (NIOSH) 1998; ANSI 2005).

- Non-impulsive: produce sounds that can be broadband, narrowband, or tonal, brief or prolonged, continuous or intermittent) and typically do not have a high-peak sound pressure with rapid rise/decay time that impulsive sounds do (ANSI 1995; NIOSH 1998).

Sound sources such as sonars and vibratory pile drivers would therefore be considered non-impulsive, while explosives, impact pile drivers, and air 
guns would be considered impulsive. Harmonic signals or sounds with duration greater than 5 to 10 cycles were generally considered to be steady state. Based on these definitions, while it is possible that dredges could emit impulsive sounds (e.g., hard-bottom strike from bucket or backhoe dredges); the vast majority of dredge-related sounds would be considered non-impulsive (e.g., marine vessels, engines, pumps, etc.), according to this definition.

Because there is a frequency-dependent nature to the effect of sound, auditory weighting functions were used to account for frequency hearing sensitivities of marine mammals. The auditory weighting function is a mathematical function used to emphasize marine mammal-sensitive sound frequencies. A function-dependent filter (i.e., the frequency where weighting function amplitude begins to decline from the flat, central portion of the function) is applied to a sound level before a single, weighted sound exposure level (SEL) is calculated. This weighting function is a "band-pass" type filter that resembles an inverted " $U$ " when plotted versus frequency (see Figure 20 as an example). The weighting function is essentially flat over a limited range of frequencies, called the "pass-band," and drops off at frequencies above and below the "pass-band."

By comparison, auditory weighting functions for humans are based on equal loudness contours in a human listener. Equal loudness contours are defined as curves that show the combination of SPL over the frequency spectrum that results in a sensation of constant loudness when presented as a pure tone. For humans, NMFS created equal loudness contours from data collected during loudness comparison tasks (i.e., feedback during auditory tasks). But these data were difficult to collect from non-verbal animals; therefore, equal loudness contours were only available for a single marine mammal (a dolphin) and only for a limited range (2.5 $113 \mathrm{kHz}$ ). A substitute used for these loudness comparison tasks was to measure reaction times to tones and correlated behavioral responses to subjective loudness. From these, reaction time versus SPL curves of equal response latency were created and used to give an approximate equal loudness curve.

The Equal Energy Hypothesis (EEH) is one assumption that NMFS made when applying the SELcum metric. It assumes that sounds of equal SELcum produce equal risk for hearing loss (i.e., short-duration sounds with a higher energy level would have a similar risk as a longer duration sound 
with a lower energy). Henderson et al. (1991) showed this to be the case in humans and terrestrial mammals, but the EEH does not always accurately describe the exposure situations for marine mammals due to the inherent complexity of predicting threshold shifts (e.g., Kastak et al. 2007; Mooney et al. 2009a; Mooney et al. 2009b; Finneran et al. 2010a; Finneran et al. 2010b; Finneran and Schlundt 2010; Kastelein et al. 2012; Kastelein et al. 2013b; Kastelein et al. 2014; Popov et al. 2014).

The factors associated with TS-like sound level (i.e., sensation level, overall level, and level above background), the duration, duty cycle (intermittent or continuous), number of transient components, and frequency of sound are all important considerations (e.g., Buck et al. 1984; Clark et al. 1987; Ward 1991; Lataye and Campo 1996). This is especially the case for exposure to impulsive sound sources (Danielson et al. 1991; Henderson et al. 1991; Hamernik et al. 2003), which is why acoustic thresholds in this technical guidance are also expressed as a Peak SPL Metric (PK). In most cases, the EEH method gives a good first-order approximation, especially for the higher-level, short duration sound exposures, such as those that are most likely to result in TTS for marine mammals (Finneran 2015).

For terrestrial mammals, impulsive sounds can have a greater risk of causing direct mechanical fatigue to the inner ear compared to sounds that are strictly non-impulsive (Henderson and Hamernik 1986; Levine et al. 1998; Henderson et al. 2008). The risk of damage from impulsive (transient) sounds usually does not depend on the duration of the exposure. This concept of "critical level" (where the damage switches from primarily metabolic to more mechanical and short-duration impulses can be less than the ear's integration time) leading to the potential to damage beyond the level the ear can perceive (Akay 1978).

Industrial noise standards for humans recognize and provide for separate acoustic thresholds for impulsive sound sources using the PK metric (Occupational Safety and Health Administration; OSHA 2013; 29 CFR 1910.95; Starck et al. 2003). Due to this, Selcum is not the appropriate metric to use for all the effects of impulsive sounds (National Institute for Occupational Safety and Health [NIOSH] 1998), which is why the instantaneous PK level has also been included as part of the NMFS's dual metric for threshold of impulsive sounds. Auditory weighting is not used with the PK threshold as the direct mechanical damage associated with 
high peak sound pressures typically does not strictly reflect the frequencies an individual species hears best (Ward 1962; Saunders et al. 1985; ANSI 1986; DOD 2004; OSHA 2013; 29 CFR 1910.95). Thus, the NMFS (2016) guidance recommends that the PK thresholds should be unweighted/flatweighted within the entire frequency band of a hearing group. It should be noted that for non-impulsive sounds, the SELcum threshold will likely result in the largest isopleth (delineation of area from source) as compared to the PK threshold. So, for the majority of non-impulsive sounds, the PK threshold is considered unnecessary. However, if the non-impulsive sound has the potential of exceeding the PK threshold associated with impulsive sounds, these thresholds should be considered (i.e., using dual metrics.)

For the development of the NMFS auditory-weighted functions, marine mammals were divided into six hearing groups. For each group, a frequency-dependent weighting function and threshold for onset of TTS and PTS were derived from the available data on hearing abilities and effects of sound on these marine mammals. Available measured or predicted auditory threshold data and equal latency contours were used to create the weighting function curves for each of the groups. Marine mammal groups with measured TTS data were used to adjust the weighting function parameters to provide the best fit to the experimental data. This method was then applied to weighting functions of the other marine mammal groups that did not have measured TTS data. This methodology was used to develop the updated NMFS auditory weighted functions used to predict auditory thresholds for select marine mammals.

The NMFS auditory guidelines were not specifically targeting dredging. The study was assessing the ranges of the marine mammal hearing and what levels of anthropogenic sounds generated from human activities could adversely impact the hearing of select marine mammal groups. The NMFS guidance is intended to develop acoustic thresholds for assessing the effects of anthropogenic underwater sound on marine mammals. The potential uses and implications for dredging-related activities are discussed below.

\subsection{Implication to dredging-induced underwater sound}

The NMFS (2016) technical guidance document does not identify or address dredging sounds. Instead, the technical guidance document focused on a number of other anthropogenic sound activities; for example, pile driving, airguns, and tactical sonar. The majority of dredging occurs in the relatively 
shallow water depths ( $<20 \mathrm{~m}$ ) of coastal waterways and is performed by hydraulic and mechanical dredges. These shallow-water coastal areas are dynamic environments with a variety of bottom habitats as well as many types of ambient and anthropogenic sound sources; therefore, estimations of received sound levels should be made with caution. Considerations of how the NMFS (2016) technical guidance relates to dredging-related sounds, data limitations, and uncertainties are outlined below.

\subsubsection{Acoustic terminology - application to dredging sounds}

The sound thresholds proposed in the NMFS technical guidance are organized into two broad categories: (1) impulsive and (2) non-impulsive sounds. The acoustic metrics chosen for impulsive sound thresholds include peak SPL (SPLpeak; $1 \mu \mathrm{Pa}$ ) and cumulative SEL (SELcum; $1 \mu \mathrm{Pa}^{2} \mathrm{~S}$ ). These are defined as "dual" metrics, meaning that NMFS considered onset of PTS to occur if either metric is exceeded. For non-impulsive sounds, the single metric SELcum $\left(1 \mu \mathrm{Pa}^{2} \mathrm{~s}\right)$ is used. The updated NMFS (2016) guidance eliminated the use of a single exposure metric (SPLrms) for non-impulsive sounds, and relies exclusively on a time-integrated exposure metric SELcum.

To date, the primary metric used to describe dredging sounds have been the SPLrms metric (Dickerson et al. 2001; Clarke et al. 2002; Reine et al. 2012; Reine et al. 2014), which are not directly comparable to either of the NOAA sound threshold metrics (SPLpeak or SELcum). Efforts are underway to establish standardized methods for measuring and reporting sounds related to dredging activities, but to date no single method has been adopted (Jones and Marten 2016). The SELcum metric has duration incorporated ( $\left.1 \mu \mathrm{Pa}^{2} \mathrm{~s}\right)$, and therefore is not directly comparable to other metrics that compare SELs ( $1 \mu \mathrm{Pa}$; NMFS 2016) and cannot be converted to SELrms with any reliability. Since there is no direct conversion between SPL $L_{\text {rms }}$ and SELcum, it is difficult to know what SEL would be generated by dredging activities; therefore, it is unclear if dredging would exceed the proposed PTS thresholds for non-impulsive sounds. Additionally, the NMFS intends for the SELcum metric to account for the accumulated exposure within a twenty-four-hour period. For dredging and other sources of anthropogenic noise, NOAA does not address how a 24-hour exposure criterion could be measured or applied by considering intermittent periods of no sound production. Dredge-related sounds are often intermittent due to stoppages for crew changes, placement transit, maintenance of equipment, and/or breakdowns. Additionally, dredging 
activities have diverse sound characteristics occurring over various spatial and temporal scales. The NMFS guidelines state:

"The recommended application of the SELcum metric is for individual activities/sources. It is not intended for accumulating sound exposure from multiple activities occurring within the same area or over the same time or to estimate the impacts of those exposures to an animal occurring over various spatial or temporal scales. Current data available for deriving acoustic thresholds using this metric are based on exposure to only a single source and may not be appropriate for situations where exposure to multiple sources is occurring." (page 28; NMFS 2016). For this reason, the methodology proposed in the NOAA guidance is not applicable to operating dredges where multiple sounds are being generated from various components of the dredge (e.g., propeller, drag arm, etc.) that are acting in concert, producing an overall continuous, non-impulsive sound source.

It should be noted that "effective quiet" is the maximum SPL that will fail to produce any significant auditory threshold shift despite the duration of accumulation (Ward et al. 1976; NMFS 2016). This should be considered when estimating SELcum so that risk expectations are managed. For example, low SPLs with sufficiently long durations could theoretically accumulate to exceed SELcum acoustic thresholds, when the actual or likely risk is extremely low (e.g., humans exposed to normal conversation $\mathrm{dB}$ levels every day are not subjected to greater risk of TTS onset; NMFS 2016; p.122).

\subsubsection{Uncertainty and data limitations}

NMFS (2016) recognizes the inherent data limitations for establishing effects thresholds, including a limited number of species, individuals within a species, and the presence of multiple concurrent sound sources. Broad data limitations for the development of the NMFS guidelines include the following:

- No direct measurements of marine mammal PTS have been published. PTSs have been derived from mathematical models, TTS is used to extrapolate onset of PTS;

- Estimations of PTS are based on very limited TTS data within each hearing functional group; 
- Existing use of "representative" surrogate individuals for establishing PTS onset thresholds for species where limited (or no) data exist (e.g., LF cetaceans); and

- Hearing sensitivity can vary among individuals within the same species based on a variety of parameters (e.g., age, previous exposure, etc.).

Currently, TSS measurements exist for four species of cetaceans (bottlenose dolphins, belugas, harbor porpoises, and Yangtze finless porpoises) and three species of pinnipeds (northern elephant seal, harbor seal, and California sea lion). Due to the absence of LF cetacean audiogram data, multiple assumptions were made to estimate TS onset. For these reasons, NOAA incorporated a broader weighting/ exposure function than any other functional hearing group to account for the inherent uncertainty associated with these estimates.

NMFS recognizes the limitations of the available data for the development of certain aspects of the criteria; therefore, re-evaluations of effects thresholds will be conducted as new data become available. NMFS expects to update the effects thresholds every 3 to 5 years to incorporate new data and methods. NMFS (2016) indicates that the authors of Southall et al. (2007) are preparing an updated publication of the original "Marine Mammal Noise Exposure Criteria: Initial Scientific Recommendations." If alternative methods are proposed by Southall et al. for predicting lowfrequency cetaceans, the NMFS are likely to re-evaluate the methodology to be applied to additional receptors (e.g., other marine mammals and fish) and other anthropogenic sound sources.

As the understanding of effects of underwater sound improves, it is anticipated that acoustic thresholds are going to become more complex; and likely more challenging for implementation (NMFS 2016). For example, prior NMFS guidance relied on only two generic marine mammal auditory effects thresholds, SPL RMS 180 and $190 \mathrm{~dB}$ for cetaceans and pinnipeds, respectively. Clearly, more complex sound effects thresholds need to be balanced with practical application (cost versus benefit) to aid in proper implementation by users (e.g., action proponents, managers, etc.; NMFS 2016). It should be noted that standardization of measurement parameters and protocols has been identified as a critical need by the international scientific community engaged in underwater sound research. Until such standardization has been sufficiently developed to be 
implementable, it will remain difficult-if not impossible-to establish criteria sufficiently robust to be site- and activity-specific.

\subsection{Summary}

The NMFS (2016) technical guidance document does not specifically address dredging-related sounds and the proposed thresholds are not broadly applicable to navigation dredging. The NMFS (2016) technical guidance states that it is not meant to represent the entirety of an effects analysis; rather, it should provide an additional tool to aid in evaluating the adverse effects of underwater sound for marine mammals (NMFS 2016). In terms of evaluating risks associated with underwater sound for site-specific activities, the technical guidance recommends the use of effects thresholds to be used in conjunction with site-specific characterization. NMFS site parameter recommendations include characterization of the sound source, environmental site conditions that influence sound propagation, and marine mammal occurrence and behavior near the sound activity (e.g., species, density, occurrence, etc.). NMFS acknowledges that alternative approaches may be used if sitespecific information or data indicate it can produce a more accurate estimation of auditory risk. Alternative approaches that have been subjected to independent peer review may be proposed by federal agencies or prospective action proponents if the approach demonstrates it is "likely to produce a more accurate estimate of auditory impact for the project being evaluated" (NMFS 2016). The scope of the NMFS (2016) guidelines limits their applicability for addressing dredge-related sounds due to the limitations in comparable sound exposure metrics and acoustical exposure considerations. Alternatively, a risk-based approach specific to dredginginduced sounds is needed to sufficiently understand the potential ecological risks to effectively apply such threshold limits in practice. 


\section{Summary and Path Forward}

This literature review was needed to develop an improved understanding about underwater dredging sound effects on aquatic life. Underwater sound from natural and anthropogenic sources are composed of many frequencies and amplitudes, which produce a combination of acoustic waves that can be disordered or random and difficult to spatially quantify. The sound pressure levels (SPLs) in decibels (dB) are commonly used to quantify underwater sounds. SPLs are typically specified in metrics referring to the acoustical properties. Common examples include rootmean-square (RMS), peak-to-peak, or frequency bands ( $1 / 3$ octave analysis or $\mathrm{Hz}$ range). Due to the diversity of acoustic metrics, it is critical to use caution when comparing reported sound levels across studies. Additionally, it is crucial to understanding the differences between sound source levels and organism-received levels (the latter is dependent on the sound source characteristics and the sound propagation in the aquatic environment, and the receptor sensitivity).

Dredge-induced underwater sounds are temporally and spatially dynamic, and dependent on site-specific activities and conditions. Dredging produces predominantly low-frequency $(<1,000 \mathrm{~Hz}$; Figure 21$)$ sounds that are typically continuous and non-impulsive (e.g., do not exhibit a rapid sound pressure rise time and decay). A notable exception is during blasting activities when rock and other hard substrata need to be removed in ship channels to ensure navigation safety. Dredging sounds are comparatively lower intensities in contrast to other activities (e.g., explosions, pile driving, seismic airguns, echosounders, and large ships). It should be noted that the acoustical characteristics are often summarized as single maximum recorded values near the sound source (i.e., $1 \mathrm{~m}$ from the source). Additionally, a single sound event (e.g., propeller cavitation) can skew the calculated SPLs (RMS) and may not provide an accurate representation of the sounds being generated by a dredging operation.

Based on the review results of existing effects data, direct mechanical injury and mortality in aquatic species following underwater sound exposures are limited to high-intensity impulsive sounds (e.g., explosions, pile driving). The currently available effects data from anthropogenic sources indicate that dredging-induced sounds do not pose a significant risk to direct injury or mortality to aquatic biota. In terms of potential non-lethal responses, low-frequency sounds produced by dredging 
activities overlap with the hearing frequency ranges of select fish and mammal species; this may pose risks for auditory temporary threshold shifts, auditory masking, and behavioral responses. Overall, there has been significant progress in the understanding of the characteristics of dredgerelated sounds in the last couple of decades. Although there are gaps of exposure-response data for dredging-induced sounds, in general there is no direct evidence of lethal effects to aquatic biota, and few data indicating that non-lethal effects (e.g., behavioral) are pervasive.

A critical aspect of any successful underwater sound risk framework is to identify and mitigate appropriate ecological risks, and to avoid managing ecologically insignificant risks that would pose unnecessary constraints and costs on operations. Mitigation strategies to manage risks of underwater sound effects on aquatic biota generally include avoidance and minimization. Prior to the application of mitigation technologies, cost of implementation should be weighed against risk reduction to ensure practical and cost-efficient approaches are selected (i.e., cost versus benefit comparisons).

Recently updated technical guidelines have been developed by the NMFS (2016) that proposed acoustic exposure criteria for select classes of marine mammals (NMFS 2016). The NMFS technical guidance document does not specifically address dredging-related sounds and the proposed exposure criteria are not broadly applicable to dredging. In terms of evaluating risks associated with underwater sound for site-specific activities, the technical guidance recommends the use of effects thresholds to be used with site-specific characteristics such as the sound source, environmental site conditions that influence sound propagation, and marine mammal occurrence and behavior near the sound activity (e.g., species, density, occurrence, etc.). NMFS acknowledges that alternative approaches may be used if site-specific information or data indicate it can produce a more accurate estimation of auditory risk.

To improve understanding of the ecological risks associated with dredging sounds, a risk-based approach is needed that maximizes the data and other site-specific information to evaluate the underwater sound of concern. Additional study is needed to improve our understanding of whether the updated thresholds developed by NOAA indicate potential risks during dredging rock-blasting activities and whether the thresholds are relevant to dredging in coastal waterways. Overall, the information 
reported herein regarding underwater sound produced by dredging can be used in an exposure assessment as part of a broader framework for assessing and managing underwater sound effects on aquatic life.

Figure 21. Hearing frequency ranges of selected fish and mammal species and main energy frequencies reported for anthropogenic sources. See Appendix A for source data.

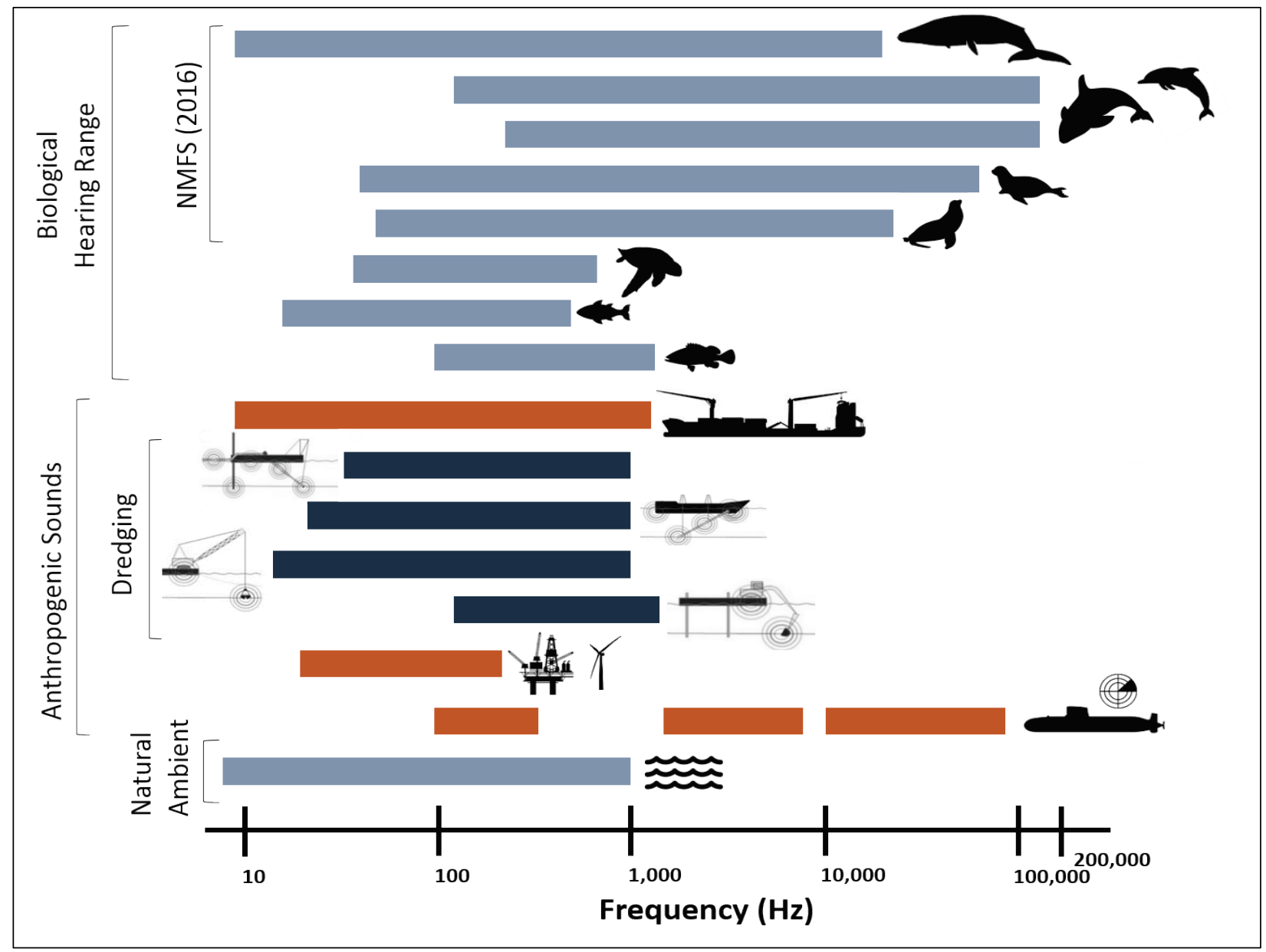




\section{References}

ACCOBAMS. 2013. Methodological Guide: Guidance on Underwater Noise Mitigation Measures. ACCOBAMS-MOP5/2013/Doc24.

Ainslie, M. A., C. A. F. de Jong, H. S. Dol, G. Blacquière, and C. Marasini. 2009. Assessment of natural and anthropogenic sound sources and acoustic propagation in the North Sea. Report TNO-DV 2009 Co85. The Netherlands Ministry of Transport, Public Works and Water Affairs; Directorate-General for Water Affairs.

Ainslie, M. A., C. A. F. de Jong, J. Janmaat, and H. J. M. Heemskerk, 2012. Dredger noise during Maasvlakte 2 construction: Noise maps and risk assessment. Report TNO, R10818.Au WWL.

Akay, A. 1978. A review of impact noise. Journal of the Acoustical Society of America 64:977-987.

Amoser, S. and F. Ladich. 2003. Diversity in noise-induced temporary hearing loss in otophysine fishes. Journal of the Acoustical Society of America. 113: 2170-2179.

Andriguetto-Filho, J. M., A. Ostrensky, M. R. Pie, U. A. Silva, and W. A. Boeger. 2005. Evaluating the impact of seismic prospecting on artisanal shrimp fisheries. Continental Shelf Research 25:1720-1727.

Anonymous. 1948. Effects of underwater explosions on oysters, crabs and fish. Publication No. 70. Chesapeake Biological Laboratory.

ANSI (American National Standards Institute). 1986. Methods of Measurement for Impulse Noise (ANSI S12.7-1986). New York: Acoustical Society of America. . 1994. American National Standard Acoustical Terminology (ANSI S1.1-1994). New York: Acoustical Society of America.

. 1995. Bioacoustical Terminology (ANSI S3.20-1995).New York: Acoustical Society of America.

. 2005. Measurement of Sound Pressure Levels in Air (ANSI S1.13-2005). New York: Acoustical Society of America.

$\mathrm{Au}$, W. W. L., and K. Banks, 1998. The acoustics of the snapping shrimp Synalpheus parneomeris in Kaneohe Bay. Journal of the Acoustical Society of America 103: 41-47.

Baker, K., D. Epperson, G. Gitschlag, H. Goldstein, J. Lewandowski, K. Skrupky, B. Smith, and T. Turk. 2013. National standards for a protected species observer and data management program: A model using geological and geophysical surveys. NMFS-OPR-49. NOAA. U.S. Department of Commerce. Technical Memorandum. 
Baker, K., D. 2008. Assessment and mitigation of marine explosives: guidance for protected species in the Southeast U.S. National Marine Fisheries Service (NMFS). Draft Report (Version 1).

Banks K. 1998. The acoustics of the snapping shrimp Synalpheus parneomeris in Kaneohe Bay. Journal of the Acoustical Society of America 103:41-47.

Blackwell, S. B., and C. R. Greene. 2003. Acoustic measurements in Cook Inlet, Alaska, during August 2001. Greenridge Report 271-2. Prepared for National Marine Fisheries Service.

Bolle, L. J., C. A. de Jong, M. Bierman, P. van Beek, P. W. Wessels, E. Blom, C. J. van Damme, H. V. Winter, and R. P. Dekeling. 2016. Effect of pile-driving sounds on the survival of larval fish. In The Effects of Noise on Aquatic Life II. New York: Springer.

Booman, C., J. Dalen, H. Leivestad, A. Levsen, T. van der Meeren, K. Toklum. 1996. Effects of seismic air-gun shooting on fish eggs, larvae and fry. Institute of Marine Research. Fisken og Havet 3: 83.

Boyd, I. L., B. Brownell, D. H. Cato, C. Clarke, D. Costa, P. Evans, J. Gedamke, R. Gentry, and B. Gisiner. 2008. The effects of anthropogenic sound on marine mammals: a draft research strategy. ESF Marine Board Position Paper 13. European Science Foundation, Marine Board. Oostende, Belgium. ISBN 2-912049-85-7.

Bradley, D. L., and R. Stern, 2008. Underwater sound and the marine mammal acoustic environment: A guide to fundamental principles, Report (U.S. Marine Mammal Commission). Available from https://www.mmc.gov/wpcontent/uploads/sound_bklet.pdf

Brandt, M. J., A. Diederichs, K. Betke, G. Nehls. 2011. Responses of harbour porpoises to pile driving at the Horns Rev II offshore wind farm in the Danish North Sea. Mar Ecol Prog Ser 421: 205-216

Brown, C. 2016. Vancouver noise mitigation efforts. GreenPort. Winter 2016/2017: 17-22.

Bruns, B., C. Kuhn, P. Stein, J. Gattermann, and K. H. Elmer.2014. The new noise mitigation system 'Hydro Sound Dampers': history of development with several hydro sound and vibration measurements. In Proc Internoise, 16-19.

Buck, K., A. Dancer, and R. Franke. 1984. Effect of the temporal pattern of a given noise dose on TTS in guinea pigs. Journal of the Acoustical Society of America 76:1090-1097.

Carlson, T., M. Hastings, and A. N. Popper. 2007. Update on Recommendations for Revised Interim Sound Exposure Criteria for Fish during Pile Driving Activities. Available at: http://www.dot.ca.gov/hq/env/bio/files/ct-arlington_memo_1221-07.pdf. Accessed August 2018. 
Carlson, T. J., G. E. Johnson, C. M. Woodley, J. R. Skalski, and A. G. Seaburg. 2011. Compliance monitoring of underwater blasting for rock removal at Warrior Point, Columbia River Channel improvement. Project, 2009/2010. PNNL20388. Prepared by Pacific Northwest National Laboratory, Richland, Washington, for the US Army Corps of Engineers, Portland District, Portland, Oregon.

Carr, S. A., and C. Erbe. 2008. Assessing the impact of underwater noise on marine fauna: a software tool. In: Bioacoustics (special issue) 17:241-242.

Casper, B. M., T. J. Carlson, and M. B. Halvorsen, A. N. Popper. 2016. Effects of impulsive pile-driving exposure on Fishes. In The Effects of Noise on Aquatic Life II. New York: Springer.

Casper, B. M., A. N. Popper, F. Matthews, T. J. Carlson, and M. B. Halvorsen. 2012. Recovery of Barotrauma Injuries in Chinook Salmon, Oncorhynchus tshawytscha from Exposure to Pile Driving Sound. PLoS ONE 7(6): e39593. doi:10.1371/journal.pone.0039593

CEDA 2011. CEDA Position Paper: Underwater Sound in Relation to Dredging. Terra et Aqua 125:23-28. www.dredging.org.

CEFAS 2015. Impacts of noise and use of propagation models to predict the recipient side of noise. Report prepared under contract: ENV.D.2/FRA/2012/0025 for the European Commission. UK: Centre for Environment, Fisheries \& Aquaculture Science.

Celi, M. F. Filiciotto, G. Maricchiolo, L. Genovese, E. M. Quinci, V. Maccarrone, S. Mazzola, M. Vazzana, G. Buscaino. 2016. Vessel noise pollution as a human threat to fish: assessment of the stress response in gilthead sea bream (Sparus aurata Linnaeus 1758). Fish Physiol Biochem. 42: 631-641.

Chapman, C. J. and A. D. Hawkins. 1973. A field study of hearing in the cod, Gadus morhua. Journal of Comparative Physiology 85: 147-167.

Christensen-Dalsgaard, J., C. Brandt, K. L. Willis, C. B. Christensen, D. Ketten, P. EddsWalton, R. R. Fay, P. T. Madsen, C. E. Carr. 2012. Specialization for underwater hearing by the tympanic middle ear of the turtle. Trachemys scripta elegans. Proceedings of the Royal Soceity B. doi:10.1098/rspb.2012.0290

Clark, C. W., W. T. Ellison, B. L. Southall, L. Hatch, S. M. Van Parijs, A. Frankel, D. Ponirakis. 2009. Acoustic masking in marine ecosystems: intuitions, analysis, and implication. Marine Ecology Progress Series 395:201-222.

Clark, W. W., B. A. Bohne, and F. A. Boettcher. 1987. Effect of periodic rest on hearing loss and cochlear damage following exposure to noise. Journal of the Acoustical Society of America 82:1253-1264.

Clarke, D., C. Dickerson, and K. Reine. 2002. Characterization of underwater sounds produced by dredges. In Dredging 2002, American Society of Civil Engineers, Orlando, Florida, USA: 64-81. 
Codarin, A., L. E. Wysocki, F. Ladich, and M. Picciulin. 2009. Effects of ambient and boat noise on hearing and communication in three fish species living in a marineprotected area (Miramare, Italy). Marine Pollution Bulletin 58: 1880-1887.

Convention on Biological Diversity (CBD). 2012. Scientific synthesis on the impacts of underwater noise on marine and coastal biodiversity and habitats. Item 6.2 at the sixteenth meeting of the subsidiary body on scientific technical and technological advice, Montreal, Canada. April 30- May 5; Ref doc number:

$\mathrm{UNEP} / \mathrm{CBD} / \mathrm{SBSTTA} / 16 / \mathrm{INF} / 12$

Cox, T. M., T. J. Ragen, A. J. Read, E. Vos, R. W. Baird, K. Balcomb, J. Barlow, J. Caldwell, T. Cranford, L. Crum, A. D’Amico, G. D’Spain, A. Fernandez, J. Finneran, R. Gentry, W. Gerth, F. Gulland, J. Hildebrand, D. Houser, T. Hullar, P. D. Jepson, D. Ketten, C. D. MacLeod, P. Miller, S. Moore, D. C. Moutain, D. Palka, P. Ponganis, S. Rommel, T. Rowles, B. Taylor, P. Tyack, D. Wartzok, R. Gisinger, J. Mead, L. Benner. 2006. Understanding the impacts of anthropogenic sound on beaked whales. J. Cetacean Res. Manage. 7(3): 177-187.

Dahne, M., A. Gilles, K. Lucke, V Peschkpo, S. Adler, K. Krugel, J. Sundermeyer, U. Siebert. 2013. Effects of pile-driving on harbour porpoises (Phocoena phocoena) at the first offshore wind farm in Germany. Environmental Research Letters $8(2)$.

Danielson, R., D. Henderson, M. A. Gratton, L. Bianchai, and R. Salvi. 1991. The importance of "temporal pattern" in traumatic impulse noise exposures. Journal of the Acoustical Society of America 90:209-218.

de Jong, C., M. Ainslie, J. Dreschler, E. Jansen, E. Heemskerk, and W. Groen. 2010. Underwater noise of trailing suction hopper dredgers at Maasvlakte 2: Analysis of source levels and background noise. TNO Report TNO-DV-2010 C335.

de Soto, N. A., N. Delorme, J. Atkins, S. Howard, J. Williams, M. Johnson. 2013. Anthropogenic noise causes body malformation and delays development in marine larvae. Scientific Reports 3:2831.

Department for Environment, Food and Rural Affairs (DEFRA) 2003. Preliminary investigation of the sensitivity of fish to sound generated by aggregate dredging and marine construction. Project AEo914 Final Report.

Department of Defense (DOD). 2004. Department of Defense Instruction: DOD Hearing Conservation Program (HCP). Washington, DC: Department of Defense.

Dickerson, C., K. J. Reine, and D. G. Clarke. 2001. Characterization of underwater sounds produced by bucket dredging operations. DOER Technical Notes Collection ERDC TN-DOER-E14. Vicksburg, MS: US Army Engineer Research and Development Center. www.wes.army.mil/el/dots/doer.

Diederichs A., M. Brandt, G. Nehls.2010. Does sand extraction near Sylt affect harbour porpoises? Wadden Sea Ecosystem 26:199-203

Erbe, C. 2011. Noise and the effects on marine mammals: A Pocket Handbook, 3rd Edition. JASCO Applied Sciences. 
Erbe, C., M. A. Ainslie, C. A.de Jong, R. Racca, M. Stocker. 2016. Summary Report Panel 1: The need to protocols and standards in research on underwater noise impacts on marine life. In The Effects of Noise on Aquatic Life II. New York: Springer.

Everley, K. A., A. N. Radford, S. D. Simpson. 2016. Pile-driving noise impairs anipredator behavior of the European sea bass (Dicentrarchus labrax). In The Effects of Noise on Aquatic Life II. New York: Springer.

Finneran, J. J. 2008. Auditory effects of intense sounds on odontocetes: continuous, intermittent, and impulsive exposures. Bioacoustics (special issue). 17:301-304.

Finneran, J. J. 2015. Noise-induced hearing loss in marine mammals: A review of temporary threshold shift studies from 1996 to 2015. Journal of the Acoustical Society of America 138:1702-1726.

Finneran, J. J. 2016. Auditory weighting functions and TTS/PTS exposure functions for cetaceans and marine carnivores. May 2016. San Diego, California: SPAWAR Systems Center Pacific.

Finneran, J. J. and A. K. Jenkins. 2012. Criteria and thresholds for U.S. Navy acoustic and explosive effects analysis. San Diego, California: SPAWAR Systems Center Pacific. http://www.dtic.mil/dtic/tr/fulltext/u2/a561707.pdf

Finneran, J. J., C. E. Schlundt, R. Dear, D. A. Carder, S. H. Ridgway. 2002. Temporary shift in masked hearing thresholds in odontocetes after exposure to single underwater impulses from a seismic watergun. Journal of the Acoustical Society of America 111(6): 2929-2940.

Finneran, J. J., D. A. Carder, C. E. Schlundt, and R. L. Dear. 2010a. Growth and recovery of temporary threshold shift at $3 \mathrm{kHz}$ in bottlenose dolphins: experimental data and mathematical models. Journal of the Acoustical Society of America 127:3256-3266.

Finneran, J. J., D. A. Carder, C. E. Schlundt, and R. L. Dear. 2010b. Temporary threshold shift in a bottlenose dolphin (Tursiops truncatus) exposed to intermittent tones. Journal of the Acoustical Society of America 127:3267-3272.

Finneran, J. J., and C. E. Schlundt. 2010. Frequency-dependent and longitudinal changes in noise-induced hearing loss in a bottlenose dolphin (Tursiops truncatus). Journal of the Acoustical Society of America 128:567-570.

Fischer, R., and L. Pettit. 2014. The noise control decision making process. SNAME's Ship Production Symposium. Houston, TX. October 20-25, 2014.

Foote, A. D., Osborne, R. W., Rus Hoelzel, A. 2004. Whale-call response to masking boat noise. Nature (London) 428: 910.

Gerstein, E. R., J. E. Blue, G. F. Pinto, and S. Barr. 2006. Underwater noise and zones of masking with respect to hopper dredging and manatees in the St. Johns River in Jacksonville. Journal of the Acoustical Society of America 120: 3145-3222. 
Gilmartin, W. G. 2003.Responses of Hawaiian monk seals to human disturbance and handling. In Workshop on the Management of Hawaiian Monk Seals on Beaches in the Main Hawaiian Islands, p. 8. Kauai, Hawaii: Marine Mammal Commission, National Marine Fisheries Service, Hawaii Division of Aquatic Resources.

Govoni, J. J., M. A. West, L. R. Settle, R. R. Lynch, M. D. Greene. 2008. Effects of underwater explosions on larval fish: implications for a coastal engineering project. J Coast Res 24:228-233

Greene, C. R. 1987. Characteristics of oil industry dredge and drilling sounds in the Beaufort Sea. Journal of the Acoustical Society of America 82(4):1315-1324.

Greene, C. R., and S. B. Blackwell.2008. Mitigation. Bioacoustics (special issue). 17:240.

Hall, M. V. 2010. Underwater signals from confined explosions in very shallow water. Proceeding of the $2 O^{\text {th }}$ International Congress on Acoustics, ICA. 23-27 August 2010. Sydney, Australia.

Halvorsen M. B., B. M. Casper, C. M. Woodley, T. J. Carlson, A. N. Popper. 2011. Predicting and mitigating hydroacoustic impacts on fish from pile installations. NCHRP Res Results Digest 363, Project 25-28, Washington, DC: National Cooperative Highway Research Program, Transportation Research Board, National Academy of Sciences.

Halvorsen, M. B., B. M. Casper, F. Matthews, T. J. Carlson, A. N. Popper.2012a. Effects of exposure to pile-driving sounds on the lake sturgeon, Nile tilapia and hogchoker. Proceedings of the Royal Society of London B: Biological Sciences 279(1748): 4705-4714.

Halvorsen, M. B., B. M. Casper, C. M. Woodley, T. J. Carlson, A. N. Popper. 2012b. Threshold for onset of injury in Chinook salmon from exposure to impulsive pile driving sounds. PLOS One 7(6): e38968.

Hamernik, R. P., W. Qiu, and B. Davis. 2003. The effects of the amplitude distribution of equal energy exposures on noise-induced hearing loss: The kurtosis metric. Journal of the Acoustical Society of America 114:386-395.

Handegard, N. O., K. Boswell, A. De Robertis, G. J. Macaulay, G. Riecau, L. D. Sivle. 2016. Investigating the effects of tones and frequency sweeps on the collective behaviour of penned herring (Clupea harengus). New York: Springer. In The Effects of Noise on Aquatic Life II.

Hastings, M. C., and A. Popper. 2005. Effects of Sound on Fish. California Department of Transportation. Project P476; Final Report \# CA05-0537. Noise Thresholds for Endangered Fish.

Hawkins, A. D., and A. D. F. Johnstone. 1978. The hearing of Atlantic salmon, Salmo salar. Journal of Fish Biology 13: 655-673.

Hawkins, A. D. 2008. Effects of noise on aquatic life: The key issues. Bioacoustics (special issue) 17:7-12. 
Hawkins, A. D., A. E. Pembroke, A. N. Popper. 2015. Information gaps in understanding the effects of noise on fishes and invertebrates. Reviews in Fish Biology and Fisheries 25(1): 39-64.

Hawkins, A. D., and A. N. Popper, 2016. Developing sound exposure criteria for fishes. New York: Springer. In The Effects of Noise on Aquatic Life II. pp. 431.

Hawkins, A. D., and A. N. Popper. 2017. A sound approach to assessing the impact of underwater noise on marine fishes and invertebrates. ICES Journal of Marine Science 74(3): 635-651.

Heinis, F., C. deJong, M. Ainslie, W. Borst, T. Vellinga. 2013. Monitoring programme for the Maasvlakte 2, Part III - The effects of underwater sound. Terra et Aqua 132:21-32.

Hempen, G. L., T. M. Keevin, T. L. Jordan, 2007. Underwater blast pressures from a confined rock removal during the Miami Harbor deepening project. International Society of Explosives Engineers.

Henderson, D., M. Subramaniam, M. A. Grattona, S. S. Saunders. 1991. Impact noise: The importance of level, duration, and repetition rate. Journal of the Acoustical Society of America 89:1350-1357.

Henderson, D., and R. P. Hamernik. 1986. Impulse noise: Critical review. Journal of the Acoustical Society of America 80:569-584.

Henderson, D., B. Hu, E. Bielefeld, 2008. Patterns and mechanisms of noise-induced cochlear pathology. In Auditory Trauma, Protection, and Repair, ed. J. Schacht, A. N. Popper, and R. R Fay, 195-217. New York: Springer.

High Energy Seismic Survey (HESS). 1999. High energy seismic survey review process and interim operational guidelines for marine surveys offshore Southern California. Prepared for The California State Lands Commission and The United States Minerals Management Service Pacific Outer Continental Shelf Region. Camarillo, California: High Energy Seismic Survey Team.

Hoffman, C. 2010. Mitigating impacts of underwater noise from dredging on beluga whales in Cook Inlet, Alaska. In 2nd International Conference on the Effects of Noise on Aquatic Marine Life, p. 5. Cork, Ireland.

Holt, D. E., and Johnston, C. E. 2014. Evidence of the Lombard effect in fishes. Behavioral Ecology 25(4): 819-826.

International Association of Dredging Companies (IADC). 2016. Underwater Drilling and Blasting. Facts About: An information update from the IADC. ISSN 23521422.

International Maritime Organization (IMO). 2014. Guidelines for the reduction of underwater noise from commercial shipping to address adverse impacts on marine life. Final Report. The Marine Environment Protection Committee. March 31 to April 4, 2014. MEPC.1/Circ.833; p. 8. 
International Organization for Standardization (ISO) 12001:1996 Acoustics -- Noise emitted by machinery and equipment -- Rules for the drafting and presentation of a noise test code.

Janik, V. M., 2005. Underwater acoustic communication networks in marine mammals. In Animal Communication Networks, ed. P. K. McGregor, 390-415. Cambridge, UK: Cambridge University Press.

Jones, D., and K. Marten. 2016. Dredging sound levels, numerical modelling, and EIA. Terra et Aqua 144: 21-29.

Jung, C. A., and S. E. Swearer. 2011. Reactions of temperature reef fish larvae to boat sound. Aquatic Conservation: Marine and Freshwater Ecosystems 21: 389-396.

Kastak, D., C. Reichmuth., M. M. Holt., J. Mulsow, B. L. Southall, R. J. Schusterman. 2007. Onset, growth, and recovery of in-air temporary threshold shift in a California sea lion (Zalophus californianus). Journal of the Acoustical Society of America 122:2916- 2924.

Kastelein, R. A., R. Gransier, L. Hoek. 2012. Temporary theshold shifts and recovery in a harbor porpoise (Phocoena phocoena) after octave-band noise at $4 \mathrm{kHz}$. J Acoust Soc Am 132: 3525-3537

. 2013a. Comparative temporary theshold shifts in a harbor porpoise and harbor seal, and severe shift in a seal (L). $J$ Acoust Soc Am 134: 13-17

Kastelein, R. A., R. Gransier, L. Hoek, M. Rambags. 2013b. Hearing frequency thresholds of harbor porpoise (Phocoena phocoena) temporarily affected by a continuous 1.5 kHz tone. Journal of the Acoustical Society of America 134:2286-2292.

Kastelein, R. A., L. Helder-Hoek, R. Gransier, L. Rambags, N. Claeys. 2014. Effects of level, duration, and inter-pulse interval of 1-2 kHz sonar signal exposures on harbor porpoise hearing. Journal of the Acoustical Society of America 136:412422.

Kastelein, R. A., L. Helder-Hoek, S. Van de Voorde, A. M. von Benda-Beckmann, F. P. A. Lam, E. Jansen, C. A. de Jong, M. A. Ainslie, 2017a. Temporary hearing threshold shift in a harbor porpoise (Phocoena phocoena) after exposure to multiple airgun sounds. Journal of the Acoustical Society of America 142(4): 2430-2442.

Kastelein, R. A., N. Jennings, A. Kommeren, L. Helder-Hoek, J. Schop. 2017b. Acoustic dose-behavioral response relationship in sea bass (Dicentrarchus labrax) exposed to playbacks of pile driving sounds. Marine Environmental Research 130: 315-324.

Kastelein, R. A., S. Van Der Heul., W. Verboom, D. D. Haan, P. Reijnders, 2008. Acoustic dose-response effects in marine fish. Bioacoustics (special issue) 17:201-202.

Kats, A. M. 2009. Underwater noise in the North Sea - Effects on marine life and possible mitigation measures. Internship Aquatic Ecology and Water Quality Management Report number P421. Wageningen University Msc. Management of Marine Ecosystems Profile Marine Ecology. 
Keevin, T. M., and G. L. Hempen. 1997. The environmental effects of underwater explosions with methods to mitigate impacts. USACE. Doc ID 550560.

Ketten, D. 1995. Estimates of blast injury and acoustic trauma zones for marine mammals from underwater explosions. In Sensory systems of aquatic mammals, ed. R. Kastelein, J. Thomas, and P. Nachtigal, 391-407. the Netherlands: De Spil, Woerdwen.

Ketten D. R., S. Cramer, J. Arruda. 2005. Experimental measures of blast trauma in sea turtles. Symposium on Environmental Consequences of Underwater Sound, Office of Naval Research, Arlington, VA.

Ketten, D. R., and S. M. Bartol. 2006. Functional measures of sea turtle hearing. Woods Hole Oceanographic Institution (WHOI). Report number: OMB NO. 0704-0188. Woods Hole, Massachusetts.

Koper, R. P. and S. Plön. 2012. The potential impacts of anthropogenic noise on marine animals and recommendations for research in South Africa. EWT Research \& Technical Paper No. 1. South Africa: Endangered Wildlife Trust.

Kuhn, C., B. Bruns, J. Fischer, J. Gattermann, K. H. Elmer. 2012. Development of a new underwater piling noise mitigation system: Using hydrosound dampers (HSD). In ASME 2012 31st International Conference on Ocean, Offshore and Arctic Engineering 195-202. New York, NY: American Society of Mechanical Engineers.

Lagardere, J. P. 1982. Effects of noise on growth and reproduction of Crangon crangon in rearing tanks. Marine Biology 71: 177-185.

Lataye, R., and P. Campo. 1996. Applicability of the Leq as a damage-risk criterion: An animal experiment. Journal of the Acoustical Society of America 99:1621-1632.

Lewis, J. K., and W. W. Denner. 1987. Arctic ambient noise in the Beaufort Sea: Seasonal space and time scales. Journal of the Acoustical Society of America 82(3): 988997.

Levine, S., P. Hofstetter, X. Y. Zheng. D. Henderson. 1998. Duration and peak level as cofactors in hearing loss from exposure to impact noise. Scandinavian Audiology Supplementum 48:27-36.

Linton, T. L., A. M. Landry, Jr., J. E. Buckner, Jr., R. L. Berry. 1985. Effects upon selected marine organisms of explosives used for sound production in geophysical exploration. Texas Journal of Science 37:341-353.

Liu, B. M., Q. W. Wei, H. Du, Z. Y. Fu, Q. C. Chen. 2013. Ship noise-induced temporary hearing threshold shift in the Chinese sucker Myxocyprinus asiaticus (Bleeker, 1864). J. Appl. Ichthyol. 29:1416-1422.

Lucke, K., U. Siebert, P. A. Lepper, M. A. Blanchet. 2009. Temporary shift in masking hearing thresholds in a harbor porpose (Phocoena phocoena) after exposure to seismic airgun stimuli. J. Acoust Soc Am 125: 4060-4070.

Madsen P. T. 2005. Marine mammals and noise: problems with root mean square sound pressure levels for transients. Journal of the Acoustical Society of America 117(6): 3952-3957. 
Martin, K. J., S. C. Alessi, J. C. Gaspard, A. D. Tucker, G. B. Bauer, D. A. Mann. 2012. Underwater hearing in the loggerhead turtle (Caretta caretta): a comparison of behavioral and auditory evoked potential audiograms. Journal of Experimental Biology 215(17): 3001-3009.

Martin, B., D. G. Zeddies, B. Gaudet, and J. Richard. 2016. Evaluation of three sensor types for particle motion measurement. Advances in Experimental Medicine and Biology 875:679-686.

McKenna, M. F., D. Ross, S. M. Wiggins, and J. A. Hildebrand. 2012. Underwater radiated noise from modern commercial ships. Journal of Acoustic Society of America 131(1): 92-103.

Merchant, N. D., K. L. Brookes, B. C. Faulkner, A. W. Bicknell, B. J. Godley, and M. J. Witt. 2016. Underwater noise levels in the UK waters. Scientific Reports. 6, 36942DOI: 10.1038/srep36942.

Merchant, N. D., R. C. Faulkner, R. Martinez, R. 2017. Marine noise budgets in practice. Conservation Letters. Journal of the Society for Conservation Biology 00:1-9.

Moein, S. E., J. A. Musick, J. A. Keinath, D. E. Barnard, M. Lenhardt, R. George. 1994. Evaluation of seismic sources for repelling sea turtles from hopper dredges. Report prepared for the U.S. Army Corps of Engineers Waterways Experiment Station by the Virginia Institute of Marine Science College of William and Mary.

Møhl, B., M. Wahlberg, P. Madsen, A. Heerfordt, A. Lundt. 2003. The mono-pulse nature of sperm whale clicks. Journal of the Acoustical Society of America 114:11431154 .

Mooney, T. A., P. E. Nachtigall, S. Vlachos. 2009a. Sonar-induced temporary hearing loss in dolphins. Biology Letters 5:565-567.

Mooney, T. A., P. E. Nachtigall, M. Breese, S. Vlachos, W. W. L. Au. 2009b. Predicting temporary threshold shifts in a bottlenose dolphin (Tursiops truncatus): The effects of noise level and duration. Journal of the Acoustical Society of America 125:1816-1826.

National Institute for Occupational Safety and Health (NIOSH). 1998. Criteria for a recommended standard: Occupational noise exposure. Cincinnati, Ohio: United States Department of Health and Human Services.

National Marine Fisheries Service (NMFS). 2016. Technical guidance for assessing the effects of anthropogenic sound on marine mammal hearing: Underwater acoustic thresholds for onset of permanent and temporary threshold shifts. Ed. by Resources O.O.P. Silver Spring, MD: U.S. Department of Commerce.

National Oceanic and Atmospheric Administration (NOAA). 1998. Incidental taking of marine mammals; acoustic harassment. Federal Register 63(143):40103.

National Oceanic and Atmospheric Administration (NOAA). 2014. Taking and importing marine mammals; precision strike weapon and air-to-surface gunnery training and testing operations at Eglin Air Force Base, FL. Federal Register 79(47):13568-13591. 
National Oceanic and Atmospheric Administration (NOAA). 2015. Marine mammal nonlethal deterrents: Summary of the technical expert workshop on marine mammal non-lethal deterrents, 10-12 February 2015. NPFS-OPR-50. Seattle, Washington. NOAA technical memorandum.

National Oceanic and Atmospheric Administration (NOAA). 2016. Ocean Noise Strategy Roadmap. Accessed online: http://cetsound.noaa.gov/road-map

National Research Council (NRC). 2003. Ocean Noise and Marine Mammals. Washington DC: Committee on Potential Impacts of Ambient Noise in the Ocean on Marine Mammals.

National Research Council (NRC). 2005. Marine Mammal Populations and Ocean Noise: Determining When Noise Causes Biologically Significant Effects. Washington, DC: National Academies Press.

Nedelec, S. L., J. Campbell, A. N. Radford, S. D. Simpson, N. D. Merchant. 2016. Particle motion: the missing link in underwater acoustic ecology. Methods in Ecology and Evolution 7:836-842.

Nedwell, J. R., D. Howell. 2004. A review of offshore windfarm related underwater noise sources. Report \# 544 R 0308. p. 63

Nedwell, J. R, S. J. Parvin, B. Edwards, R. Workman, A. G. Brooker, J. E. Kynoch. 2007. Measurement and interpretation of underwater noise during construction and operation of offshore windfarms in UK waters. Subacoustech Report No. 544Ro738 to COWRIE Ltd. ISBN: 978-0-9554279-5-4.

Nedwell, J. R., S. J. Parvin, A. G. Brooker, D. R. Lambert. 2008. Modelling and measurement of underwater noise associated with the proposed Port of Southampton capital dredge and redevelopment of berths 201/202 and assessment of the disturbance to salmon. Subacoustech Report, 805Ro444.

Neenan, S. T., R. Piper, P. R. White, P. Kemp, T. G. Leighton, P. J. Shaw, 2016. Does Masking Matter? Shipping Noise and Fish Vocalizations. In The Effects of Noise on Aquatic Life II. New York: Springer.

Nehls, G., K. Betke, S. Eckelmann, M. Ros. 2007. Assessment and costs of potential engineering solutions for the mitigation of the impacts of underwater noise arising from the construction of offshore windfarms. BioConsult SH report, Husum, Germany. On behalf of COWRIE Ltd.

Nolet 2017. Understanding anthropogenic underwater noise. Prepared for transportation development centre of Transport Canada. Green Marine Management Corporation. Final Report \# TP 15348 E; Pp. 84.

Normandeau Associates, Inc. 2012. Effects of noise on fish, fisheries, and invertebrates in the U.S. Atlantic and Arctic from Energy Industry Sound-Generating Activities. A Workshop Report for the U.S. Dept. of the Interior, Bureau of Ocean Energy Management. 72 pp. plus Appendices.

Occupational Safety and Health Administration (OSHA). 2013. OSHA Technical Manual. Washington, DC: United States Department of Labor. 
Oestman, R., D. Buehler, J. A. Reyff. Rodkin, R. 2009. Technical guidance for assessment and mitigation of the hydroacoustic effects of pile driving on fish. Prepared for California Department of Transportation.

http://www.dot.ca.gov/hq/env/bio/files/bio_tech_guidance_hydroacoustic_effects_110215.p df (last accessed 25 April 2017).

Offutt, G. C. 1974. Structures for the detection of acoustic stimuli in the Atlantic codfish, Gadus morhua. Journal of the Acoustical Society of America 56: 665-671.

OSPAR 2009a. Overview of the Impacts of Anthropogenic Underwater Sound in the Marine Environment. OSPAR Convention for the Protection of the Marine Environment of the North-East Atlantic. www.ospar.org.

OSPAR 2009b. Assessment of the Environmental Impacts of Underwater Noise. OSPAR Convention for the Protection of the Marine Environment of the North-East Atlantic. www.ospar.org.

Parmentier, E., K. Mann, D. Mann. 2011. Hearing and morphological specializations of the mojarra (Eucinostomus argenteus). Journal of Experimental Biology 24: 2697-2701.

Parry, G. and A. Gason. 2006. The effect of seismic surveys on catch rates of rock lobsters in western Victoria, Australia. Fisheries Research 79:272-284.

Parvin, S. J., J. R. Nedwell, J. Kynoch, J. Lovell, A. G. Brooker. 2008. Assessment of underwater noise from dredging operations on the Hasting Shingle Bank. Report No. 758Ro137. United Kingdom: Southhampton Subacoustech.

Pirotta, E., B. E. Laesser, A. Hardaker, N. Riddoch, M. Marcoux, D. Lusseau. 2013. Dredging displaces bottlenose dolphins from an urbanised foraging patch. Marine Pollution Bulletin 74: 396-402.

Popov, V. V., A. Ya Supin, V. V. Rozhnov, D. I. Nechaev, E. V. Sysueva, 2014. The limits of applicability of the sound exposure level (SEL) metric to temporal threshold shifts (TTS) in beluga whales, Delphinapterus leucas. The Journal of Experimental Biology 217:1804-1810.

Popper, A. N. 2003. Effects of anthropogenic sounds on fishes. Fisheries 28(10): 24-31.

Popper, A. N., and A. D. Hawkins. (Eds.). 2016. The effects of noise on aquatic life II. New York, New York: Springer.

2018. The importance of particle motion to fishes and invertebrates. The Journal of the Acoustical Society of America 143(1): 470-488.

Popper, A. N., and M. C. Hastings. 2009. The effects of anthropogenic sources of sound on fishes. Journal of Fish Biology 75: 455-489.

Popper, A. N., A. D. Hawkins, R. R. Fay, D. A. Mann, S. Bartol, S., T. J. Carlson, S. Coombs, W. T. Ellison, R. L. Gentry, M. B. Halvorsen, S. Løkkeborg, P. H. Rogers, B. I. Southall, D. G. Zeddies, W. N. Tavolga. 2014. Sound Exposure Guidelines for Fishes and Sea Turtles. Springer Briefs in Oceanography ASA S3/SC1.4 TR2014, Springer. DOI 10.1007/978-3-319-06659-2_1. 
Popper, A. N., M. E. Smith, P. A. Cott, B. W. Hanna, , A. O. MacGillivray, M. E. Austin, D. A. Mann, 2005. Effects of exposure to seismic airgun use on hearing of three fish species. J. Acoust. Soc. Am. 117:3958-3971

Radford, C. A., J. C. Montgomery, P. Caiger, D. M. Higgs. 2012. Pressure and particle motion detection thresholds in fish: a re-examination of salient auditory cues in teleosts. The Journal of Experimental Biology 215:3429-3435.

Regnault, M., and J. P. Lagardere. 1983. Effects of ambient noise on the metabolic level of Crangon crangon (Decapoda, Natantia). Marine Ecology Progress Series 11:7178 .

Reine, K. J., D. D. Dickerson, D. G. Clarke. 1998. Environmental windows associated with dredging operations. DOER Technical Notes Collection. TN DOER-E2. Vicksburg, MS: U.S. Army Engineer Research and Development Center. www.wes.army.mil/el/dots/doer.

Reine, K. J., D. G. Clarke, C. Dickerson. 2012a. Characterization of underwater sounds produced by a backhoe dredge excavating rock and gravel. DOER technical notes collection. ERDC TN-DOER-E36. Vicksburg, MS: US Army Engineer Research and Development Center. http://el.erdc.usace.army.mil/elpubs/pdf/doere36.pdf.

2012b. Characterization of underwater sounds produced by a hydraulic cutterhead dredge fracturing limestone rock. DOER technical notes collection. ERDC TN-DOER-E34. Vicksburg, MS: US Army Engineer Research and Development Center. http://el.erdc.usace.army.mil/elpubs/pdf/doere34.pdf.

. 2014a. Characterization of underwater sounds produced by hydraulic and mechanical dredging operations. J. Acoust. Soc. Am. 135(5): 3280-3294.

Reine, K. J., D. G.Clarke, C. Dickerson, G. Wikel. 2014b. Characterization of underwater sounds produced by trailing suction hopper dredges during sand mining and pump-out operations. ERDC/EL TR-14-3. Vicksburg, MS: US Army Engineer Research and Development Center. http://el.erdc.usace.army.mil/elpubs/pdf/trel143.pdf.

Reine, K. J., and C. Dickerson. 2014. Characterization of underwater sounds produced by a hydraulic cutterhead dredge during maintenance dredging in the Stockton Deepwater Shipping Channel, California. DOER technical notes collection. ERDC TN-DOER-E38. Vicksburg, MS: US Army Engineer Research and Development Center. http://el.erdc.usace.army.mil/elpubs/pdf/doere38.pdf.

Reinhall, P. G., T. Dardis, P. H. Dahl. 2015. Underwater noise reduction of marine pile driving using a double pile. WSDOT Report WA-RD 849.1.Richardson, W. J., B. Würsig, C. R. Greene. Jr. 1990. Reactions of bowhead whales, Balaena mysticetus, to drilling and dredging noise in the Canadian Beaufort Sea. Marine Environmental Research 29: 135-160.

Richardson, J. W., C. R. Greene, C. I. Malme, D. H. Thomson. 1995. Marine mammals and noise. Academic Press. 
Robinson, S. P., P. D. Theobald, G. Hayman, L. S. Wang, P. A. Lepper, V. Humphrey, S. Mumford. 2011. Measurement of noise arising from marine aggregate dredging operations. Final Report. Marine Aggregate Levy Sustainability Fund (MALSF) (MEPF Ref. no. 09/P108). Published by the MALSF. ISBN 9780907545576.

Saunders, J. C., S. P. Dear, M. E. Schneider. 1985. The anatomical consequences of acoustic injury: A review and tutorial. Journal of the Acoustical Society of America 78:833-860.

Scheifele, P. M., S. Andrew, R. A.Cooper, M. Darre, F. E. Musiek.L. Max. 2005. Indication of a Lombard vocal response in the St. Lawrence River beluga. The Journal of the Acoustical Society of America 117(3): 1486-1492.

Schlundt, C. E., J. J. Finneran, B. K. Branstetter, J. S. Trickey, V. Bowman , K. Jenkins. 2016. Auditory effects of multiple impulses from a seismic air gun on bottlenose dolphins (Tursiops truncates). In The effects of noise on aquatic life II. New York: Springer.

Simpson S. D., J. Purser, A. N. Radford. 2015. Anthropogenic noise compromises antipredator behaviour in European eels. Global Change Biology 21: 586-593.

Sivle, L. D., P. H. Kvadsheim, C. Curé, S. Isojunno, P. J. Wensveen, F. P. A. Lam, F. Visser, L. Kleivance, P. L. Tyack, C. M. Harris, P. J. Miler. 2015. Severity of expert-identified behavioural responses of humpback whale, minke whale, and northern bottlenose whale to naval sonar. Aquatic Mammals 41(4): 469.

Slabbekoorn, H. 2016. Aiming for progress in understanding underwater noise impact on fish: Complementary need for indoor and outdoor studies. In The Effects of Noise on Aquatic Life II. New York: Springer.

Smith, M. E. 2016. Relationship between hair cell loss and hearing loss in fishes. In The Effects of Noise on Aquatic Life II. New York: Springer.

Smith, M. E., A. B. Coffin, D. L. Miller, A. N. Popper. 2006. Anatomical and functional recovery of the goldfish (Carassius auratus) ear following noise exposure. The Journal of Experimental Biology 209: 4193-4202.

Sole, M., M. Lenoir, M. Durfort, M. Lopez-Bejar, A. Lombarte, M. van der Schaar, M. Andre. 2013. Does exposure to noise from human activities compromise sensory information from cephalopod statocyst. Deep Sea Research II 95: 160-181.

Southall, B. L., A. E. Bowles, W. T. Ellison, J. J. Finneran, R. L. Gentry, C. R. Greene, Jr., D. Kastak, D. R. Ketten, J. H. Miller, P. E. Nachtigall, W. J. Richardson, J. A. Thomas, P. L. Tyack, 2007. Marine mammal noise exposure criteria: Initial scientific recommendations. Aquatic Mammals 33:411-521.

Spense, J. H. 2007. A summary of existing and future potential treatments for reducing underwater sounds from Oil and Gas industry Activities. In: OCEANS 2007. IEEE.

Starck, J., E. Toppila, I. Pyykkö. 2003. Impulse noise and risk criteria. Noise \& Health $5: 63-73$. 
Suedel, B. C., J. Kim, D. G. Clarke, I. Linkov. 2008. A risk-informed decision framework for setting environmental windows for dredging projects. Science of the Total Environment 403:1-11.

Thomsen, F., F. Borsani, D. Clarke, C. de Jong, P. de Wit, , F. Goethals, M. Holtkamp, E. San Martin, P. Spadaro, G. van Raalte, G. Y. V. Victor, . 2016. WODA technical guidance on underwater sound from dredging. In The Effects of Noise on Aquatic Life II New York: Springer.

Thomsen, F., S. McCully, D. Wood, F. Pace, P. White. 2009. A generic investigation into noise profiles of marine dredging in relation to the acoustic sensitivity of the marine fauna in UK waters with particular emphasis on aggregate dredging: PHASE 1 Scoping and review of key issues. Contract No. MEPF/o8 P, 21.

Todd, V. L. G., I. B. Todd, J. C. Gardiner, E. C. N. Morrin, N. A. MacPherson. N. A. DiMarzio, F. Thomsen. 2015. A review of impacts of marine dredging activities on marine mammals. ICES Journal of Marine Science 72: 328-340.

Tougaard, J., J. Carstensen, J. Teilmann, H. Skov, P. Rasmussen. 2009. Pile driving zone of responsiveness extends beyond $20 \mathrm{~km}$ for harbor porpoises (Phocoena phocoena, (L.)). J. Acoustic Soc. Am. 126:11-14.

Tougaard, J., A., J. Wright, P. T. Madsen. 2016. Noise Exposure Criteria for Harbor Porpoises. In The Effects of Noise on Aquatic Life II. New York: Springer.

Tripathy, G. R., and R. R. Shirke. 2015. Underwater drilling and blasting for hard rock dredging in Indian ports - A case study. Aquatic Procedia 4:248-255.

Tyack P. L., W. M. X. Zimmer, D. Moretti, B. L. Southall, D. E. Claridge, J. W. Durban, C. W. Clark, A. D’Amico., N. DiMarzio, S. Jarvis, E. McCarthy, R. Morrissey, J. Ward, I. L. Boyd. 2011. Beaked Whales Respond to Simulated and Actual Navy Sonar. PLOS One 6(3):e17009. doi:10.1371/journal.pone.0017009

Van der Graaf, A. J., M. A. Ainslie, M. André, K. Brensing, J. Dalen, R. P. A. Dekeling, S. Robinson, M. L. Tasker, F. Thomsen, S. Werner. 2012. European marine strategy framework directive-good environmental status (MSFD GES): Report of the technical zubgroup on underwater noise and other forms of energy.

Verfuss, U. K., C. E. Sparling, C. Arnot, A. Judd, M. Coyle. 2016. Review of offshore wind farm impact monitoring and mitigation with regard to marine mammals. In The Effects of Noise on Aquatic Life II New York: Springer.

Verfuss, U., D. Gillespie, J. Gordon, T. A. Marques, B. Miller, R. Plunkett, J. A. Theriault, D. J. Tollit, D. P. Zitterbart, Hubert, P., Thomas, L. 2018. Comparing methods suitable for monitoring marine mammals in low visibility conditions during seismic surveys. Marine Pollution Bulletin 126: 1-18.

Villadsgaard, A., M. Wahlberg, J. Tougaard. 2007. Echolocation signals of wild harbour porpoises, Phocoena phocoena. The Journal of Experimental Biology 210:56-64.

von Lüders, S., and A. Gill. 2008. Marine mammal observers: Real-time mitigation of anthropogenic noise. Bioacoustics (special issue) 17:284-285. 
Wale, M. A., S. D. Simpson, A. N. Radford. 2013a. Size-dependent physiological responses of shore crabs to single and repeated playback of ship noise. Biol Lett 9: 20121194. http://dx.doi.org/10.1098/rsbl.2012.1194

Wale, M. A., S. D. Simpson, A. N. Radford. 2013b. Noise negatively affects foraging and antipredator behaviour in shore crabs. Animal Behaviour 86:111-118.

Ward, W. D. 1962. Damage-risk criteria for line spectra. Journal of the Acoustical Society of America 341610-1619.

Ward, W.D., E. M. Cushing, E. M. Burns. 1976. Effective quiet and moderate TTS: Implications for noise exposure standards. Journal of the Acoustical Society of America 59:160-165.

Ward, W. D. 1991. The role of intermittence in PTS. Journal of the Acoustical Society of America 90:164-169.

Weilgart, L. S. 2007. A brief review of known effects of noise on marine mammals. International Journal of Comparative Psychology 2O(2).

Wenz, G. M. 1962. Acoustic ambient noise in the ocean: spectra and sources. Journal of the Acoustical Society of America 34:1936-1956.

Williams, R., A. J. Wright, E. Ashe, L. K. Blight, R. Bruintjes, R. Canessa, , C. W. Clark, S. Cullis-Suzuki, D. T. Daking, C. Erbe, P. S. Hammond, N. D. Merchant, P. D. O’Hara, J. Purserm, A. N. Radford, S. D. Simpson, L. Thomas, M. A. Wale. 2015. Impacts of anthropogenic noise on marine life: publication patterns, new discoveries, and future directions in research and management. Ocean \& Coastal Management 115: 17-24.

Willis, K. L. 2016. Underwater hearing in turtles. In: The Effects of Noise on Aquatic Life II. New York: Springer.

World Organization of Dredging Association (WODA). 2013. Technical guidance on underwater sound in relation to dredging. Delft, the Netherlands: World Organization of Dredging Associations.http://www.dredging.org/documents/ceda/html_page/2013-06-WODATechnicalGuidance-UnderwaterSound_Ir.pdf.

Wursig, B., C. R. Greene, T. A. Jefferson. 200o. Development of an air bubble curtain to reduce underwater noise of percussive piling. Mar. Environ. Res. 49:79-93

Wysocki, L. E., J. W. Davidson, III, M. E.Smith, A. S. Frankel, W. T. Ellison, P. M. Mazik, A. N. Popper, J. Bebak. 2007. Effects of aquaculture production noise on hearing, growth, and disease resistance of rainbow trout Oncorhynchus mykiss. Aquaculture 272:687-697.

Wysocki, L. E., J. P. Dittami, F. Ladich. 2006. Ship noise and cortisol secretion in European freshwater fishes. Biological Conservation 128: 501-508.

Yan, H. Y. 2001. A non-invasive electrophysiological study on the enhancement of hearing ability in fishes. Proceedings of the Royal Society B.: Biological Sciences 23: 15-26. 
Yelverton, J. T., D. R. Richmond, W. Hicks, K. Saunders, E. R. Fletcher, 1975. The relationship between fish size and their response to underwater blast. Report DNA 3677T. Washington, DC: Director, Defense Nuclear Agency. 


\section{Appendix A}

Table A1. Estimated hearing frequencies of aquatic biota.

\begin{tabular}{|c|c|c|c|c|c|}
\hline \multirow[b]{2}{*}{ Species/Group } & \multirow[b]{2}{*}{ Common Name } & \multirow[b]{2}{*}{ Scientific Name } & \multicolumn{2}{|c|}{$\begin{array}{l}\text { Estimated Hearing } \\
\text { Range Frequency }(\mathrm{Hz})\end{array}$} & \multirow[b]{2}{*}{ Reference } \\
\hline & & & $\min$ & $\max$ & \\
\hline $\begin{array}{l}\text { Low-frequency (LF) } \\
\text { cetaceans }\end{array}$ & Baleen whales & - & 7 & 35,000 & NMFS 2016a \\
\hline $\begin{array}{l}\text { Mid-frequency (MF) } \\
\text { cetaceans }\end{array}$ & $\begin{array}{l}\text { dolphins, toothed } \\
\text { whales, beaked } \\
\text { whales, bottlenose } \\
\text { whales }\end{array}$ & - & 150 & 160,000 & NMFS $2016^{a}$ \\
\hline $\begin{array}{l}\text { High-frequency } \\
\text { (HF) cetaceans }\end{array}$ & $\begin{array}{l}\text { true porpoises, Kogia, } \\
\text { river dolphins, } \\
\text { cephalorphynchid sp., } \\
\text { hourglass dolphin \& } \\
\text { Peale's dolphin } \\
\end{array}$ & - & 275 & 160,000 & NMFS 2016a \\
\hline $\begin{array}{l}\text { Phocid pinnipeds } \\
\text { (PW) }\end{array}$ & true seals & - & 50 & 86,000 & NMFS $2016^{a}$ \\
\hline $\begin{array}{l}\text { Otariid pinnipeds } \\
\text { (OW) }\end{array}$ & sea lions and fur seals & - & 60 & 39,000 & NMFS 2016a \\
\hline Chelonians & Loggerhead turtle & Caretta caretta & 50 & 900 & $\begin{array}{c}\text { Ketten and } \\
\text { Bartol 2006; } \\
\text { Martin et al. } \\
2012\end{array}$ \\
\hline Chelonians & Green turtle & Chelonia mydas & 100 & 800 & $\begin{array}{l}\text { Ketten and } \\
\text { Bartol } 2006\end{array}$ \\
\hline Chelonians & Kemp Ridley & Lepidochelys kempi & 100 & 500 & $\begin{array}{l}\text { Ketten and } \\
\text { Bartol } 2006\end{array}$ \\
\hline Chelonians & red-eared slider & $\begin{array}{l}\text { Trachemys scripta } \\
\text { elegans }\end{array}$ & 400 & 500 & $\begin{array}{c}\text { Christensen- } \\
\text { Dalsgaard et } \\
\text { al. } 2012\end{array}$ \\
\hline Teleosts & Brown meagre & Sciaena umbra & 100 & 3,000 & $\begin{array}{c}\text { Codarin et al. } \\
2009\end{array}$ \\
\hline Teleosts & Mojorra & $\begin{array}{l}\text { Eucinostomus } \\
\text { argenteus }\end{array}$ & 100 & 1,800 & $\begin{array}{l}\text { Parmentier et } \\
\text { al. } 2011\end{array}$ \\
\hline Teleosts & Oyster toadfish & Opsanus tau & 100 & 800 & Yan 2001 \\
\hline Teleosts & Red-mouthed goby & Gobius cruentatus & 100 & 700 & $\begin{array}{c}\text { Codarin et al. } \\
2009\end{array}$ \\
\hline Teleosts & $\begin{array}{l}\text { Mediterranean } \\
\text { damselfish } \\
\end{array}$ & Chromis chromis & 100 & 600 & $\begin{array}{c}\text { Codarin et al. } \\
2009\end{array}$ \\
\hline Teleosts & Atlantic codfish & Gadus morhua & 10 & 600 & Offutt 1974 \\
\hline
\end{tabular}

aNMFS (2016); represents generalized hearing range for species category as a composite; Table ES1; p. 3 (NMFS 2016). 
Table A2. Sound frequencies from natural and anthropogenic sources.

\begin{tabular}{|c|c|c|c|}
\hline \multirow[b]{2}{*}{ Sound Source } & \multicolumn{2}{|c|}{$\begin{array}{c}\text { Main Energy Frequency } \\
\text { Range }(\mathrm{Hz})\end{array}$} & \multirow[b]{2}{*}{ Reference } \\
\hline & $\min$ & $\max$ & \\
\hline Natural Ambient Conditions ${ }^{a}$ & 10 & 1,000 & Wenz, 1962; NRC, 2003 \\
\hline Shipping & 10 & 1,000 & NRC, 2003; McKenna et al. 2012 \\
\hline Dredging - CSD & 20 & 1,000 & $\begin{array}{l}\text { Reine et al. 2012b; } \\
\text { Reine and Dickerson } 2014\end{array}$ \\
\hline Dredging - TSHD & 30 & 1,000 & de Jong et al. 2010 \\
\hline Dredging - GD & 20 & 1,000 & Dickerson et al. 2001 \\
\hline Dredging - BHD & 130 & 1,250 & Reine et al. 2012a \\
\hline Oil and gas drilling & 10 & 100 & $\begin{array}{l}\text { OSPAR 2009a; } \\
\text { Blackwell and Green } 2003\end{array}$ \\
\hline Wind turbine & 30 & 200 & OSPAR 2009a \\
\hline Military sonar (low-frequency) & 100 & 500 & OSPAR 2009a \\
\hline Military sonar (mid-frequency) & 2,800 & 8,200 & OSPAR 2009a \\
\hline Military sonar (high frequency) & 10,000 & 15,500 & Cox et al. 2006 \\
\hline
\end{tabular}

asurface waves, precipitation, prevailing winds, surface agitation 


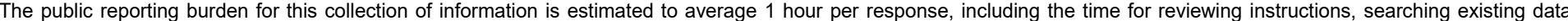

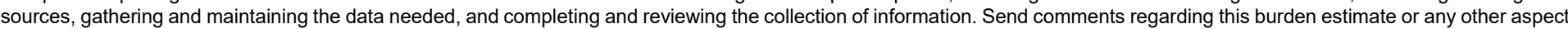

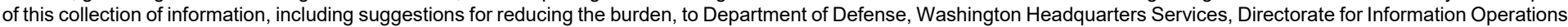

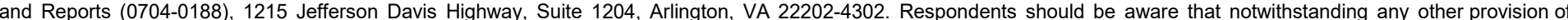
law, no person shall be subject to any penalty for failing to comply with a collection of information if it does not display a currently valid OMB control number.

PLEASE DO NOT RETURN YOUR FORM TO THE ABOVE ADDRESS.

\begin{tabular}{|c|c|c|}
\hline $\begin{array}{l}\text { 1. REPORT DATE } \\
\text { September } 2019\end{array}$ & $\begin{array}{l}\text { 2. REPORT TYPE } \\
\text { Final }\end{array}$ & 3. DATES COVERED (From - To) \\
\hline
\end{tabular}

\section{TITLE AND SUBTITLE}

Evaluating Effects of Dredging-Induced Underwater Sound on Aquatic Species: A Literature Review 5a. CONTRACT NUMBER

5b. GRANT NUMBER

5c. PROGRAM ELEMENT NUMBER

5d. PROJECT NUMBER

5e. TASK NUMBER

5f. WORK UNIT NUMBER

\section{PERFORMING ORGANIZATION} REPORT NUMBER

ERDC/EL TR-19-18

Environmental Laboratory

3909 Halls Ferry Road, Vicksburg, MS 39180-6199

9. SPONSORING/MONITORING AGENCY NAME(S) AND ADDRESS(ES)

10. SPONSOR/MONITOR'S ACRONYM(S)

Headquarters, U.S. Army Corps of Engineers

Washington, DC 20314-1000

11. SPONSOR/MONITOR'S REPORT NUMBER(S)

NOT APPLICABLE TO EVERY REPORT.

\section{DISTRIBUTION/AVAILABILITY STATEMENT}

Approved for public release; distribution is unlimited.

13. SUPPLEMENTARY NOTES

\section{ABSTRACT}

At any given moment, there may be multiple underwater sounds emanating from both natural and anthropogenic sources. Dredging activities such as the excavation, transit, and placement of material generate underwater sound. This report documents research into the biological effects of underwater sound from dredging and other anthropogenic sources to help evaluate the potential ecological risks of dredging activities. Effects data generated from exposures to anthropogenic sound sources indicate that dredging-induced sounds do not pose a significant risk of direct injury or mortality to aquatic biota. A notable exception, and much less common, is blasting activities used to remove rock and other hard substrata in navigation channels. In terms of potential non-lethal responses, low-frequency sounds produced by dredging overlap with the hearing frequency ranges of select fish and mammal species, which may pose risks for auditory temporary threshold shifts, auditory masking, and behavioral responses. To better understand the ecological risk associated with dredging sounds, a risk-based approach is needed that utilizes the available data and other site-specific information appropriate for evaluating underwater sound. Overall, the information reported herein can be used in an exposure assessment as part of a broader framework for assessing and managing underwater sound effects on aquatic life.

\section{SUBJECT TERMS}

Aquatic species, DOER, dredging, impulsive sounds, military sonar, pile driving, underwater sound, underwater sound risk framework

16. SECURITY CLASSIFICATION OF:

a. REPORT Unlimited b. ABSTRACT C. THIS Unlimited
17. LIMITATION OF SAR

\section{NUMBER OF PAGES}

138 19a. NAME OF RESPONSIBLE PERSON

19b. TELEPHONE NUMBER (Include area code) 